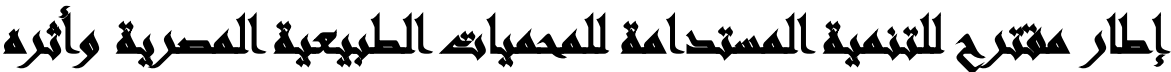

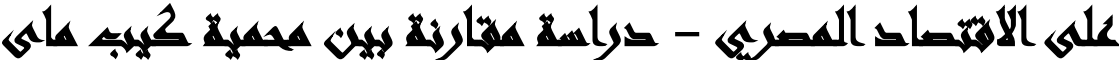

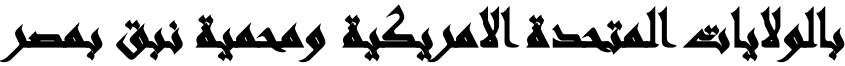

\section{$[r \mathrm{r}]$}

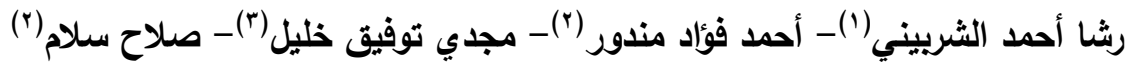

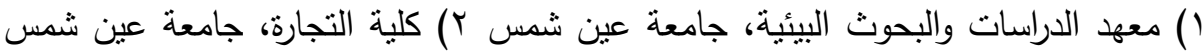

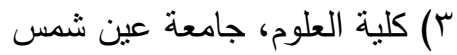

\section{المستخلصع}

بعد الركود السياحي الناتج من نضوب في الموارد وسوء الحالة البيئية وتردي الحالة

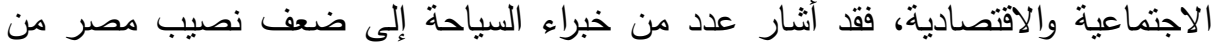

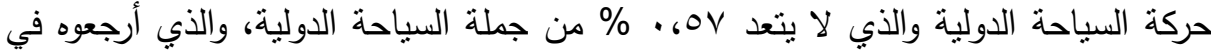

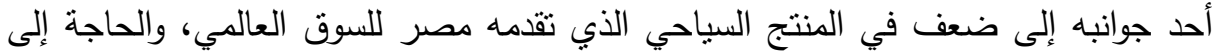

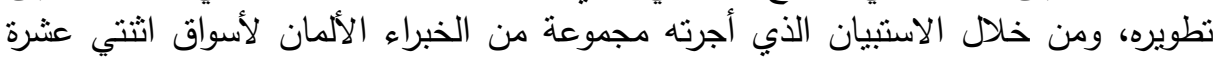

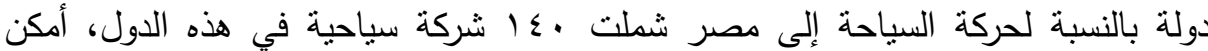
الخلوص إلى نتيجة هامة وهي ضرورة نطوير المنتج السياحي المصري "ندي "منتج سياحي متميز

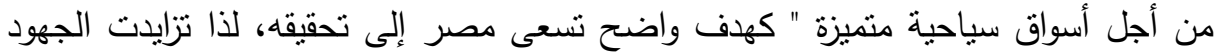

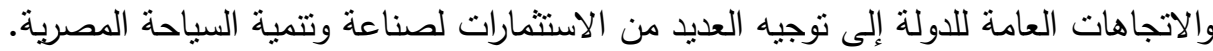

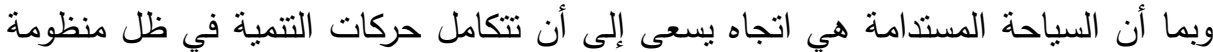
لها قدرة على استيعاب جميع المدخلات التتموية والتعامل معها بهدف حفظ حق التهات الأجيال القادمة في وجود مصادر للتنمية.

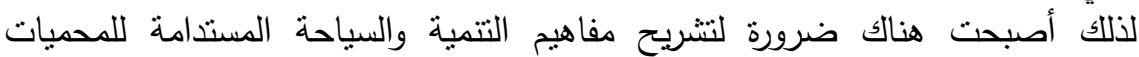
الطبيعية لتحقيق الهدف الرئيسى وهو دراسة وتحليل كيفية استفادة الاقتصاد المصرى من

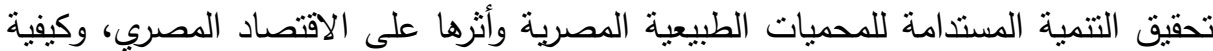

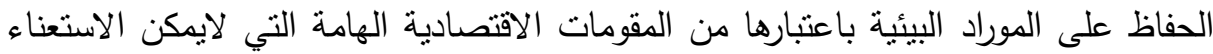

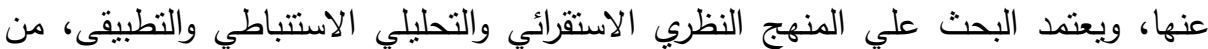

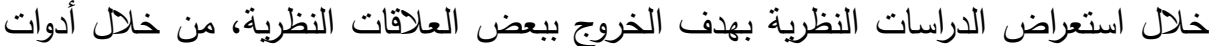
البحث الكتب والأبحاث والدوريات والتقارير والرسائل العلمية والأوراق البحثية المصرية والعاتية العربية والعالمية، ثم الدراسات التحليلية الميدانية وتم إنباع فيها المنهج الاستتباطي، بدراسة التهات وتحليل

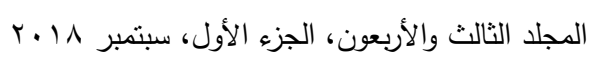


عينة مشابهة للمحميات ذات التاثير الايجابى على الاقتصاد المحلى والوطنى الامريكى، وهى

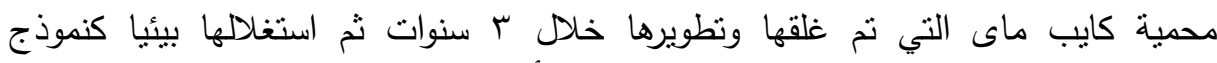

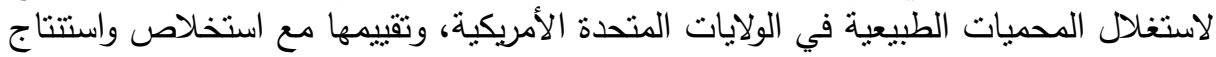

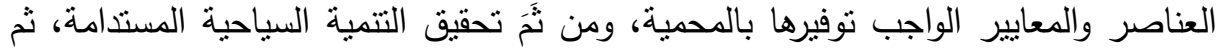

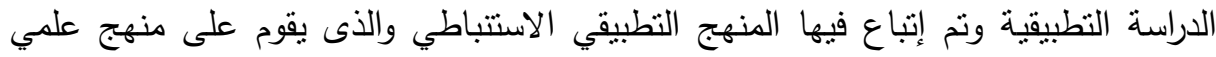

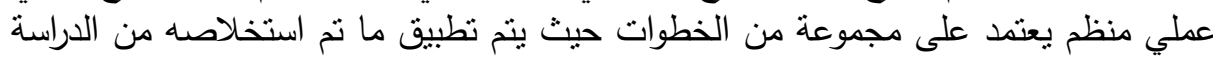
النظرية والتحليلية على محمية نبق لكونها من المحميات المغلقة التي تتملك المقومات الاقتصادية البيئية، وتم وضع منهجية لتحليلها، ومنه نم رصد المشكلات والإمكانيات

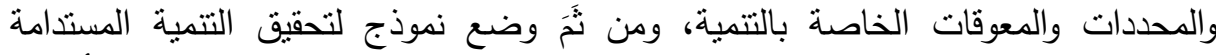

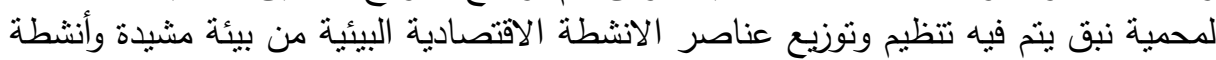

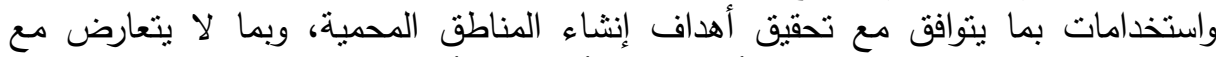

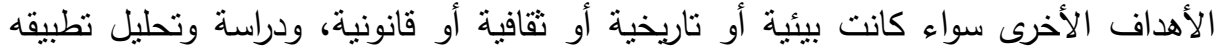

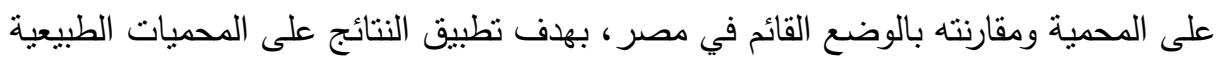

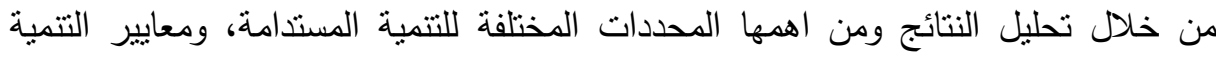
المستدامة للمحميات المصرية، وتتمية دور المحميات في التتمية المستدامة. والتوصيات على التى التئي مستوى استغلال ارض المحمية والأنشطة الترفيهية والبحوث المية المستقبلية. كلمات مفتاحية: التتمية الافتصادية المستدامة - المحميات الطبيعية - محمية كايب مالى المئية -

\section{rasid}

بالرغم من الإمكانيات الاقتصادية السياحية المتفردة والمتتوعة للمحميات الطبيعية المصرية، والتي كان من المتوقع أن تضع مصر على قمة الهرم السياحي عالمياً، سواء فيما يتعلق بعدد السائحين او الإيرادات السياحية (المنتدى الاقتصادي العالمي دافوس، تقان تقرير

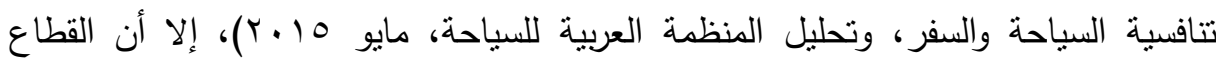
الاقتصادى السباحي المصري يواجه العديد من التحديات ومنها مناطق المحمبات التي تعانى من قصور شديد في النواحي الاقتصادية سواء فيما يتعلق بتوزيع الأنشطة والاستخدامات داخل

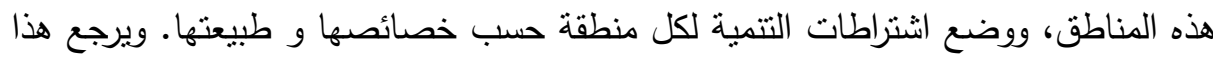

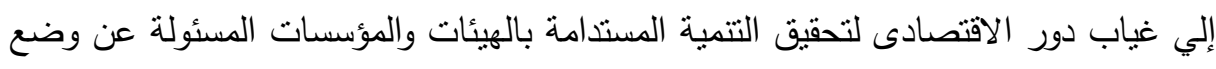
مخططات لتنمية المناطق الطبيعية، لتعمل علي إيجاد التوازن بين تحقيق أهداف حماية البيئة الطبيعية وأهداف التتمية ،حيث تطورت فكرة المحمية الطبيعية من الرغبة فى توفير مظلة 
الحماية البحتة للبيئة الطبيعية الى الحماية التى تحقق اوجه استفادة متعددة، الامر الذى بتيح

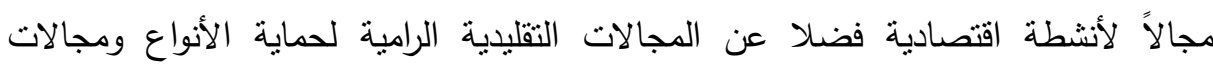

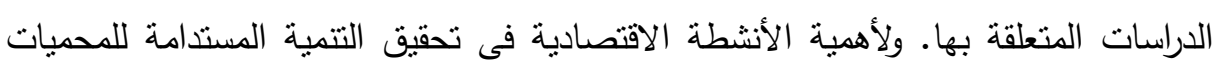
الطبيعية، كان لابد أن نتتاول بالنقاش والتحليل وجهات النظر المختلفة، والمنباينة حيال تعريف مفهوم التتمية المستدامة، وأهم الاتجاهات الرئيسية فى الانشطة الاقتصادية البيئية

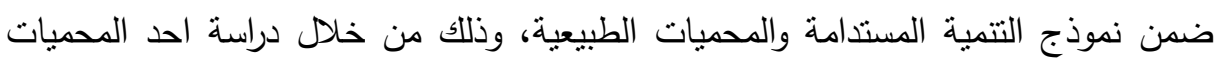
الامريكية النى تتميز بتحقيق دخل ومقارنتها بأحد المحميات الطبيعية المصرية، لبيان كيفية

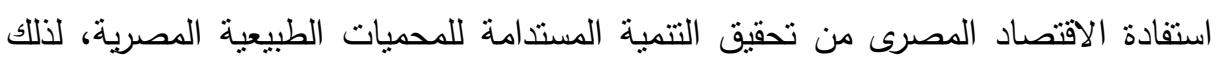
من الأهمية اعداد نظام لتحقيق التتمية المستدامة، يتم فيه نتظيم وتوزيع عناصر الإنية الانشطة الاقتصادية البيئية من بيئة مشيدة وأنشطة واستخدامات بما ينوافق مع تحقيق أهداف إنشاء

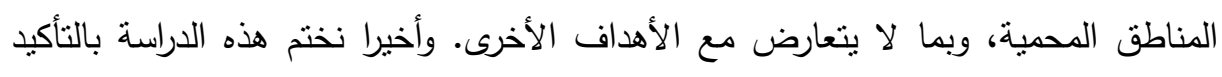

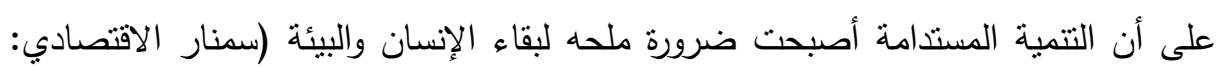

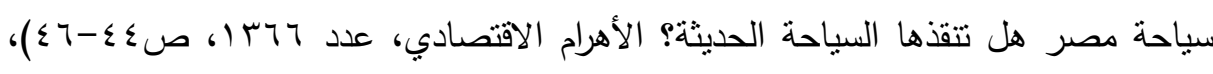
وأن انجازها يتطلب حدوث تغييرات جذرية في مجالات التفكير والبناءات الاقتصادية

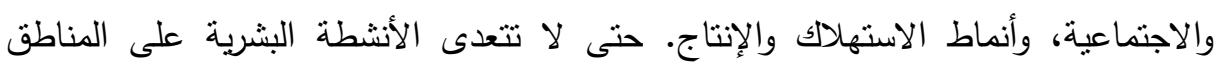

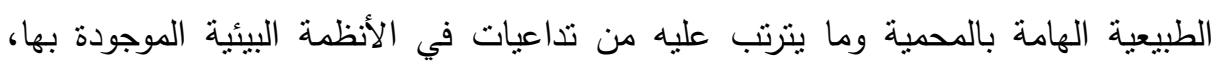

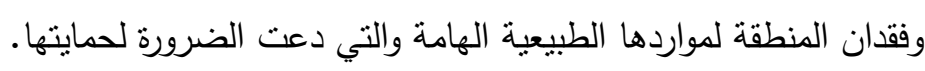

\section{مئهill}

تكمن المشكلة الرئيسية للبحث في احتلال مصر لترتيب متأخر في المؤشرات العالمية

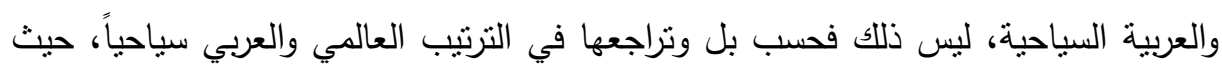

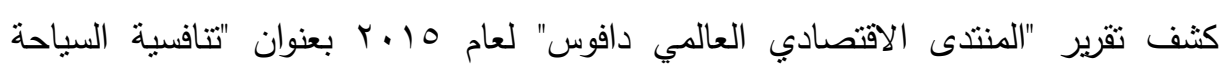

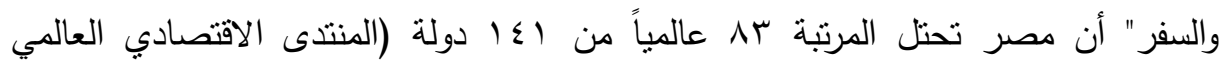

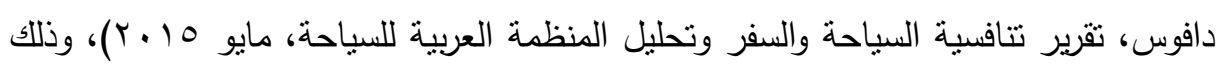

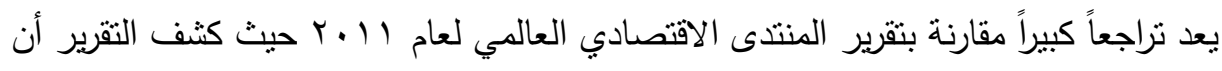

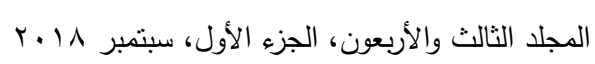


مصر تحتل المرتبة Vo عالمياً من وبا دولة (المنتدى الاقتصادي العالمي دافوس، تقرير

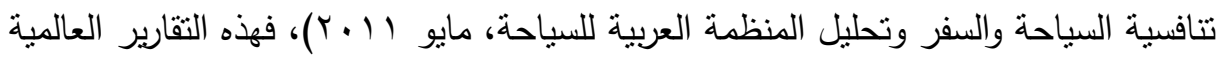

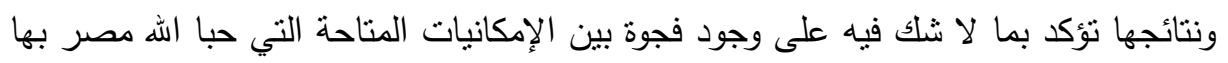

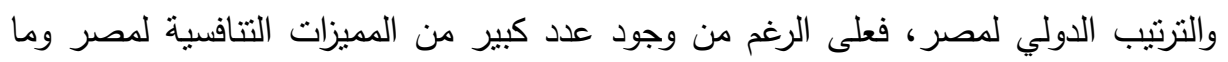

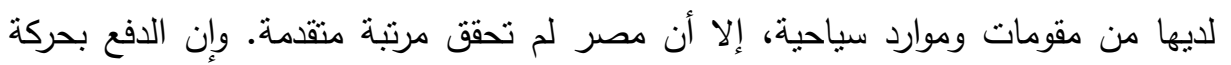

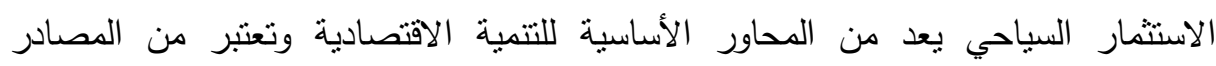

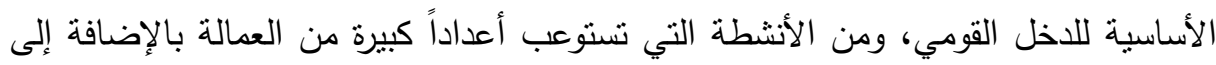
التنمية الاجتماعية المصاحبة لها. وبالرغم من امتلاك مصر لمقومات سياحية إلا أن الكثير منها لا يصل للعالم الخارجي، وتتلخص الصورة الذهنية لمصر في الخارج على الأثار الفرعونية وذلك نتيجة أنه لا يتم

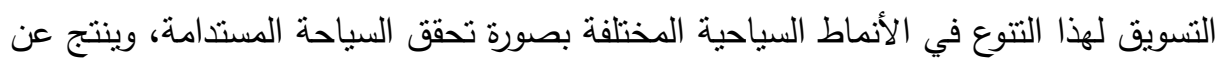
ذللك هدر للعديد من فرص التتمية الاقتصادية وزيادة الدخل القومي خاصة الأجنبي. وتتمنك المشكلة الرئيسية في أنه رغم تتوع وتعدد المناطق السياحية ومنها المحميات الطبيعية بالدولة المصرية، إلا ان المحميات الطبيعية المصرية لاتحقق التتمية الاقتصادية

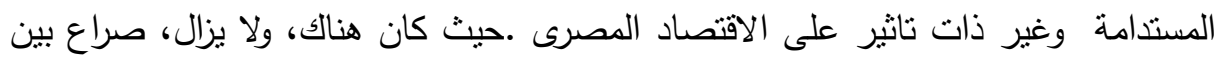

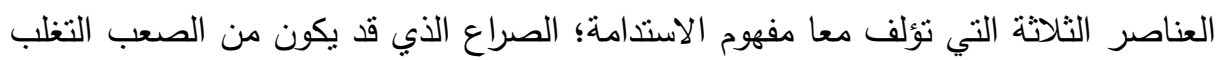
عليه. غالبا عندما يكون هناك حاجة للتتمية الاقتصادية في الجهة السياحية (خاصة المحميات الطبيعية)، وذلك لأن السكان المحليين يرغبون فى العمل بالسياحة لحاجتهم الى زيادة الدخل

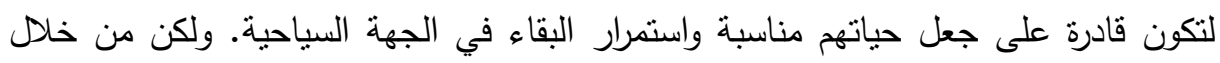

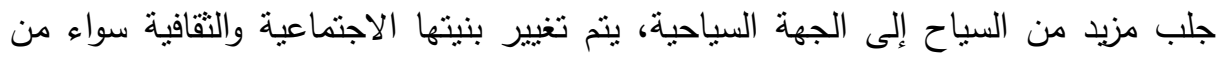

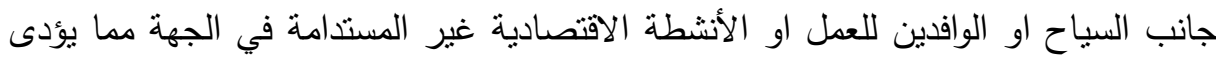

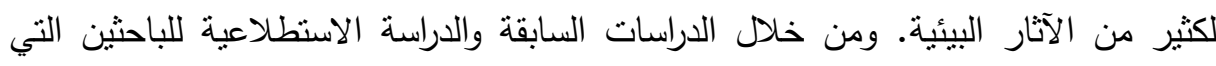

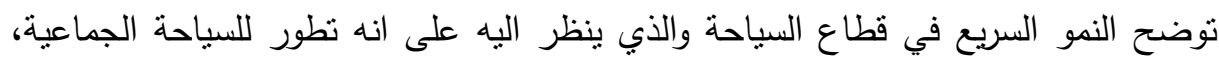
ولكن التي لا يمكن ان تتحملها البيئة، لما فى ذللك من استمرار النمو الثريطى السريع لـئه لمدينة

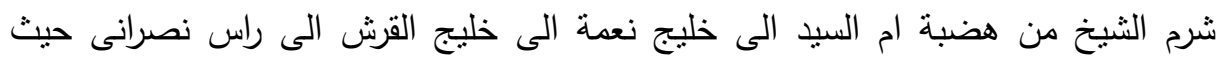

$$
\text { المجلد الثالث والأربعون، الجزء الأول، سبتمبر 11 ا. r }
$$


مطار المدينة ثم الى محمية نبق، مما أدى لتعدى الأنشطة البشرية على الحد الجنوبى للمحمية. تحديد المشكلة: الوضع الحالى سيؤدى الى تدهور الوضع البيئى بمحية نبق لذا كان لابد

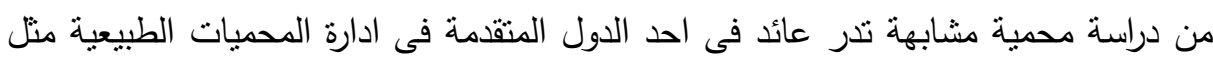
الولايات المتحدة الامريكية والاستفادة من هذه المقارنة فى تحقيق الاقتصاد المصنية احصرى للتنمية

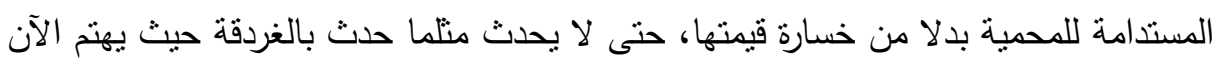

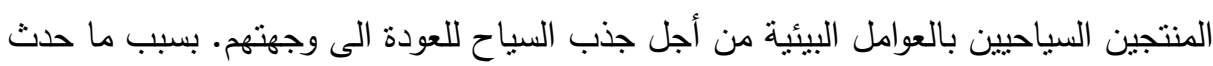

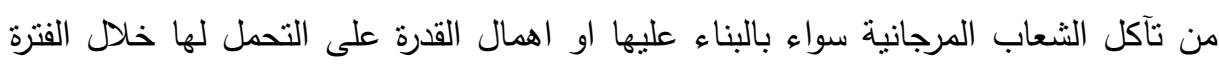

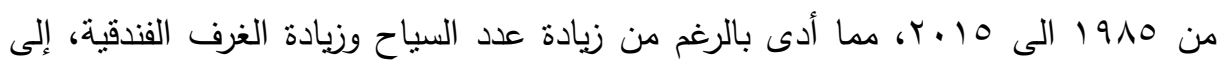
انخفاض في عدد الليالى السياحية التى يقضيها السياح وانخفاض فى الايرادات السياحية، وولجوئهم الى مناطق اخرى سياحية جنوب الغردقة مثل مرسى علم والمناطق التى ما زالت

\section{أسرئلة المهمه}

ينافش البحث بعض الموضوعات التي يمكن صياغتها في صورة مجموعة من الأسئلة

$$
\text { التي يحاول البحث أن يوضح أبعادها وإجاباتها: }
$$

سؤال جوهري: "ما إمكانية ان يستفيد الاقتصاد المصرى من تحقيق التنمية المستدامة بادية

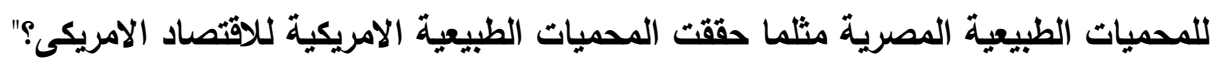
ومجموعة من الأسئلة الفرعية: • ما العناصر الاقتصادية المحققة للتتمية المستدامة بالمحميات الطبيعية؟ • ما الوسائل والاساليب والطرق التى من خلالها تحقق التتمية المستدامة للمحميات بالهيه

• والأنماط السياحية التي تخلق مناطق طبيعية أكثر تفضيلاً لاى السائحين؟ • ما التتمية السياحية المستدامة في المناطق الطبيعية وما هي تحدياتها؟

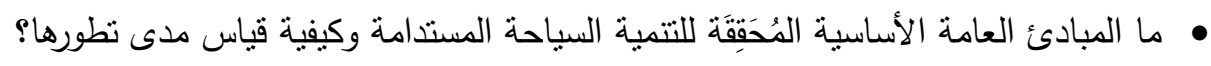

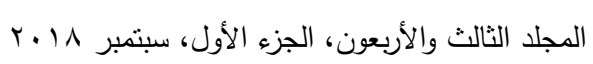




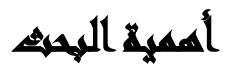

التعرف على اشتراطات التتمية المستدامة للمناطق المحمية لأعداد نظام للتنمية المستدامة لها، يتم فيه تتظيم توزيع عناصر التتمية المستدامة من بيئة مشيدة وبنية اساسية لتئه

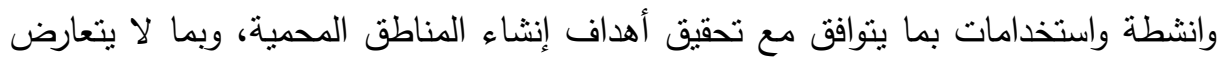

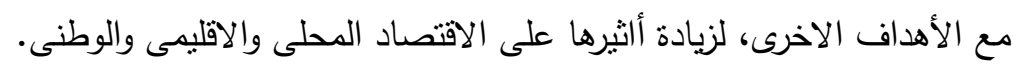
الأهمية على المستوى القومي: تدعيم الدكانة السياحية لمصر دولياً. وجذب الاستثمار

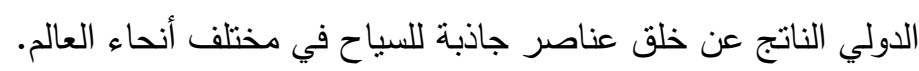
الأهمية على المستوى المحلي: تتشيط السياحة الداخلية والعالمية في مصر وزيادة الدخل القومي بمعدل كبير · زيادة فرص العمل التي تخلق ارتقاء اجتماعي واقتصادي وثقافي لتيطي في المجتمع المصري. الأهمية العلمية: لكونه محاولة لإيجاد دراسة تفصيلية وتحليلية تتتاول كيفية وضع خطط

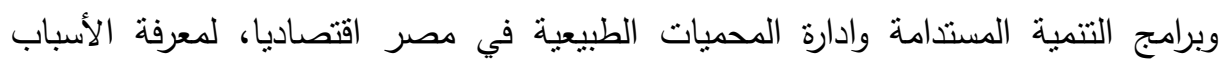

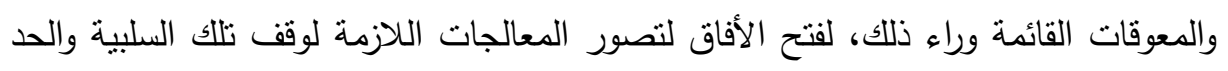

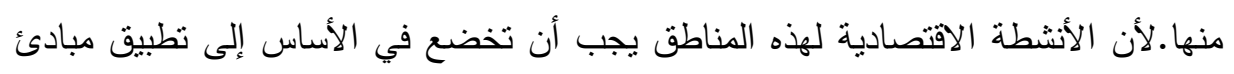
التتمية المستدامة، والتي تعتمد على أسس علمية مدروسة تضمن أن تبقى التتمية الاقتصادية

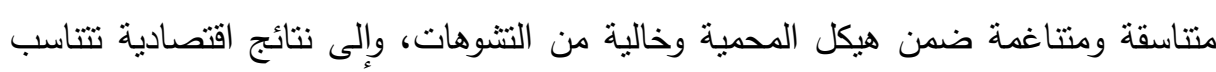
مع طبيعة المحمية. الأهمية التطبيقية: ان معرفة القوانين والتتريعات والعادات الاجتماعية والمتطلبات البيئية

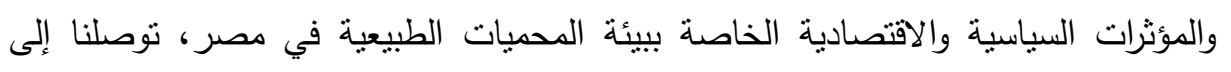
الأسباب الحقيقية الكامنة وراء عدم استغلالها، بالرغم من أن مساحة المحميات الطبيعية في

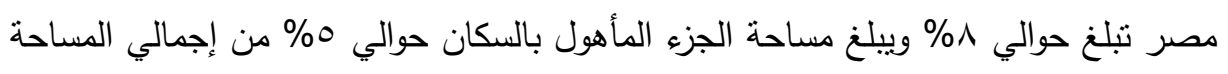
الكلية. ويلاحظ أن معظم الدراسات والرسائل العلمية تتتاول الجزء المأهول بالسكان وأهملت

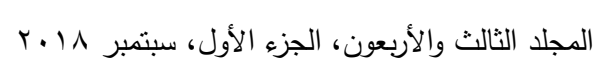


الجزء الخاص بالمحميات الطبيعية فكان الاتجاه نحو دراسته لكي يلقي مزيد من الضوء على الأفكار المختلفة التي تتعلق بتتمية وحماية المناطق الطبيعية اقتصاديا.

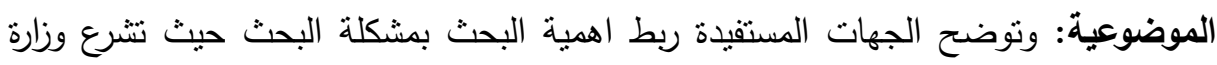
البيئة فى دراسة انثاء هيئة اقتصادية لتتمية المحميات الطبيعية. المساهمة فى مجال البحث من حيث امكانية التطبيق - النموذج لأن استخدام المحميات لتحقيق عائد اقتصادي يساعد على نتمية المنطقة المحيطة بها اقتصاديا.

\section{أهفالهي المهند}

يتمثل الهدف الرئيسى في دراسة وتحليل كيفية استفادة الاقتصاد المصرى من تحقيق التتمية المستدامة للمحيات الطبيعية المصرية من خلال دراسة مقارنة بين محمية كايب ماى داى

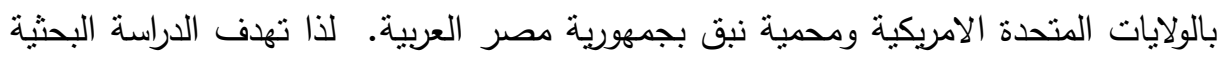

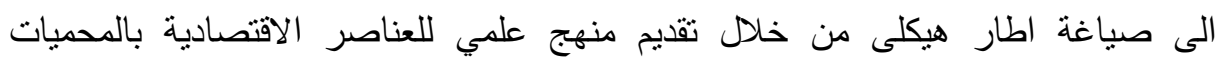

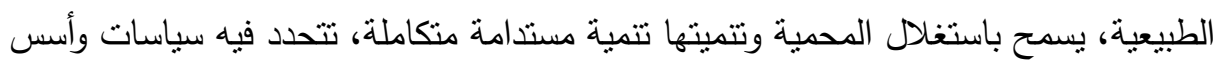

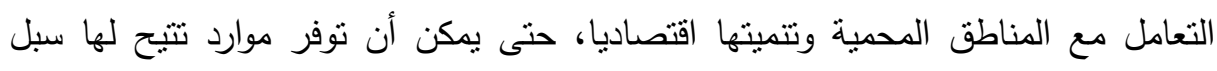

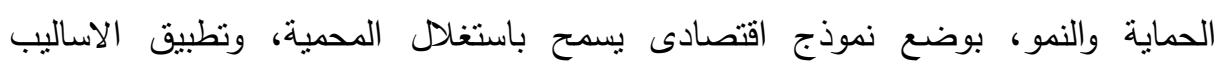
المستخدمة لتحقيق هذه التتمية فى بعض المحميات العالمية، من خلال إيجاد نوع من التوازن

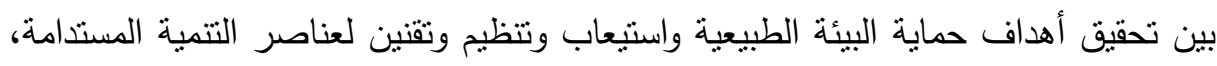
التي يمكن السماح بتواجدها في هذه المناطق.

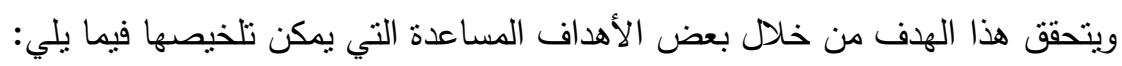
• التوصل إلى أهم العناصر الجاذبة للسياح، واستهداف فئات وشرائح كبيرة السياح.

• • دراسة حركة التنمية السياحية المستدامة في المنطقة ومدى أهميتها.

• تحقيق فهم شامل لعناصر التتمية المستدامة وكيفية تحقيقها والوصول إليها.

• أهمية الإلمام بالامكانيات الاقتصادية للمناطق الطبيعية المصرية لنطويرها والاستفادة بها.

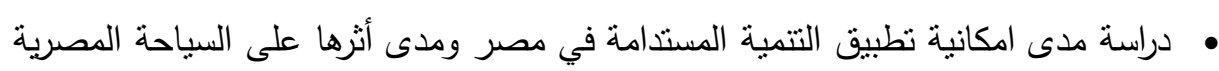
والارتقاء بها وإعادتها بنشاط غير مسبوق.

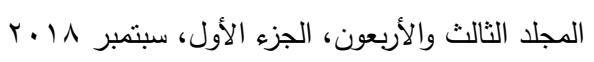




\section{التوراسايت الماريهنة}

عند استقراء الدراسات السابقة التي تهنم بدراسة السياحة البيئية والمحميات الطبيعية والتتمية المستدامة، وجد أنه لا توجد دراسات تتاولت هذا الموضوع بمصر ، لأن فرضية البحث

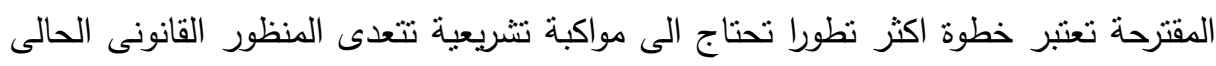

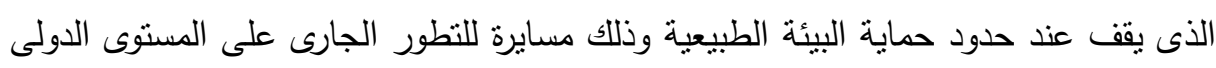

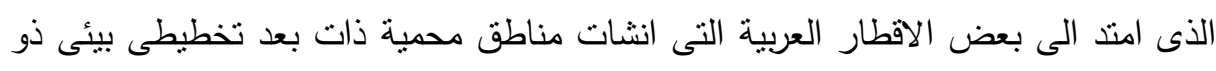

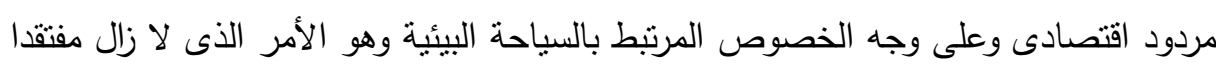

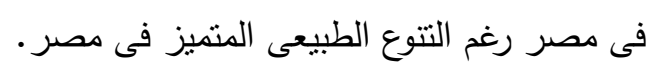
نتائج الاراسات السابقة: قام الباحثني بدراسة موضوعات لها علاقة بموضوع البحث:

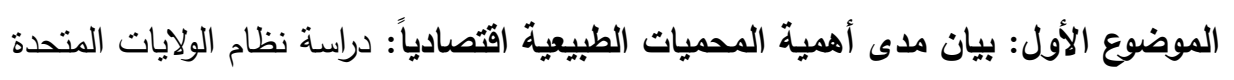

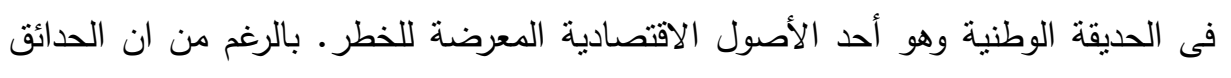

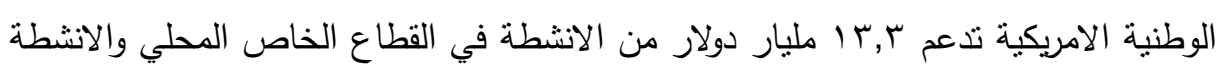

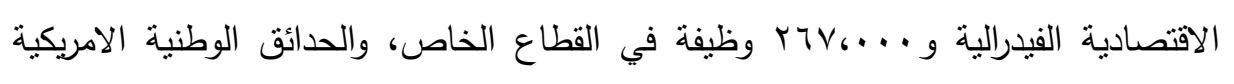

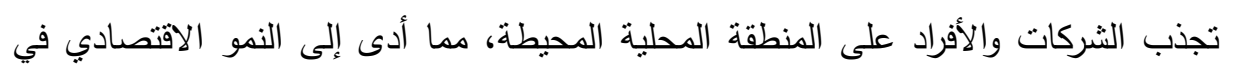

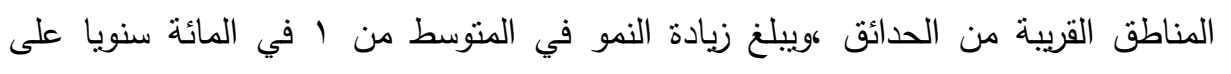

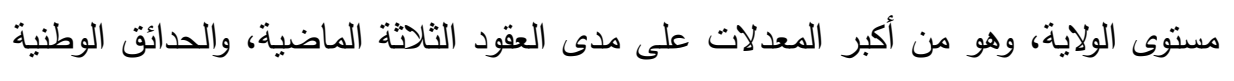

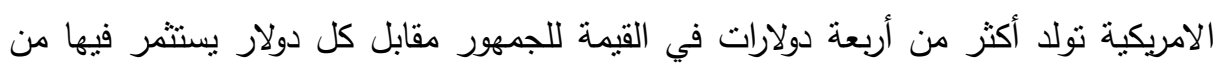

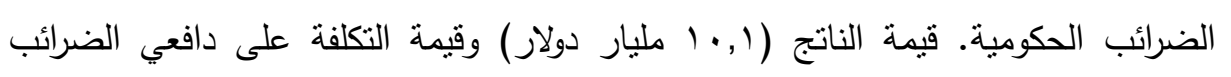

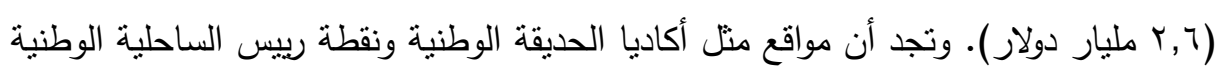
تولد أكثر من ـ ا أضعاف القيمة الاقتصادية للجمهور مقارنة بميزانياتها السنوية. ولا تتجاوز النققات فى الميزانية السنوية الفوائد الاقتصادية الناتجة عن الجمهور ـ وهذه التقديرات متحفظة

$$
\text { القيمة بسبب القيود على أساليب التقييم. }
$$

فوائد الحدائق الوطنية كثيرة وتمتد إلى ما بعد القيم الاقتصادية. وللاستدلال على الأهمية

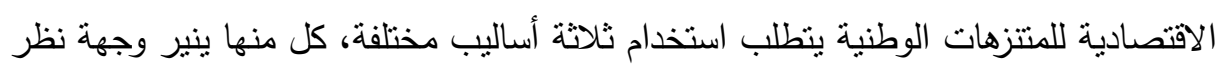

مختلفة: 
• استخدم تحليل التكاليف والفوائد لدراسة الفوائد الاقتصادية الوطنية للنظام النسبي لتكلفة حديقة لدافعي الضرائب. حيث نولد الحدائق الوطنية مجموعة واسعة من القيم الأخرى مثل: خدمات النظام الإيكولوجي مثل توفير الهواء النظيف والمياه؛ حفظ التتوع البيولوجي والبحوث العلمية، والتعليم، والقيم التقافية والروحية. وهي تثمل أيضا استخدام القيم السلبية مثل حفظ كنوز الامة الطبيعية والتاريخية. • تحليل الأثر الاقتصادي بالاضافة لما سبق تولد V,0 مليار دولار في الأجور والأرباح هذا

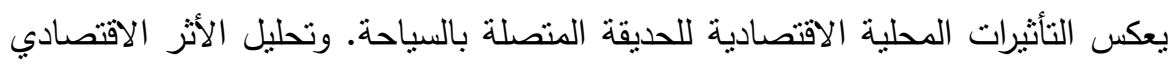
يوفر تقديرا لمستوى النشاط الاقتصادي من حيث المبيعات والوظائف والأجور والأرباح وتعتبر مؤشر إلى الاستثمار العام. وفي حالة المتتزهات الوطنية، ينفق الزوار المال على

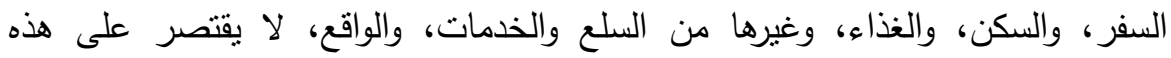
المعاملات مباشرة القابلة للقياس الكمي، لذلك نوجد الآثار غير المباشرة والنفقات السياحية من خلال تموج الاقتصاد. وبعبارة أخرى، ينفق الدخل المكتسب في قطاع السياحة محليا على السلع والخدمات الأخرى، من خلال نوليد المزيد من المبيعات، الوظائف، والدخل والأرباح وأمور السفر وطرق السفر. وكذلك المعدات وغيرها من السلع المشتراة لزيارة

قياس النمو الاقتصادي في المناطق حول الحدائق الوطنية. تلخص هذه الدراسة إجراء تحليلات أجراها باحثون في جامعة ولاية ميشيغان لدائرة الحدائق الوطنية باستخدام نموذج الجيل المالى r (MGM2) ويقارن هذا التقرير مختلف مؤشرات النمو الاقتصادي في لئي المناطق القريبة من الحدائق إلى جميع المناطق الأخرى. ويبين الأثر التراكمي للنشاط

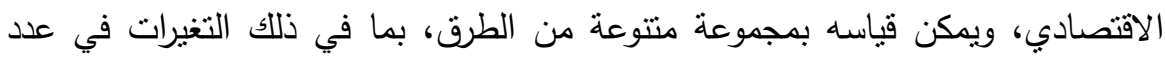

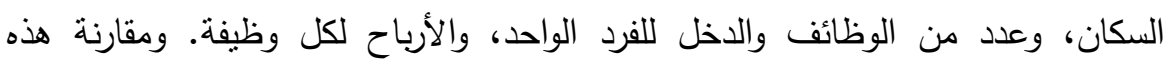
المؤشرات للمناطق القريبة من الحدائق الوطنية والمناطق البعيدة عنها يتيح لنا استخلاص استتناجات حول دور الحدائق كمحركات للنمو الاقتصادي. وهذه التحليلات تناولت السكان، والعمالة، ونصيب الفرد من الدخل على مستوى الولاية، وقد تجاوزت المعدلات

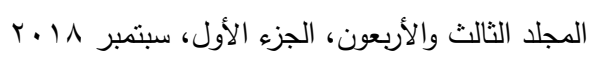


بمعدل (\% سنويا على مدى العقود الثناثة الماضية ومن أجل إجراء هذا التحليل، فإننا نعتمد على قاعدة بيانات التي وضعها معهذ سونوران لمكتب الولايات المتحدة لإدارة الأراضي. هذه البيانات نظهر بوضوح أن معدلات النمو في المقاطعات حول الحدائق تقوق المعدلات على مستوى الولاية. وهذا دليل آخر على أن الحدائق الوطنية ذات الأهمية

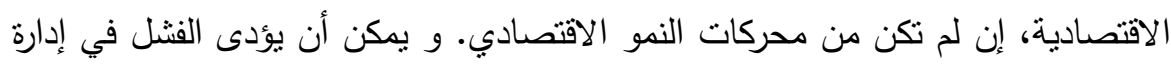

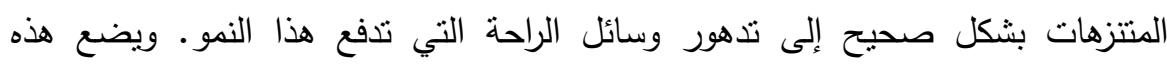

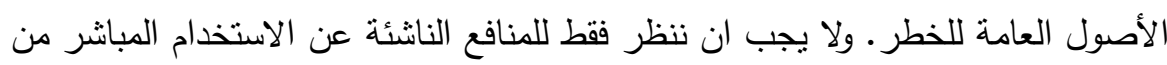

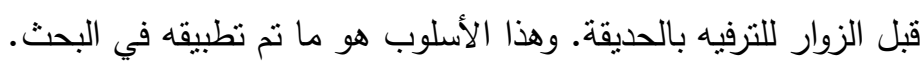

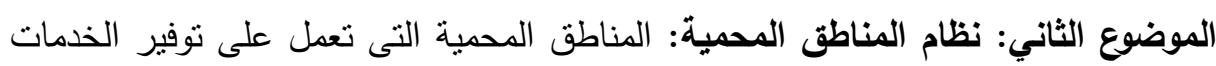

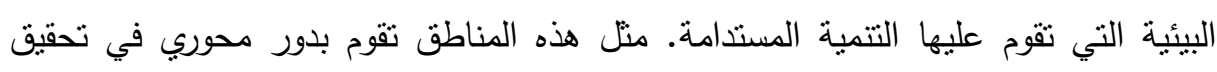
أهداف الأمم المتحدة الإنمائية للألفية الثالثة وتتفيذ توصيات مؤتمر القمة العالمي للتتمية

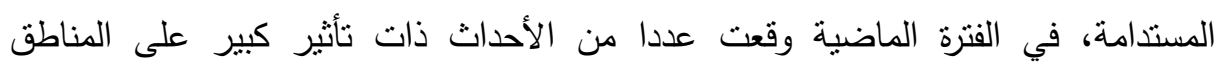

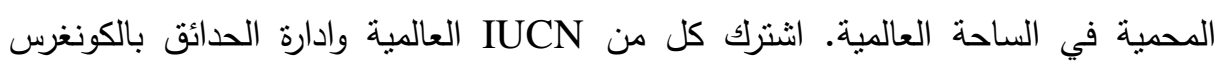

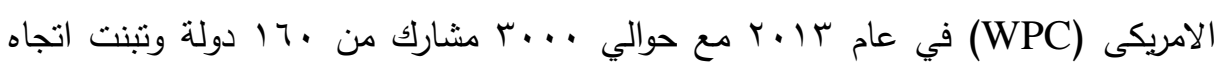

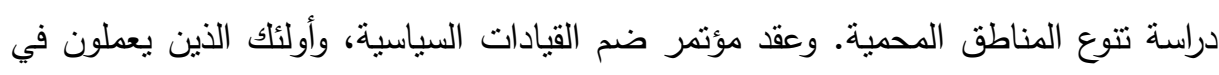
وكالات المناطق المحمية، والمنظمات غير الحكومية، ومجموعات السكان الأصليين، وركز

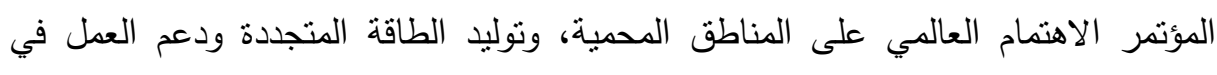
المستقبل. وأنتجت WPC أيضا مجموعة واسعة من النواتج التقنية التي لا تزال تشكل سياسة الطنة

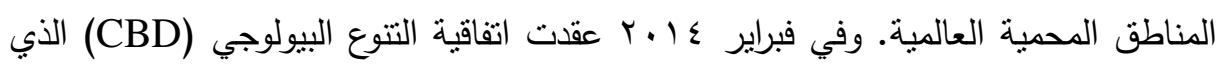
اعتمد في مؤتمرها برنامج شامل الأطراف، ووضع جدول زمني للخطط المستهدفة التى تهدف

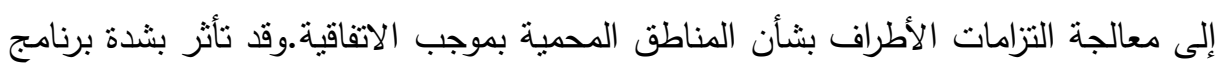
المناطق المحمية (PAPoW) من نتائج WPC التي ساعدت على صياغة سلسلة طموحة

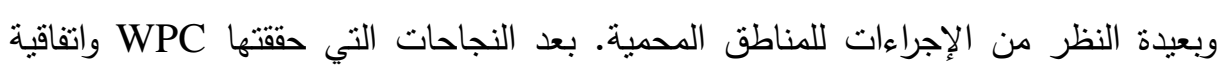
التتوع البيولوجي، ولم يكن هناك وقت أفضل، سياسيا وبرمجيا، للاستثمار في إجراءات أقوى لإنى

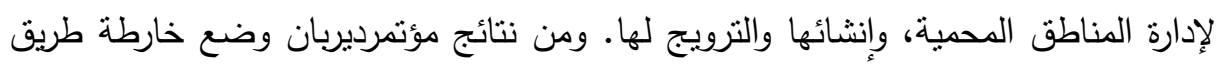


للعمل IUCN في المسنقبل في هذا المجال. وهذه الوثيقة مشروع يهدف لتوجيه العمل في المستقبل IUCN بثأن المناطق المحمية، مع التركيز على عقد الدورات الخاصة بالبرنامج.

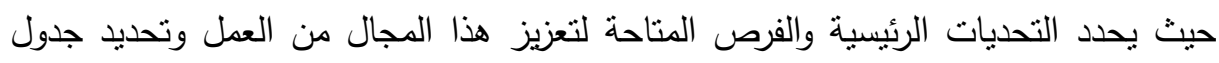

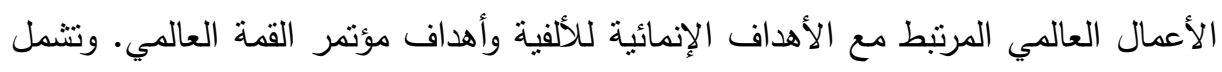
الوثيقة موضوعين: أولا، أن المناطق المحمية ليست غاية في حد ذاتها، بل يجب الأن أن تكون

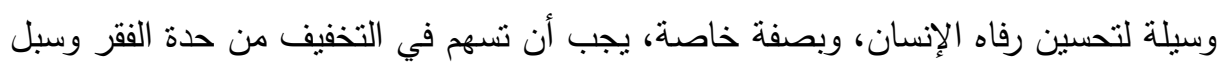

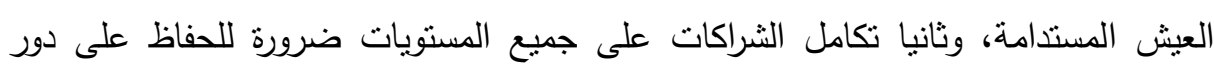

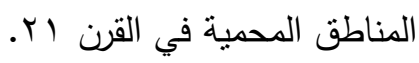

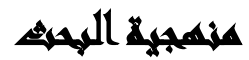

أولاً: نوع البحث: يعتمد البحث علي المنهج النظري التحليلي الاستقرائي، واستعراض

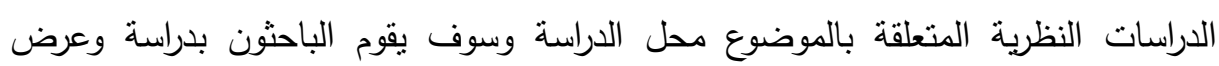

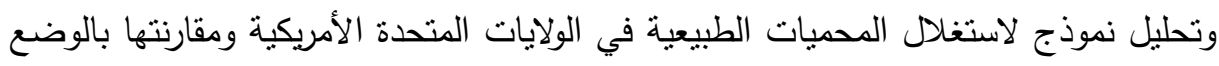

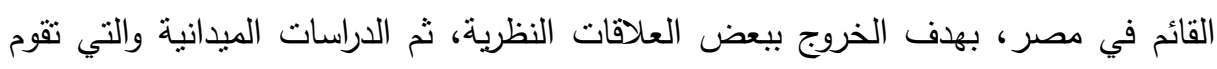
على منهج علمي عملي تطبيقي منظم بعتمد على مجموعة من الخطوات بهدف نطبيق التحليل على محمية نبق واستخلاص النتائج وعليه يأخذ البحث المراحل الآثية: الاراسة النظرية وتم اتباع فيها المنهج الاستقرائى:

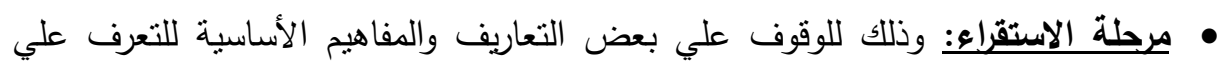
الجوانب المختلفة لأفكار حماية المناطق الطبيعية وتطورها. إضافة إلى محاولة توضيح الوضع المحلي وأوجه القصور والخلل في التجربة المحلية في حماية المناطق الطبيعية.

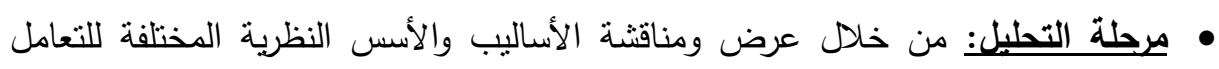
العناصر الاقتصادية ومنها السياحة البيئية لتتمية المناطق المحمية.

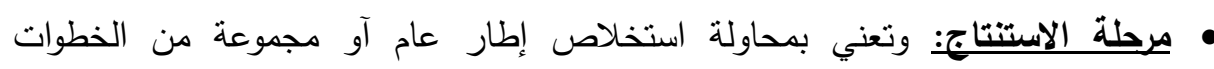

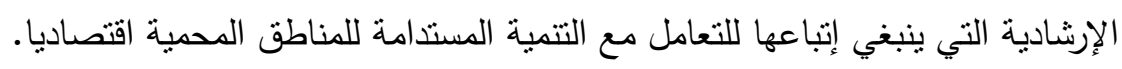

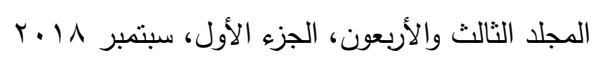


حيث إننا نحاول بناء مبادئ ونظريات عامة بواسطة جمع المعلومات الجزئية وتحليلها وربطها مع بعضها البعض،

الدراسة التحليلية وتم فبها اتباع المنهج الاستنباطى: وهو يشمل على دراسة وتحليل تجربة

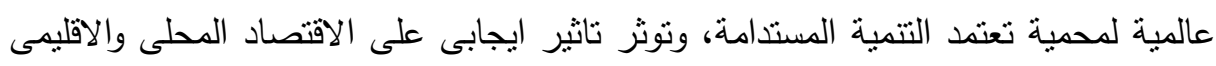
والوطنى، لتحقيق التنمية المستدامة وتقييمها مع استخلاص واستتاج العناصر والمعايير الواجب توفيرها لخلق تتمية مستدامة مميزة، ومن ثم تحقيق تاثير ايجابى على الاقتصاد، وشملت الدراسة تحليل تجربة محمية كايب ماى بولاية نيو جيرسى بالولايات الامريكية المتحدة كنموذج لدولة عالمية، قامت بالتطوير خلال ثلات سنوات، وللاسف لم نجد نموذج لمحميات في دول عربية او افريقية. من خلال مرحلتين: المرحلة الاوليى: الاراسات المبدانبة: • رصد وتوثيق لمنطقة الدراسة للإلمام بكل الجوانب التي تساهم في التحليل والتقييم.

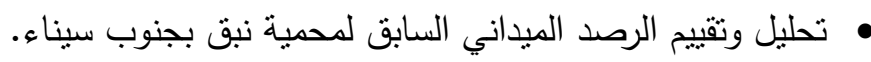

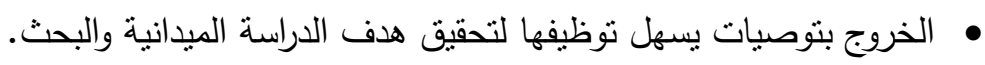
المرحلة الثانبة: نماذج المقارنة: عرض نموذج إدارة المحميات الطبيعية في الولايات المتحدة ومقارنتها بالنموذج المصري. وبتطبيق ما سبق دراسة الجزء التحليلي تمت فيه دراسة التتمية المستدامة بمحمية كيب ماى ودراسة التأثير على الاقتصاد الامريكى من خلال عدة نقاط: أولاها المقومات الطبيعية

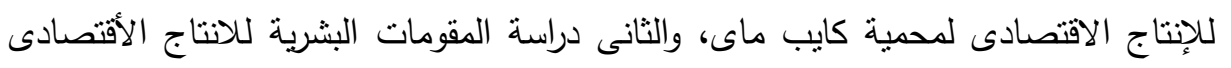

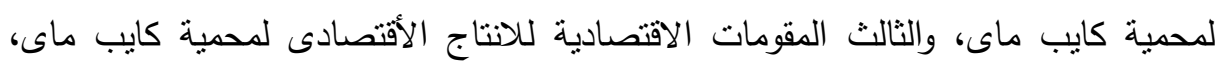

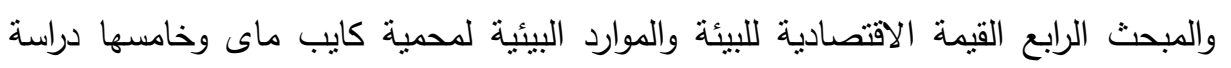
التأثير على الاقتصاد الامريكى من المحمية. ثم دراسة المبحث الثانى وهو دراسة النتمية المستدامة لمحمية نبق بمحميات سيناء ودراسة التأثثر على الاقتصاد المصرى من خلال عدة نقاط أولاها المقومات الطبيعية للإنتاج

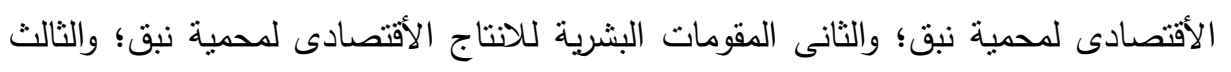


المقومات الاقتصادية للانتاج الأفتصادى لمحمية نبق؛ والرابع القيمة الاقتصادية للبيئة والموارد

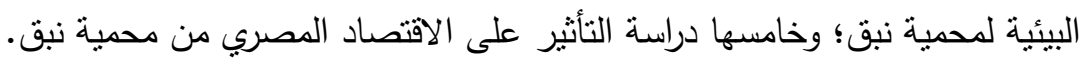
الدراسة التطبيقية: نم اتباع فيها المنهح التطبيقى الاستتباطى من خلال مرحلتين: المرحلة الأولى: أدوات البحث: سوف بدرس الباحثون استخدام السياحة البيئية للتحقيق التنمية المستدامة المحميات الطبيعية. المرحلة الثانبة: مجالات البحث: المبن: المجال المكانسي: اختير المجال المكاني للبحث بدراسة محمية نبق بجنوب سيناء، وفيهما ينت

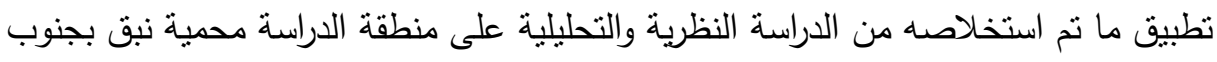

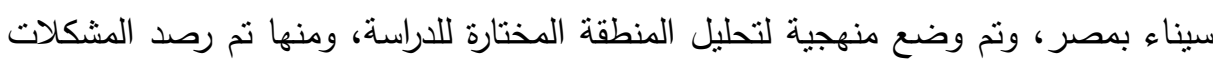
والامكانيات والمحددات والمعوقات الخاصة بالتتمية المستدامة لمحمية نبق، ومن ثم وضع

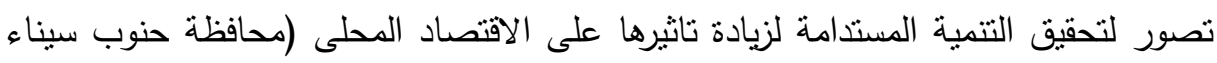
ومدينة نبق)، والاقليمى (إقليم سيناء والبحر الأحمر ) والوطنى لجمهورية مصر التهية العربية.

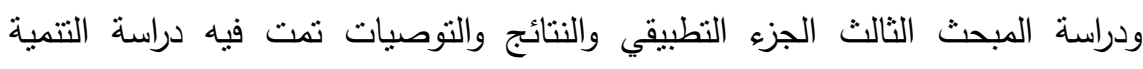
المستدامة لمحمية نبق من خلال أولاها نموذج التتمية المستدامة للمحميات الطبيعية والثانى

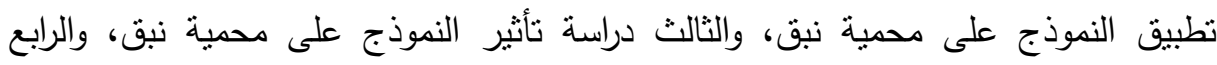
اشتراطات ومعايير التعامل مع المناطق الفرعية. ثم دراسة النتائج من خلال عدة نقاط أولاها

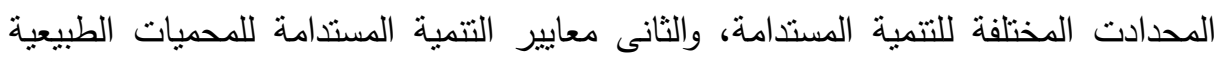
المصرية، والثالث تتمية دور المحميات في التنمية المستدامة. ثم دراسة الخروج بالتوصيات التهاته من خلال عدة نقاط أولاها مستوى استغلال الارض للمحمية، والثانى مسنوى الأنشطة الترفيهية، والثالث مستوى الدراسات والبحوث المستقبلية. 


\section{أسوامي المهمي}

المبحث الأول دراسة التثمية المستدامة بمحية كيب ماى ودراسة التأثير على الاملى الاقتصاد الامريكى:

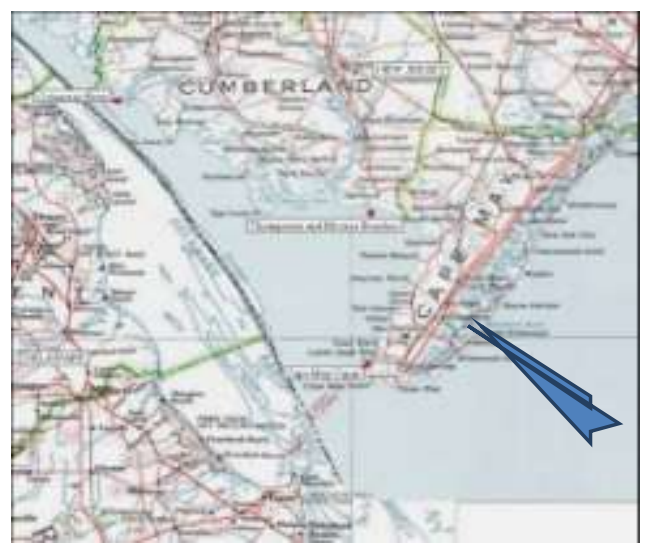
أولا: الاقتصادى المقومات الطبيعية للإنتاج - العلاقات المكانية: تقع منطقة الدراسة في مجتمع ساحلي في مقاطعة كايب ماي بولاية نيو جيرسي على طول سلى لمالي

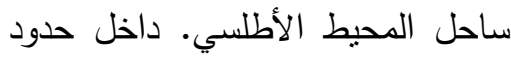

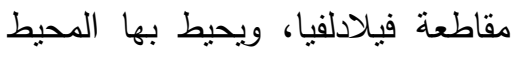
الأطلسي من الثرق والجنوب، وخليج

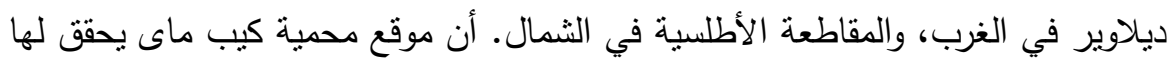

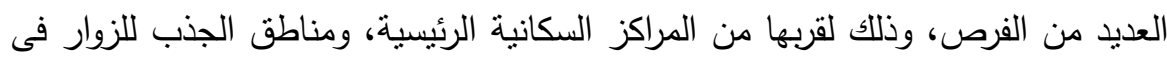

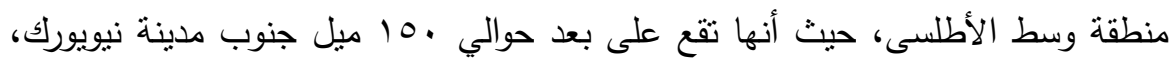
و • 17 ميل شمال بالتيمور، و عـ19 ميل شمال واشنطن العاصمة. انظر خريطة موقع المحمية للولايات الامريكية. • توزيع اليابس والماء: وتغطي المحمية r Y فدان، وتلتكون مساحة الأراضي الصالحة

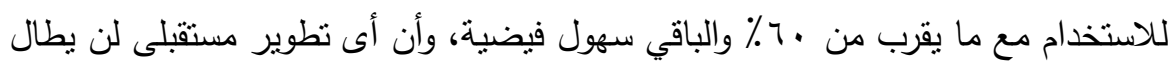

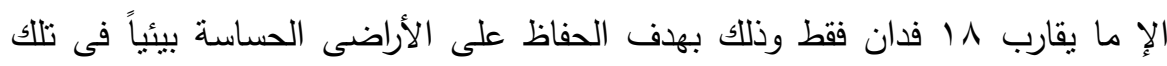

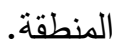
• مظاهر السطح Relief: المحمية الطبيعية مليئة بالكثبان الرملية، والأراضي الرطبة

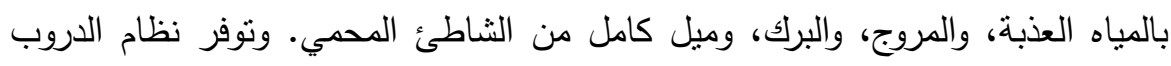

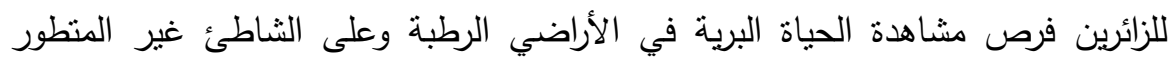

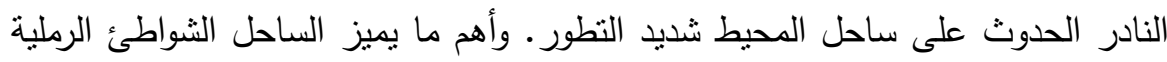

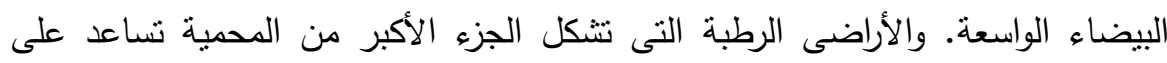
628

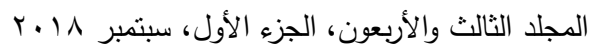


تخزين المياة والتحكم فى الجريان السطحى لها، وعلى الحفاظ على الحياة البرية، وهى تشكل خط حماية للشاطئ والذى يجب السعى للحفاظ علية لما يشكلة من قيمة. • المناخ Climate: تتمتع كايب ماي بمناخ شبه استوائي رطب (Cfa)، نموذجي في

ولاية نيو جيرسي الساحلية، مع صيف حار ورطب وشتاء معتدل إلى بارد.

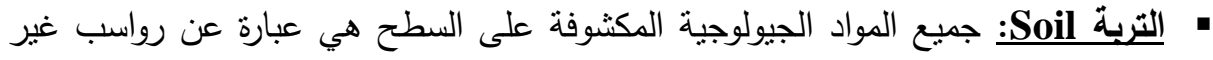
مجمعة، ترتكز على تشكيل مركب يتكون من رواسب من الرمل والحصى المهيمن مع كميات صغيرة من الطمي والطين. الحصوات الطينية بالقرب من السطح قد نكون نادرة. تتزاوح سماكة تكوين الرأس الرملي من بضعة أقدام إلى • با قدمًا.

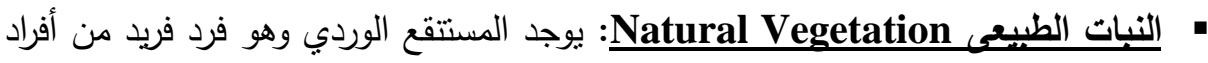
أسرة الزنبق يقع في القائمة الفيدرالية للحيوانات والنباتات المعرضة للخطر والمهددة، كما يحدث في عب نوعًا نبانيًا مُدرجًا في الولاية. ه الحيوان الطيعـ Natural animals: نعمل المحمية كقع للطيور المهاجرة على طول طريق المحيط الأطلسي. توفر الأراضي المحمية هنا البحث عن موائل للطيور والراحة

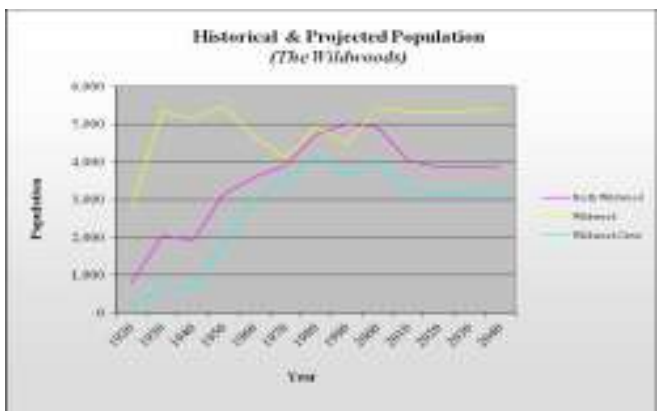

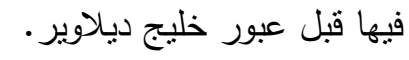

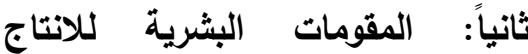

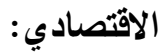
• المقومات الاجتماعبة: السكان: ازداد عدد سكان العديد من المجتمعات الساحلية على مدار الاعوام لزيادة المواليد، وللتقاعد اغلب المواطنين بهذه المجمعات الساحلية مما أدى لزيادة نطوير المساكن، وشهدت المدن المحيطة بالمحمية

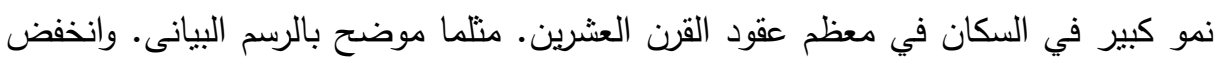
السكان على مدار السنة بشكل طفيف في جميع الثلاث مدن خلال السنوات الأولى من القرن 
الحادي والعشرين. المصدر : إدارة تخطبط مقاطعة كيب ماي. الرسم البيانى يوضح تطور عدد السكان لمدينة كايب ماى.

الكثافة السكانية: تتميز المناطق الثناث المحيطة بالمحمية بكثافة مأهولة بالسكان 97 .

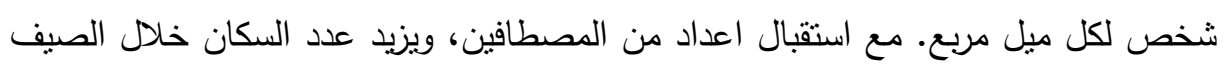

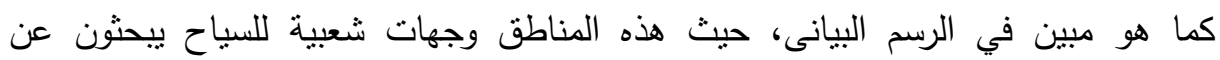

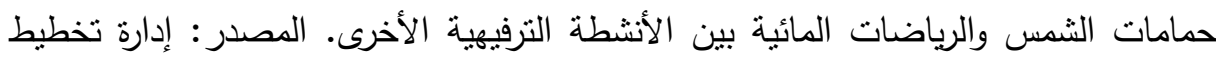
مقاطعة كيب ماي. الرسم البيانى يوضح عدد السكان خلال الصيف والثتاء لمدينة كايب ماى. - ماى نيادة السكان: ولقد شهدت المحمية نمو كبير للسكان فى معظم القرن العشرين وكانت أكبر

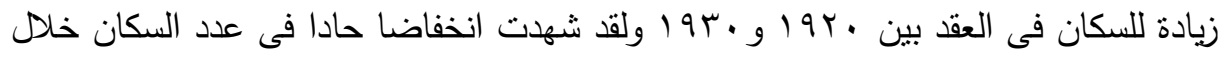

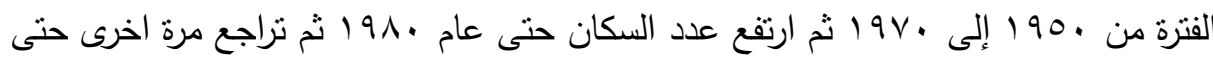

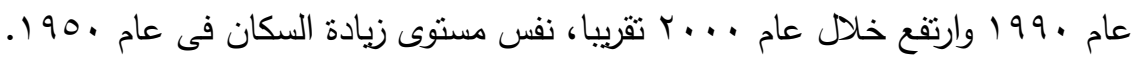

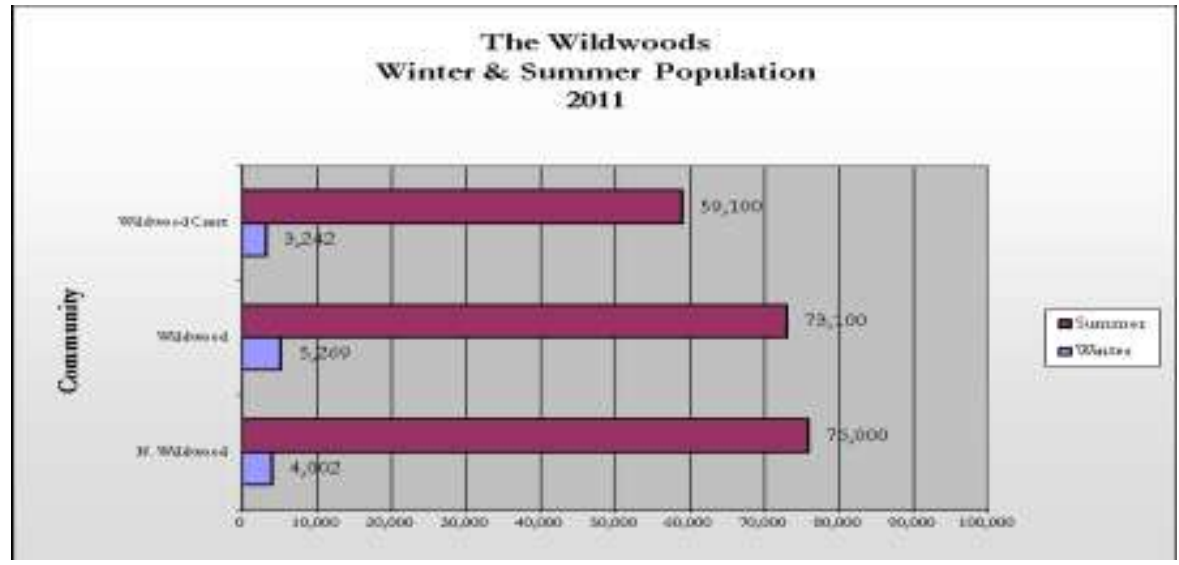

\begin{tabular}{|c|c|c|c|c|}
\hline \multirow{2}{*}{\multicolumn{4}{|c|}{ جدول( (1) دخل الفرد في كل من ولاية نيوجيرسي ومقاطعة كيب ماي }} & \multirow{3}{*}{ فيتوى المعشئة: دخل الفرد } \\
\hline & & & & \\
\hline المقارن & للفرد\$ & للاسرة\$ & قيمة السكن & \\
\hline الولايات المتحدة & TVGTYE & 01.9 & $\ln _{1} \Lambda_{6} \varepsilon \ldots$ & \\
\hline ولاية ن & $r \varepsilon_{6} \wedge 0 \wedge$ & 7961 & rov6... & ل حدة. \\
\hline مقاطعة كيب ماي & rr.oVI & $0 \leqslant$ 0रqY & $r r_{6} Y^{\prime} \ldots$ & \\
\hline
\end{tabular}




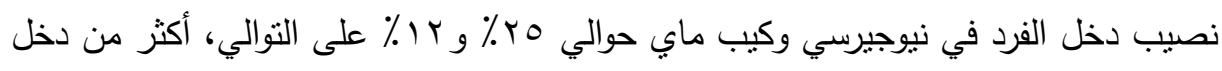

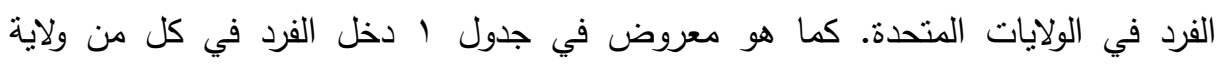
نيوجيرسي ومقاطعة كيب ماي و الولايات المتحدة.

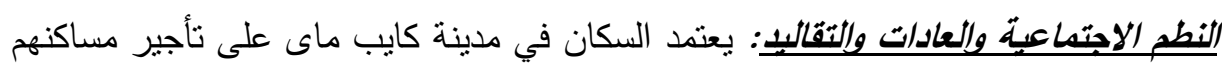

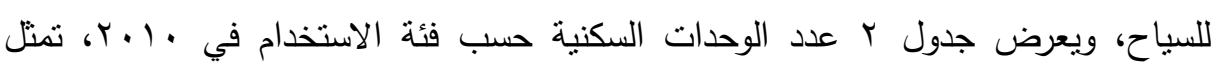

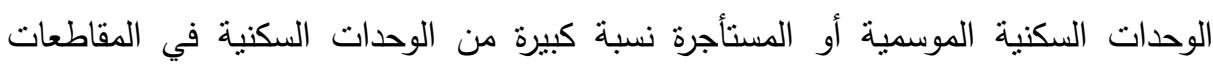

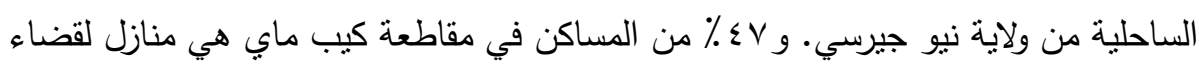

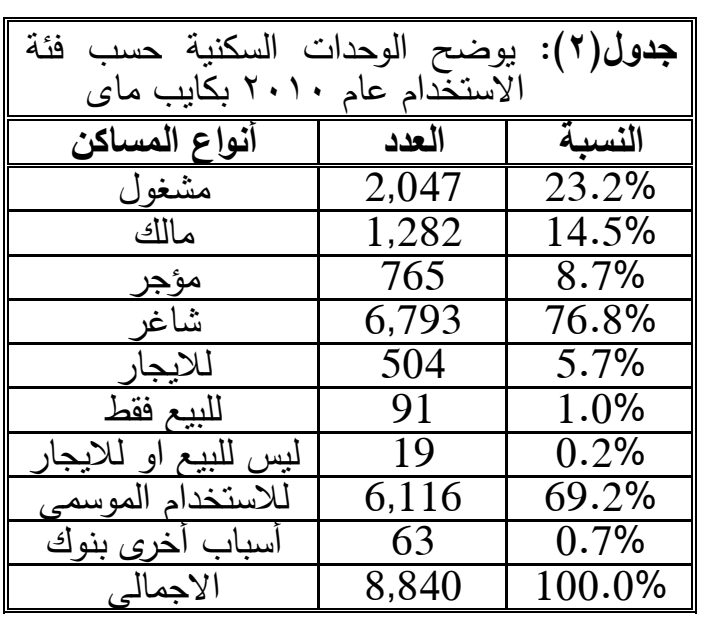
العطلات. بما يتقق مع غيرها من العيو

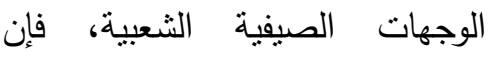
غالبية المساكن شاغرة ويتم تصنيفها

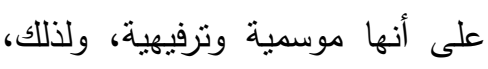

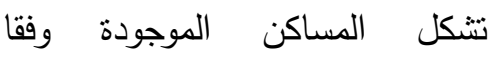

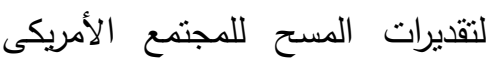

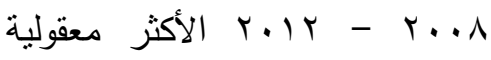
بالنسبة لقيمتها، حيث لم ينم تقييم أي بالي من الوحدات السكنية التي بشغلها لئهات المالك بقيمة فوق واحد مليون دولار .

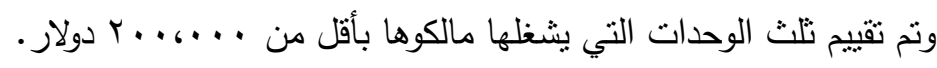
ثاثثاً: المقومات الاقتصادية للانتاج الاقتصادى:

النقل والمواصلات: يوجد شريانان رئيسيان للمواصلات يحيطان بالمحمية هما Garden State Parkway

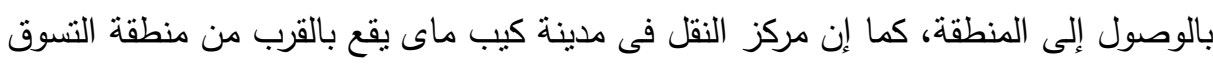

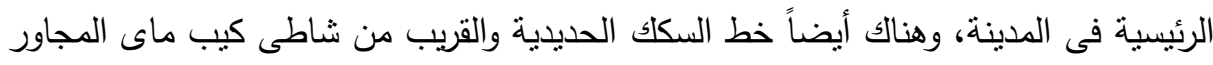


لكأس المال: التحليل الاقتصادي للمنطقة المحمية على ساحل المحيط بمحمية كايب ماي تتشمل الفوائد الإقتصادية والمحلية للمزايا المستغلة التي يتعين تقييمها لزيادة قيمة الترفيه. ونتشمل الموارد الإجتماعية، السكان واستخدام الأراضى. كما نم تحديد منطقة الدراسة على لفئل

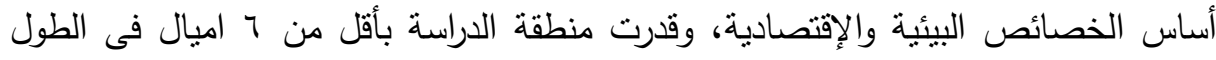

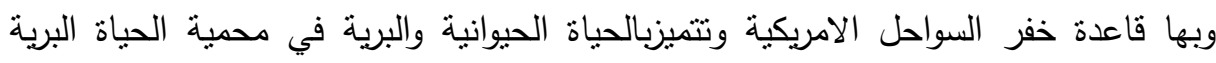

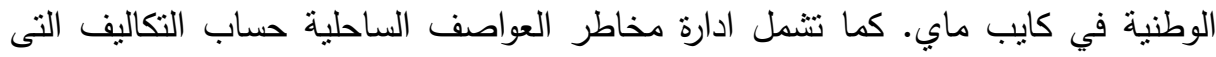
ستتفق من قبل الدولة والبلديات المحلية لحماية الممتلكات الساحلية. وتعد الثنواطئ محمية يتم

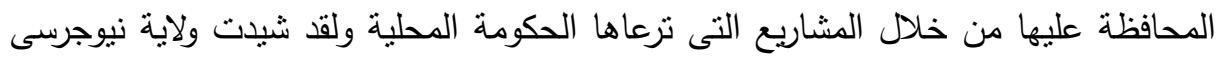

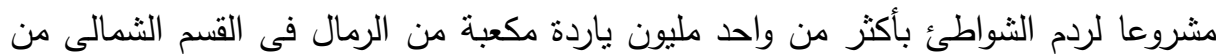

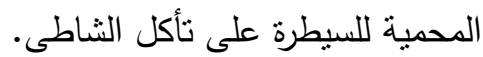
السبوق: ويتدفق السياح كل صيف إلى شواطئ محمية كايب ماي، والثُواطى والمنتزهات تمثل

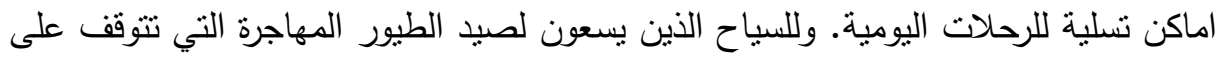

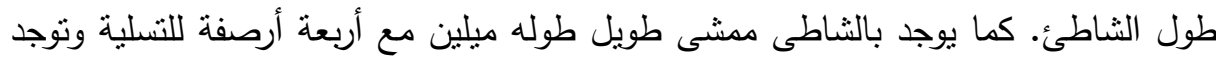

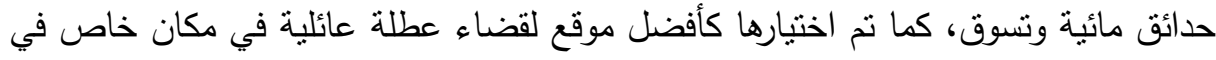

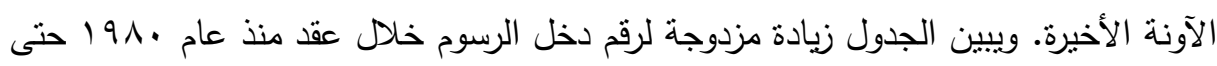

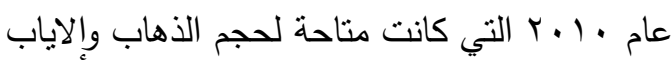

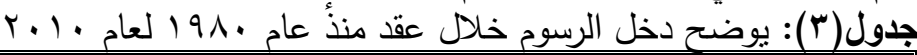

\begin{tabular}{|c|c|c|c|c|}
\hline Month & $\mathbf{2 0 1 0}$ & $\mathbf{2 0 0 0}$ & $\mathbf{1 9 9 0}$ & $\mathbf{1 9 8 0}$ \\
\hline \hline January & 496,754 & 446,112 & 228,904 & 92,442 \\
\hline February & 551,867 & 428,831 & 204,682 & 96,736 \\
\hline March & 639,809 & 487,619 & 255,719 & 131,512 \\
\hline April & 692,249 & 602,715 & 299,850 & 156,233 \\
\hline May & 986,735 & 824,296 & 521,234 & 280,945 \\
\hline June & $1,228,834$ & $1,137,115$ & 754,290 & 413,122 \\
\hline July & $1,631,363$ & $1,457,586$ & $1,085,620$ & 705,272 \\
\hline August & $1,610,985$ & $1,474,358$ & $1,222,330$ & 763,402 \\
\hline September & $1,078,875$ & 597,582 & 616,200 & 383,952 \\
\hline October & 780,884 & 602,155 & 349,060 & 163,288 \\
\hline November & 632,448 & 485,524 & 285,900 & 127,515 \\
\hline December & 598,975 & 441,973 & 267,530 & 118,150 \\
\hline Total & $10,929,778$ & $8,985,866$ & $6,091,319$ & $3,432,569$ \\
\hline Change & $22 \%$ & $48 \%$ & $77 \%$ & \\
\hline \multicolumn{5}{|l|}{} \\
\hline
\end{tabular}


التوظيف والثلخ: شهدت مقاطعة كيب ماي باستمرار معدلات البطالة أعلى من الدولة

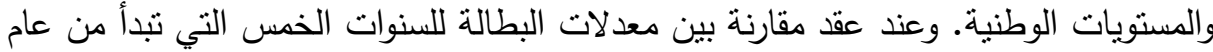

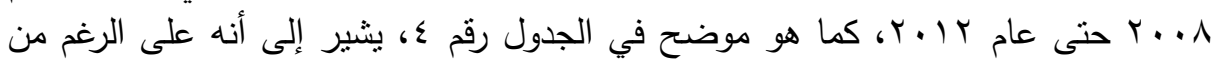
أن معدل البطالة في مقاطعة كايب ماي يتجاوز معدل البطالة في الولايات المتحدة الامريكية بأكثر من نقطتين لكل من السنوات الخمس في السطلة السلسلة الزمنية.

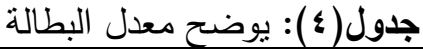

\begin{tabular}{|c|c|c|c|}
\hline السنة & امريكا & رسي & كايب ماي \\
\hline 2008 & 5.8 & 5.5 & 8.0 \\
\hline 2009 & 9.3 & 9.0 & 11.1 \\
\hline 2010 & 9.6 & 9.6 & 12.2 \\
\hline 2011 & 8.9 & 9.4 & 12.6 \\
\hline 2012 & 8.1 & 9.5 & 13.4 \\
\hline
\end{tabular}

المصدر: وزارة العمل الأمريكية

مكتب إحصاءات العمل، ومعدل البطالة أعلى بكثثر في منطقة الدراسة، ويدل على الاعنى العنماد

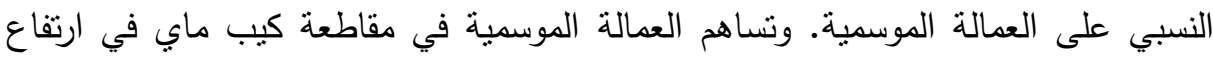

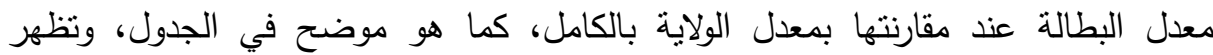
البيانات انخفاض معدلات البطالة..

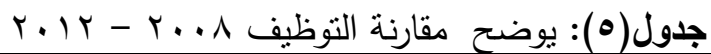

\begin{tabular}{|c|c|c|c|c|c|}
\hline \multirow{2}{*}{ 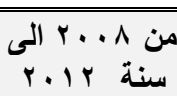 } & ولاية & \multicolumn{4}{|c|}{ المدن الثشاطية } \\
\hline & نيو جيرسى & كيب ماي & الأطلسى & المحيط & مونماوث \\
\hline معدل البطالة & 9,0 & $1 \mu, \varepsilon$ & $1 \Gamma, 0$ & $1 \cdot, r$ & $\Lambda, 9$ \\
\hline العاطلون & $\varepsilon r_{0} \ldots .$. & V.V9T & $1 \Lambda_{6} r V V$ & $Y V_{6} q \leq \varepsilon$ & $r q, q . \varepsilon$ \\
\hline عدد العاملين & $\varepsilon_{6} 101_{6} \ldots$ & $0.649 V$ & $1 T_{16} \mid Y_{0}$ & $T \leqslant \varepsilon_{6} \mid Y_{0}$ & $r \cdot \varepsilon_{6} q \cdot \varepsilon$ \\
\hline
\end{tabular}

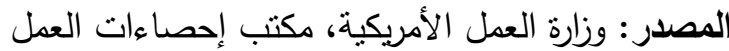

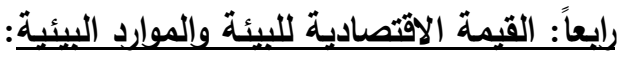
القيمة الاقتصادية الكلية = قيمة الاستخدام المباشر + قيمة الاستخدام غير المباشر + القيمة المحتملة مستقبلا + قيمة الوجود الائمادية

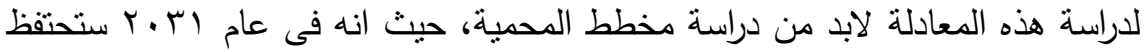
محمبة كيب ماى بشخصية فريدة من خلال المساحة المفتوحة، وحماية الموارد البيئية،

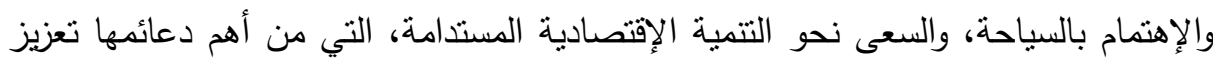
السياحة فى محمية كيب ماى من خلال استراتيجيات التتمية السياحية والإقتصادية. والتى الإنى

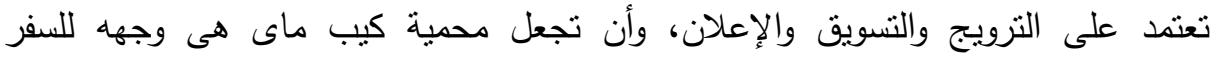

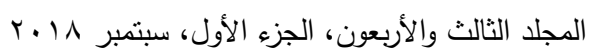


وصناعة السياحة البيئية وتوفير الحماية من العواصف، وإيجاد مصادر طاقة بديلة (استخدام

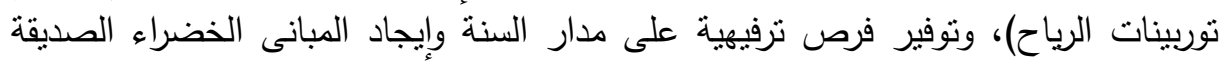

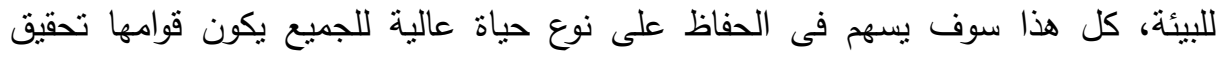

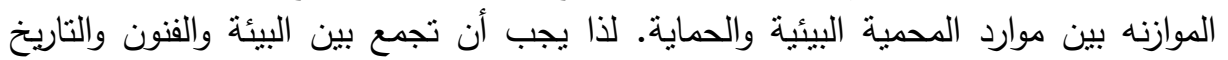

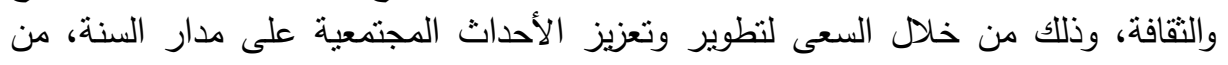

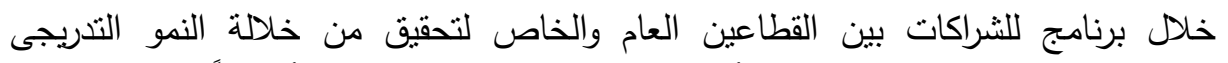

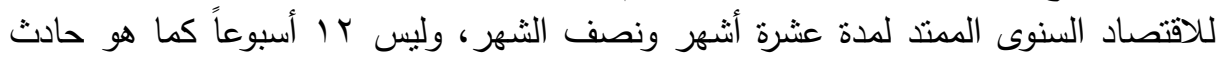

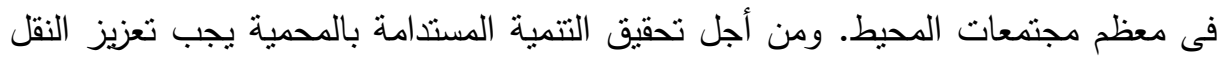

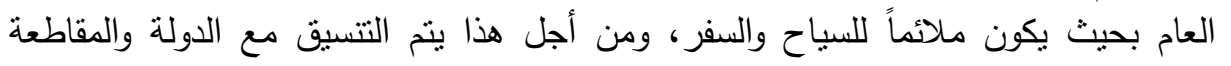

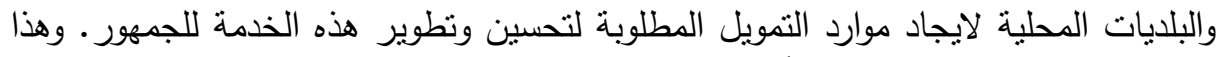

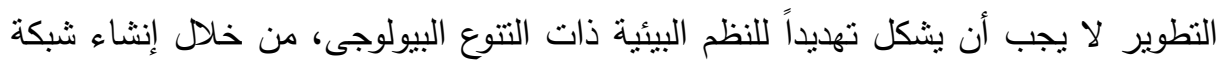

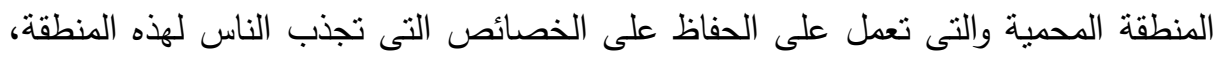

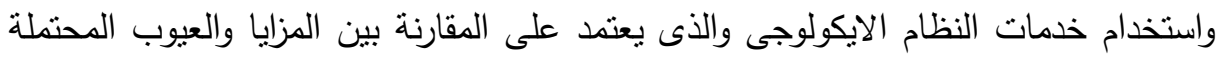

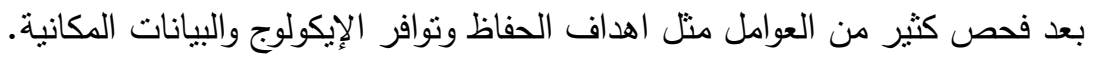

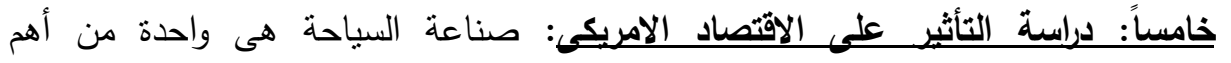

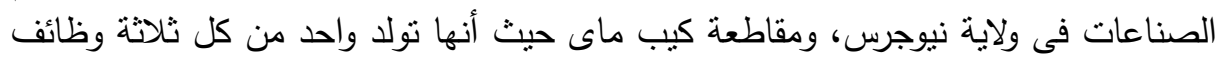

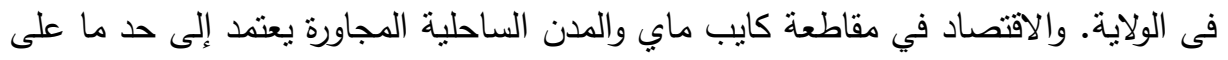

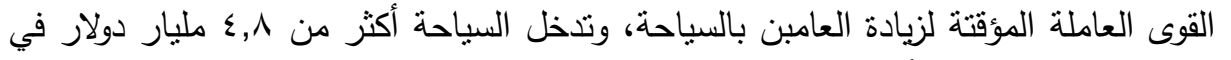

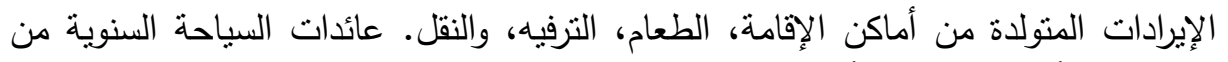

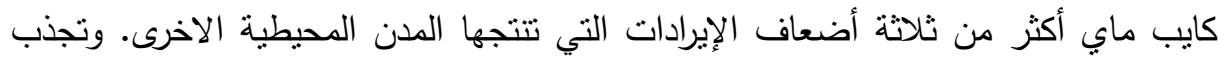

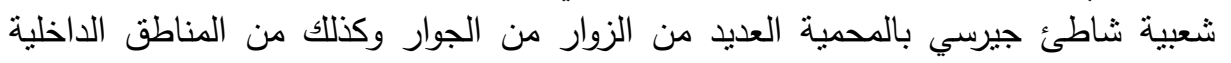

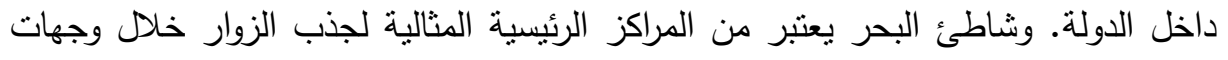

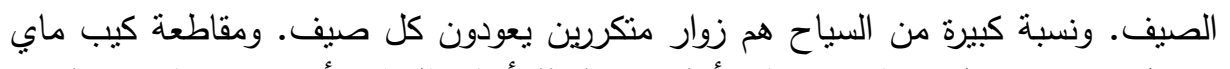

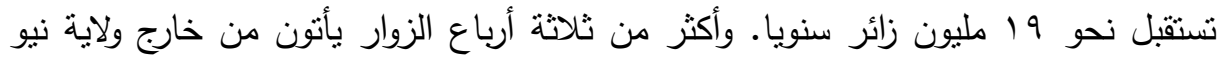

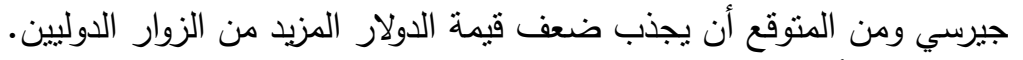

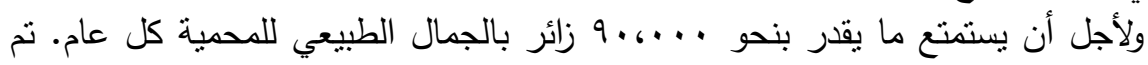

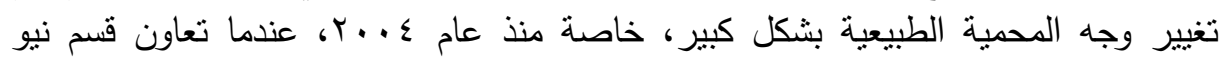

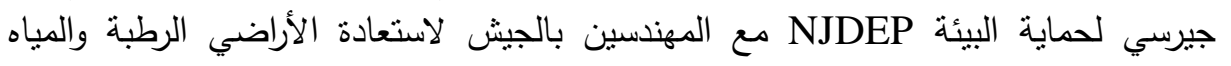

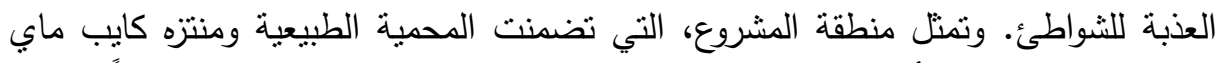

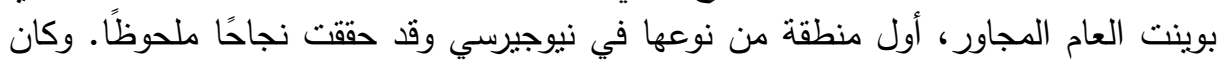
الهدف هو إعادة المشهد المتدهور إلى حالة أكثر إنتاجية وطبيعية من أجل حماية المجتمعات 


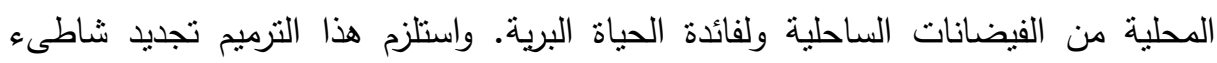

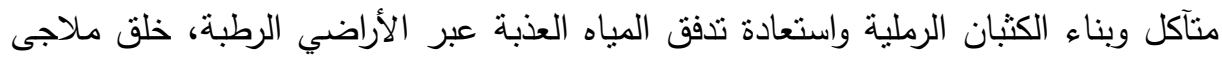

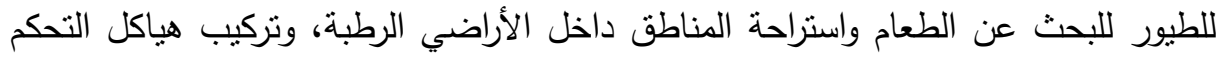

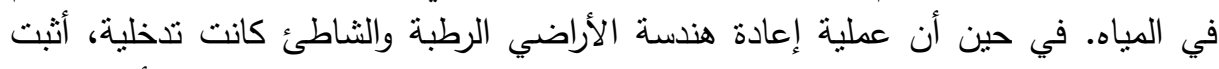

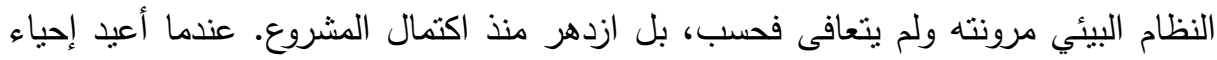

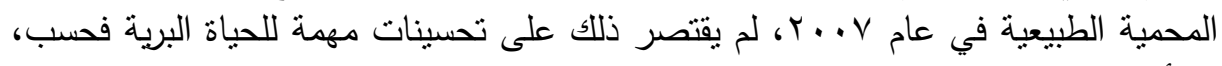

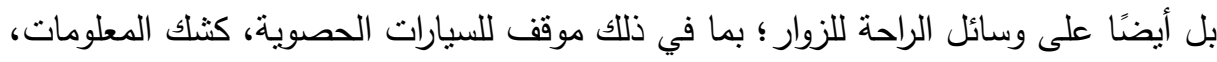

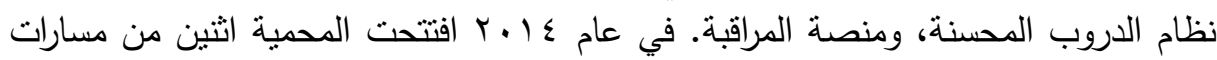
الأقدام الجديدة.

المبحث الثثاني: دراسة التثمية المستدامة لمحمية نبق بمحميات سيناء ودراسة

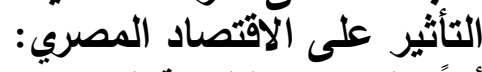

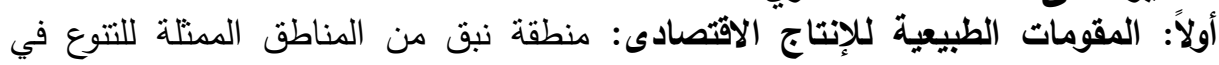

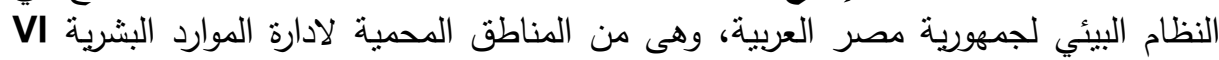

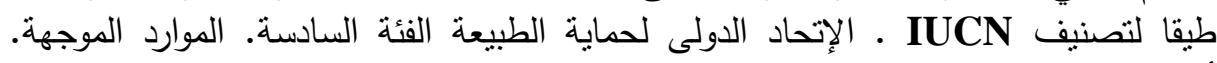

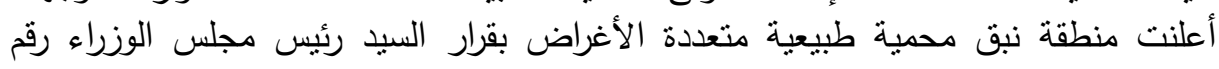

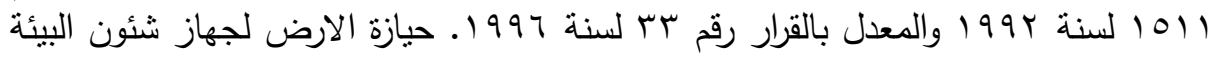

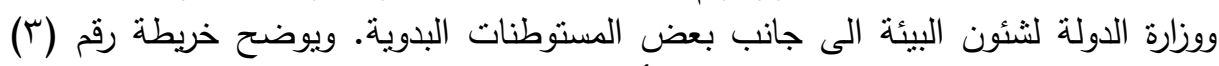

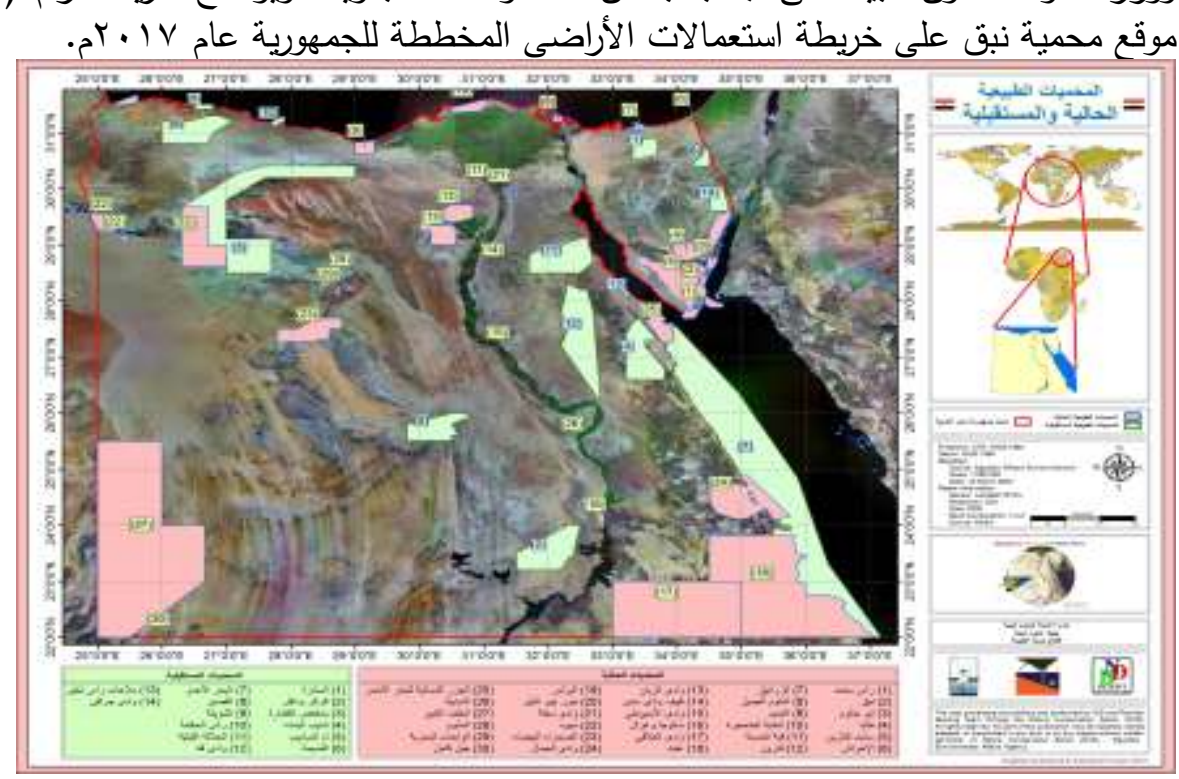

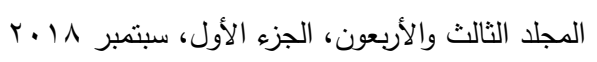




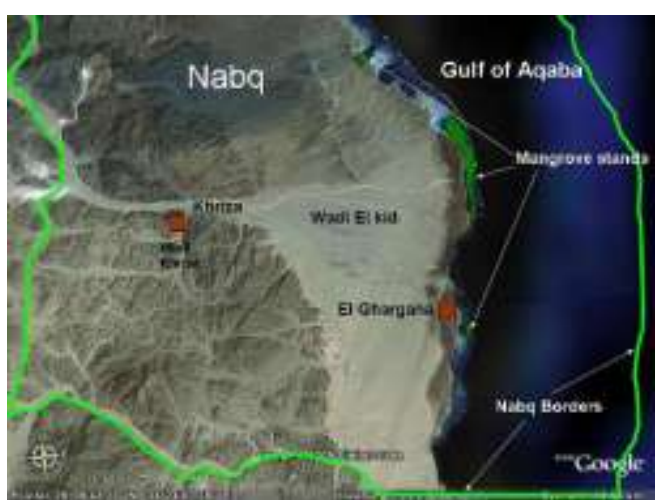

$$
\begin{aligned}
& \text { • العلاقات المكانية: تقع هذه } \\
& \text { المحمية على خليج العقبة في لقعلية }
\end{aligned}
$$

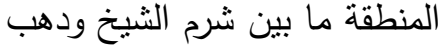

$$
\begin{aligned}
& \text { ووادي أم عدوي في جنوب سيناء } \\
& \text { وتبعد المحمية و ro كيلو منراً } \\
& \text { شمال شرم الثيخ. يحد منطقة }
\end{aligned}
$$

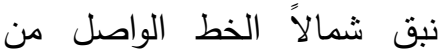

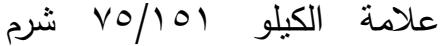

$$
\begin{aligned}
& \text { الثيخ - طلابا ماراً بوادى قنى } \\
& \text { الربان وبعمق r-0 كم من خط المان }
\end{aligned}
$$

الثعاب المرجانية- وماراً بوادى أم عدوى حتى انتقان الثقاله مع طريق شرم الثيخ/ طابا جنوباً

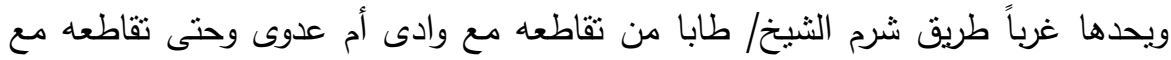

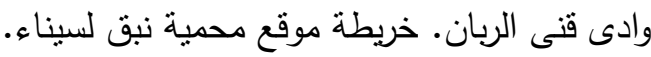

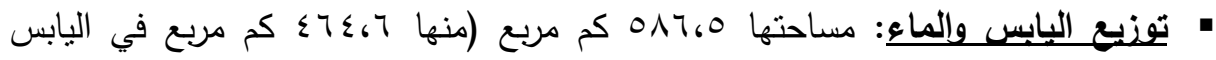

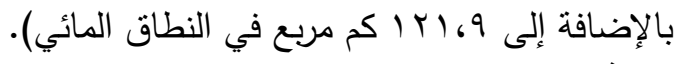

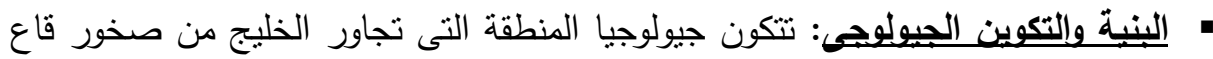
بلورية ونارية ومتحولة، يعلوها فى الثمال طبقة رسوبية رقيقة. وينقسم الترسيب في الخليج

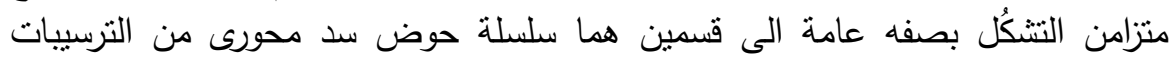

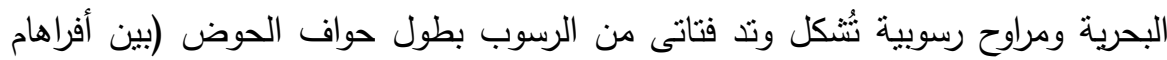

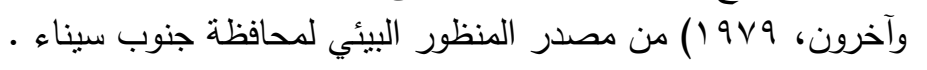

• مظاهر السطح: نتباين تضاريس المنطقة ما بين الجبال الثاهقة في الداخل وجهة الثناء الثمال

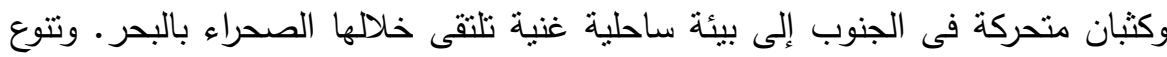

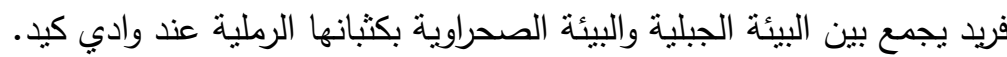

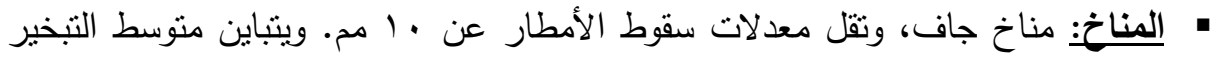
د _ . .

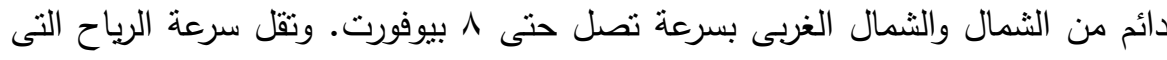
تهب من جهة الثمال عن 1 بيوفرت من مصدر المنظور البيئي لمحافظة جنوب سيناء.

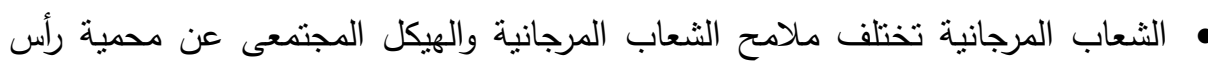

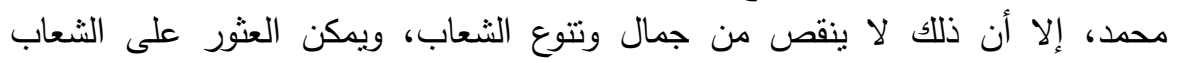
المتميزة ويسهل الوصول اليها بمنطقة شورى ونخلة التل. لفئ الفعاب، 
هالمانجروف يحد الخط الساحلى لمحية النبق ^,ـ كيلومتر من غابة المانجروف، ويتميز

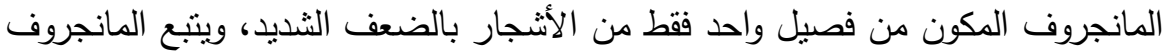

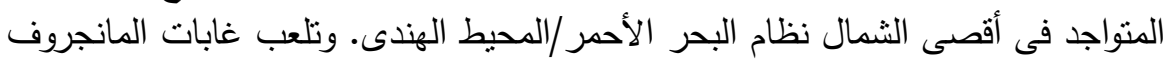

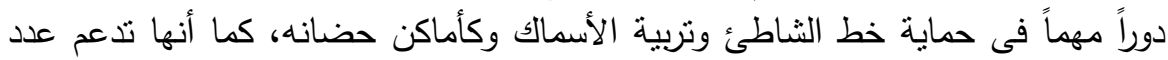

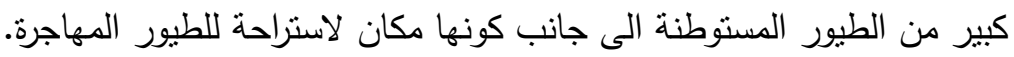

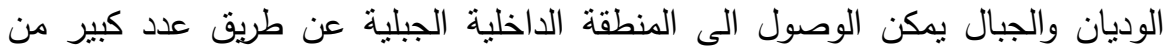

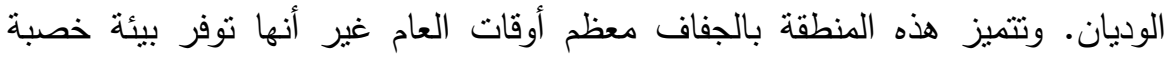

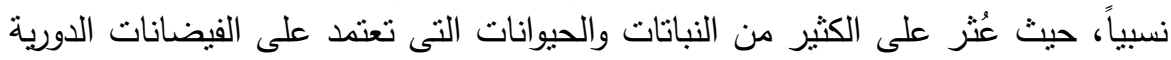
للأغوار التى تلى سقوط أمطار غزيرة. كما تُعد الوديان مصدراً للمياه العذبة للتئ للسكان

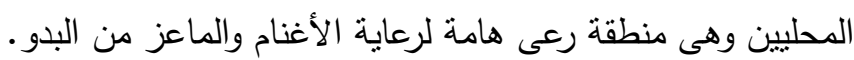

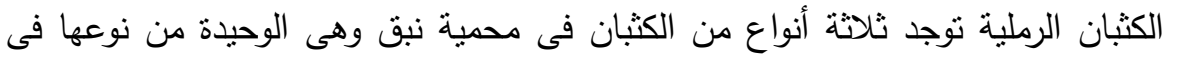

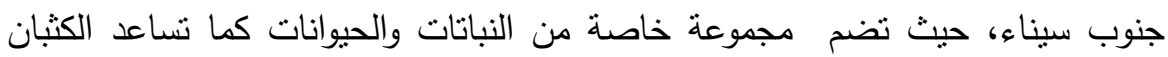

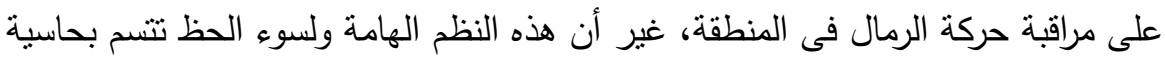

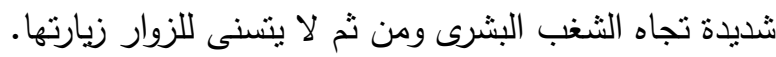

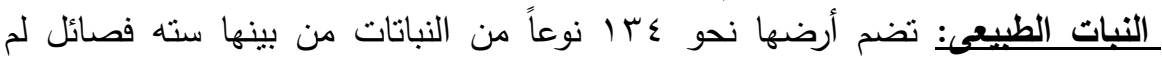

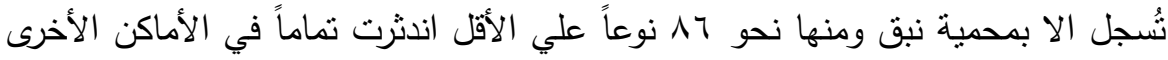

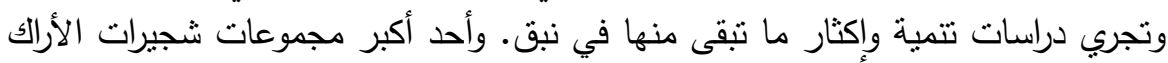

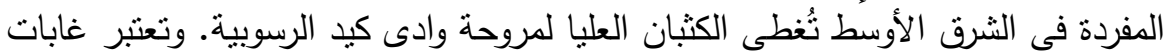

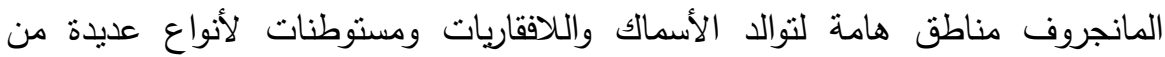

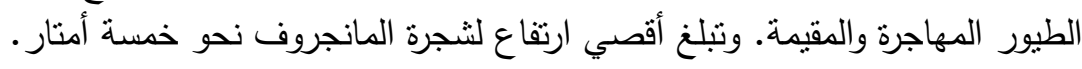

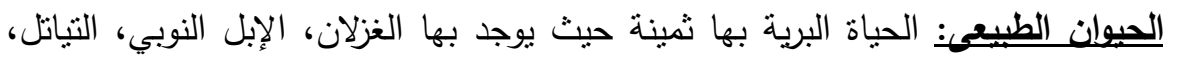

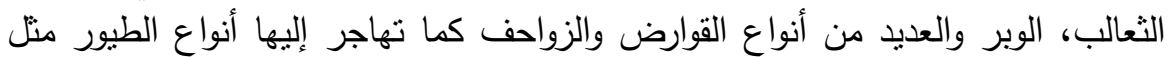

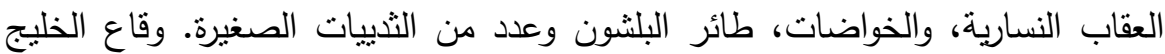

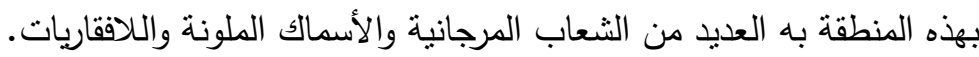

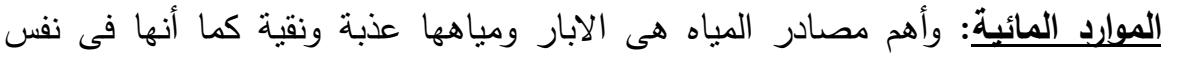

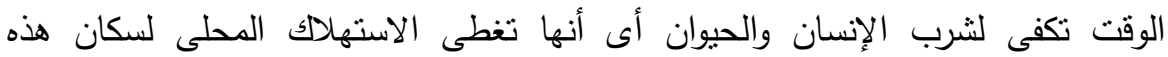

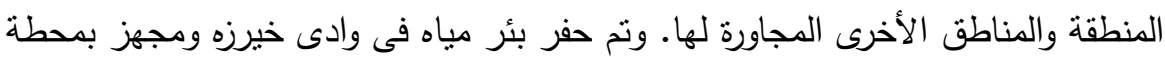

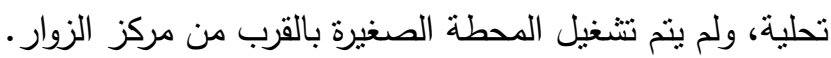


السكان: تمت دراسة واحصاء السكان المحليين وانثتطهم والحرف التى يمارسونها، وبها ثناثة

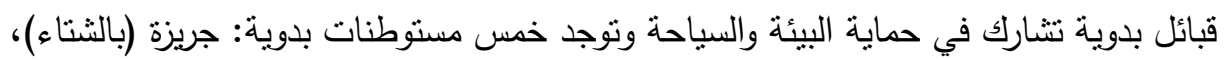

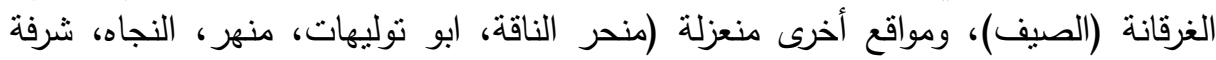

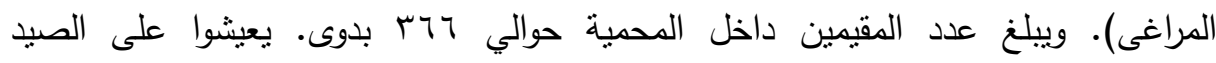

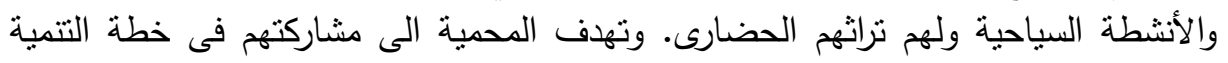

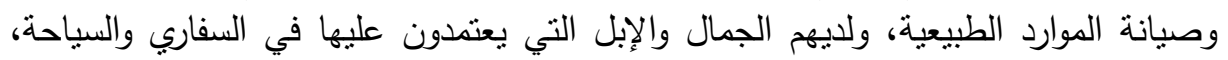

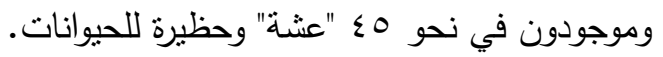

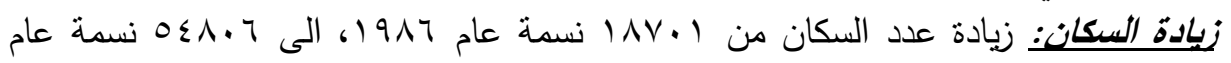

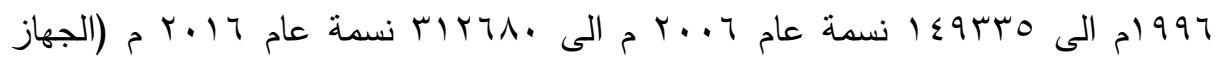

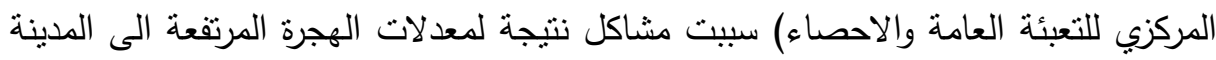

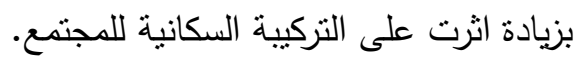
مستوى المعيشة: الدخل المرتفع للفرد من سكان مدينة شرم الثيخ يمثل مستوى اول أعلى في

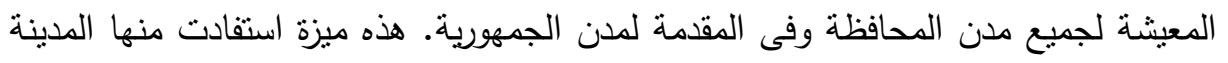

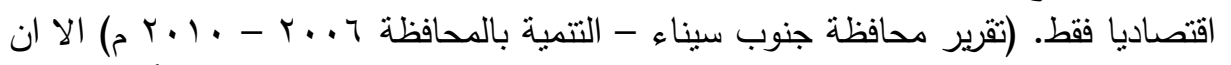

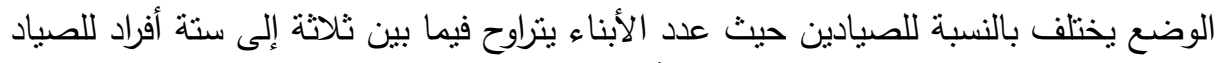

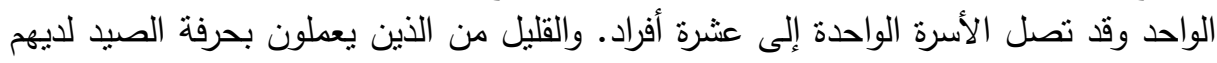

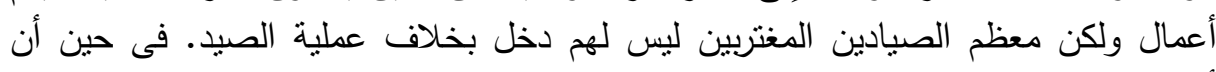

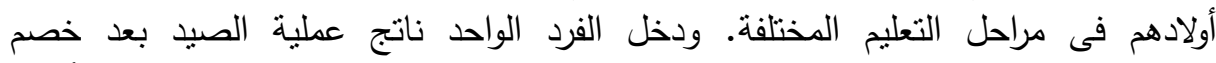

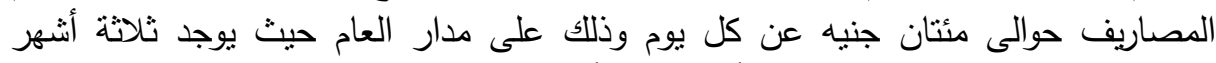

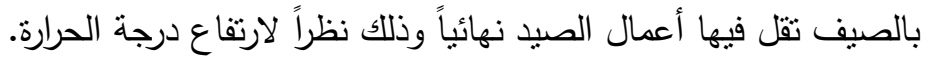

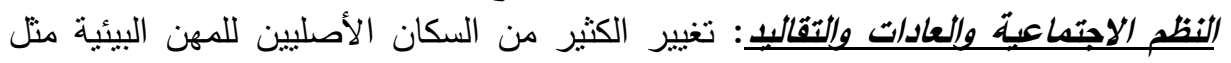

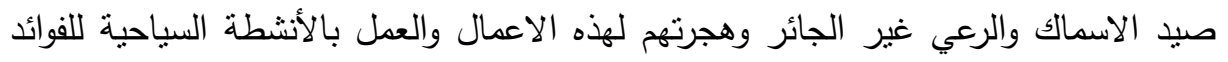

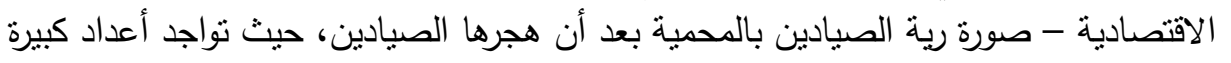

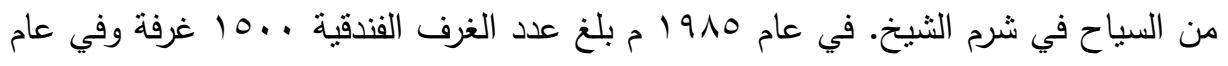

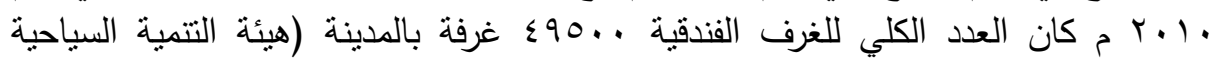




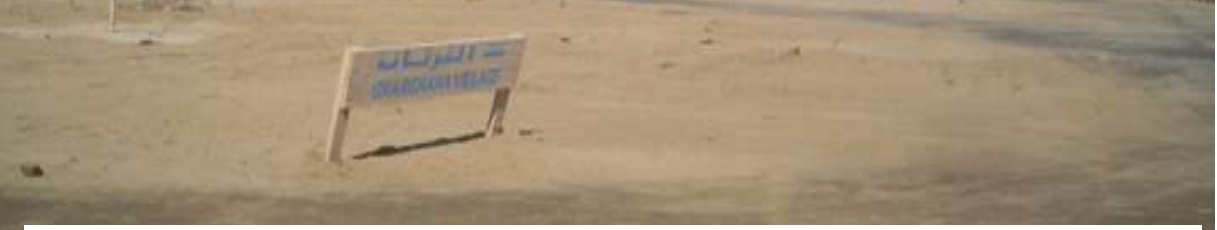

صورة رقح ا : قربة الصبادبرi) بالمحمبة بعد ارi هجرها الصبادبرi

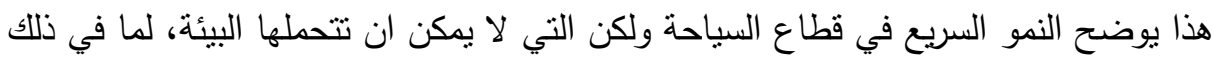

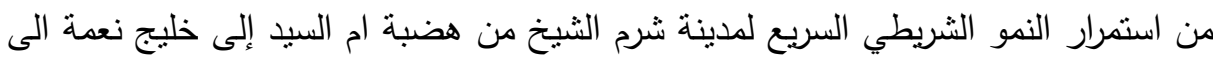

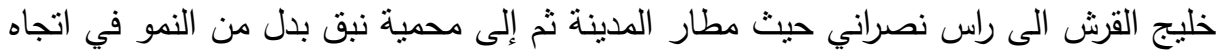

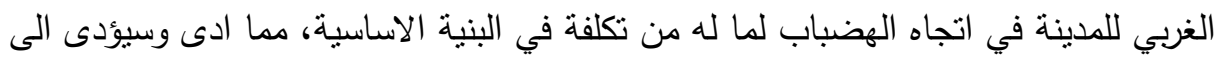

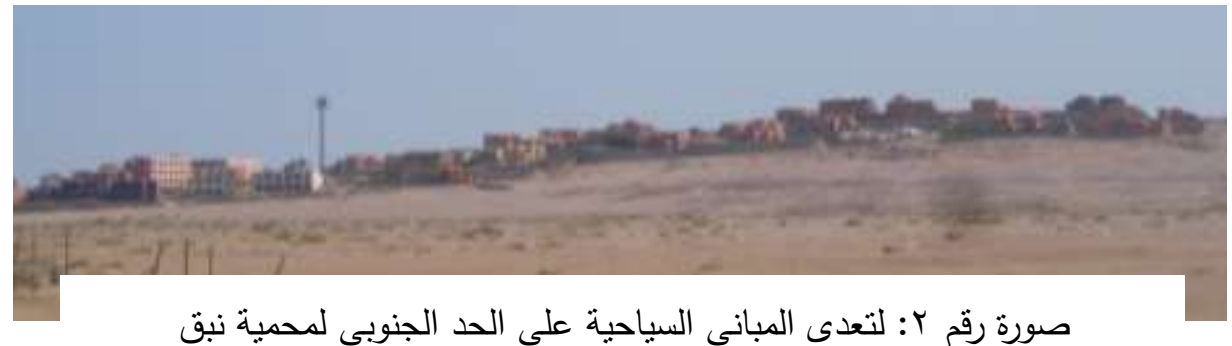

استمرار التعدي على الحد الجنوبي للمحمية. والصورة لتعدي المباني السياحية على الحد الجنوبي لمحمية نبق. وتعتبر المنطقة ذات جذب سياحى لهواة الغوص والسفارى ومراقبة الحيوانات والطيور وتوجد سفينة غارقة وتستغل كمنطقة غطس نسمى الغرقانة وأمامها قرية

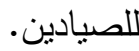

\section{ثالثاً: المقومات الاقتصادية للانتاج الاقتصادى:}

النقل وإلمولصلات: يحيط بالمحمية طريق رئيسى شرم الثيخ دهب حتى طابا، وبوجد العديد

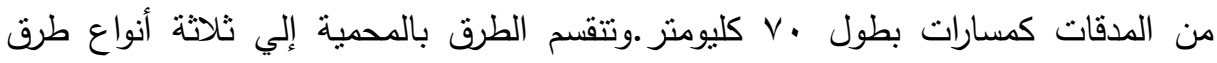
مرصوفة وطرق غير ممهدة خاصة بالسيارات (4X4)، وطرق غير مرصوفة خاصة بالزوار .

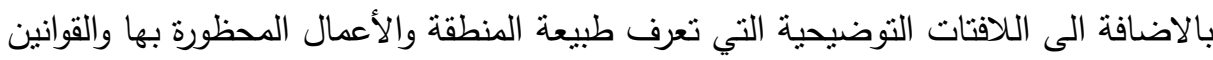

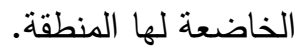




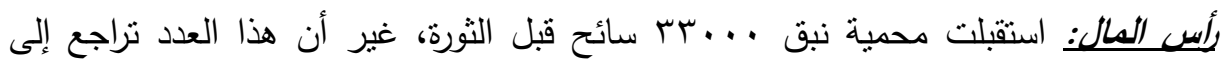

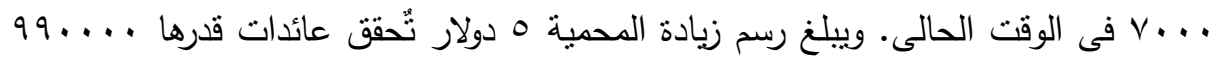

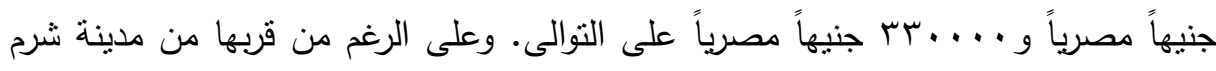

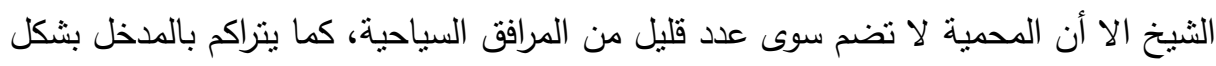

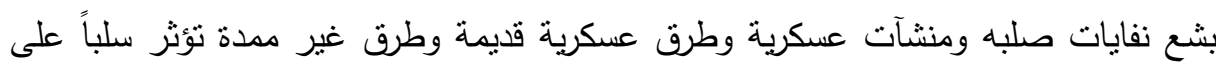

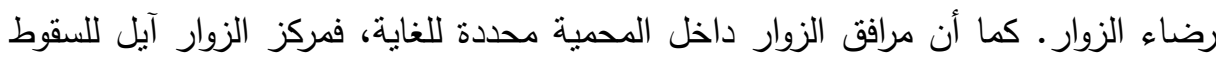
والموقع الرئيسي لمانجروف النبات به نالف نتيجة قربه من إحدى قرى الصفيح النيح البدوية.

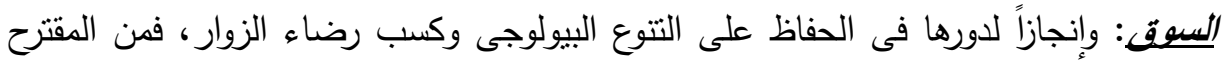

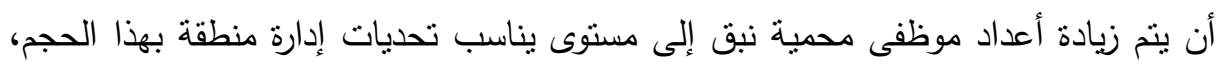

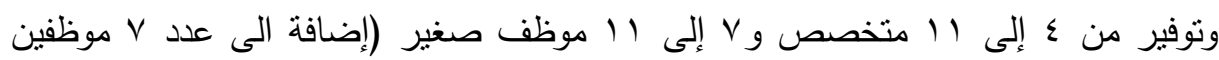

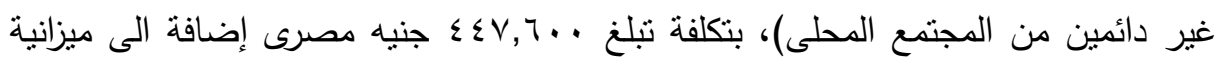

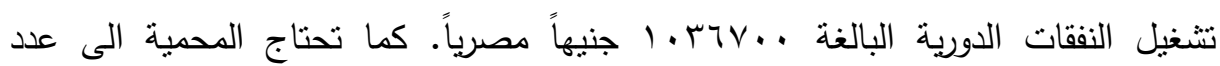

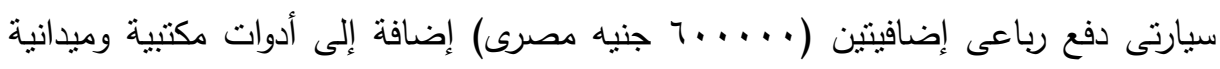

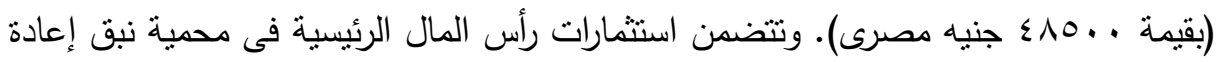

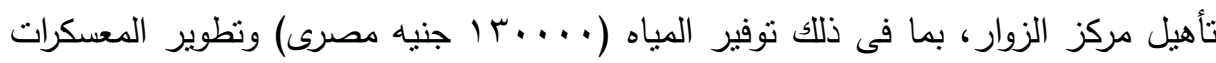

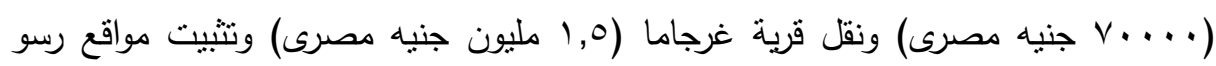

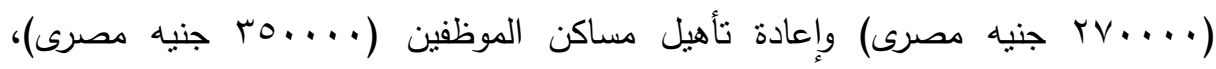

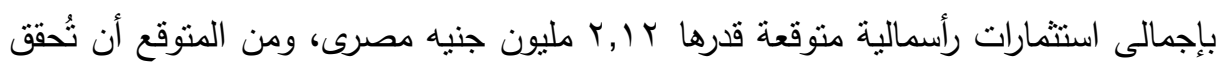

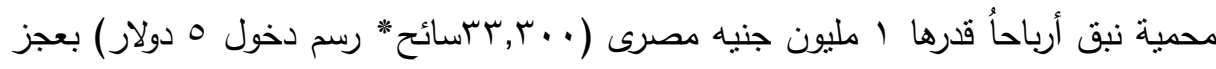
بسيط عن التكاليف الدورية. وبتحسين الإدارة، يمكن تحسين الخدمات والاستثمارات والخلل بشكل كبير بحيث نحقق محمية نبق الإكتفاء الذانى المالى لئ.

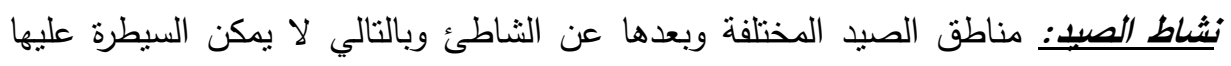

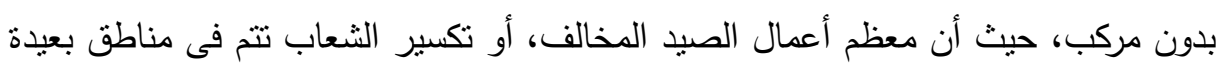

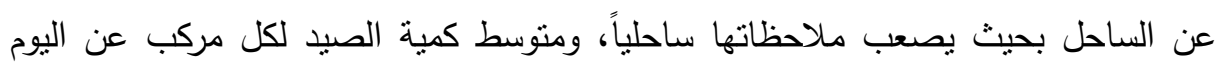

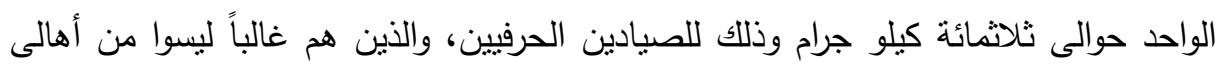


المنطقة، فى حين يصل لأهالى المنطقة حوالى خمسين كيلو جرام وذللك كد أدنى للصيد.

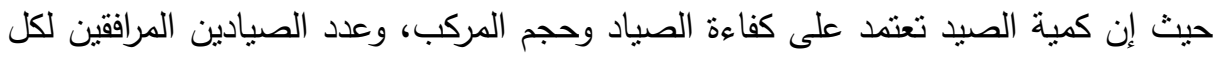

$$
\text { مركب، ونوع حرفة الصيد التى يستخدمونها. }
$$

المواقع الأثرية والثثافية: لا يوجد موقع نقافى أو تاريجى محدد (غير أنه لم يُجرى بحوث

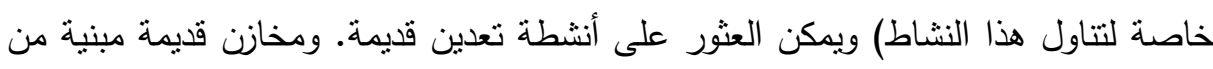
صخور المنطقة فى وادى سيالة الدلال. النينة التحتية للمحمية: يضم مركز الزوار مساحة مكتبية وإيواء لعدد (^) موظفين، وعدد واحد مسكن جاهز للموظفين والباحثين يضم ثلاث غرف وكافة المرافق، إضافية إلى غرفتين لمحصلى التذاكر عند بوابتى الدخول الى المحمية (لا يوجد مصدر جيد للمياة). ومعسكر

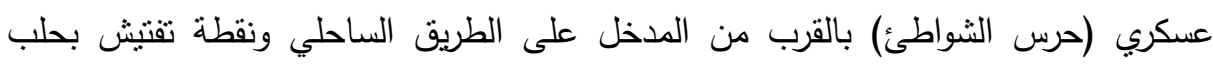
لمراقبة حركة الدخول إلى المحمية.

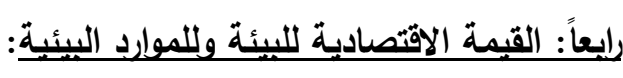

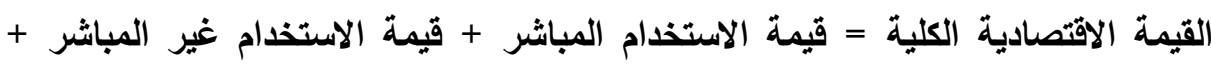
القيمة المحتملة مستقبلا + قيمة الوجود لدراسة هذه المعادلة لابد من دراسة مخطط المحمية، حيث قام جهاز شؤون البيئة وهيئة

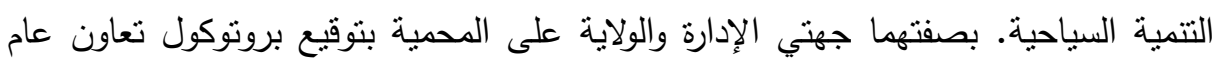

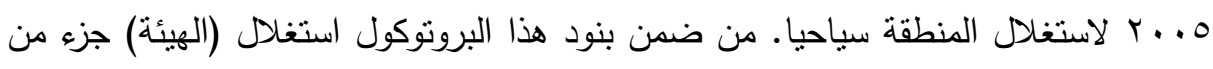

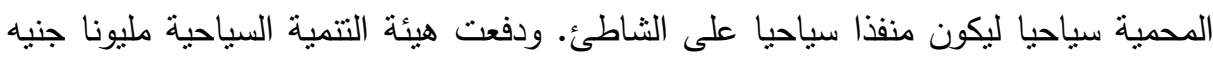

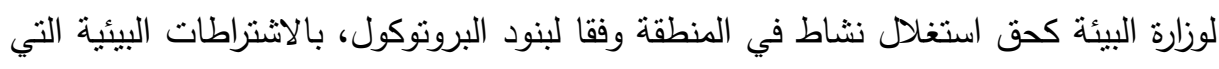
يحددها قانون المحميات الطبيعية. وأهم تللك الاشتراطات هي إعداد دراسة تقييم للأثر البيئي

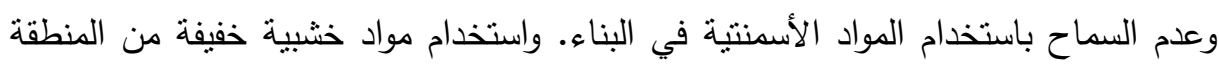
تتتاسب وطبيعة المحمية وخاماتها الطبيعية. والبعد عن المناطق ذات الحساسية البيئية،

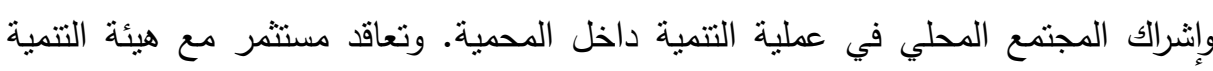
السياحية وحصل على ه ملايين متر في منطقة لبس لها منفذ بحري وخارج محمية نبق، وأقام

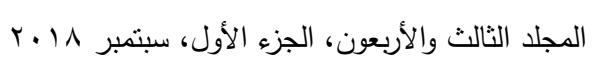


عليها مشروعا سياحيا ضخما بأكبر لاجون في الثرق الأوسط. ومن ضمن شروط العقد مع هيئة التنمية السياحية تخصيص جزء من شاطئ المحمية التي تعاقدت الهيئة عليها مع جهاز

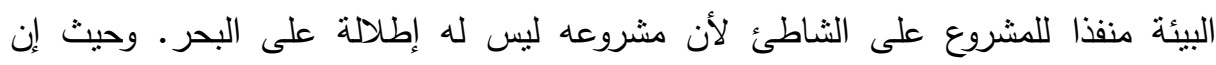

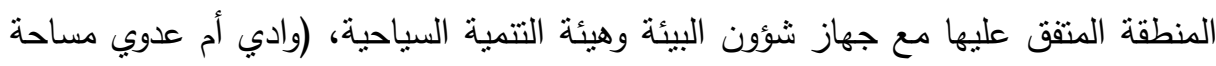

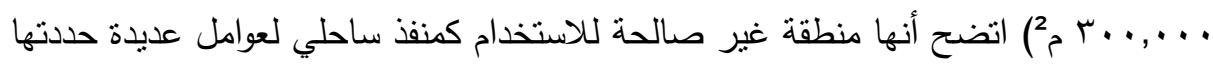
اللجنة في تقريرها، فطلبت هيئة التتمية السياحية من مجلس الوزير التهاء. استبدال المنطقة المخصصة لاستثمارها سياحيا كثاطئ ساحلي نظراً لخطورة استخدامها بسبب قربها منها من مخر فئه

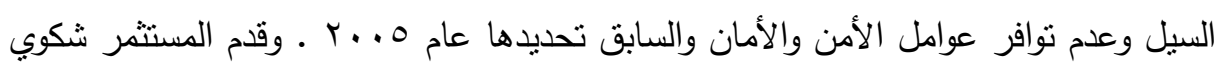

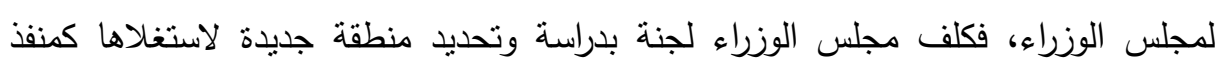

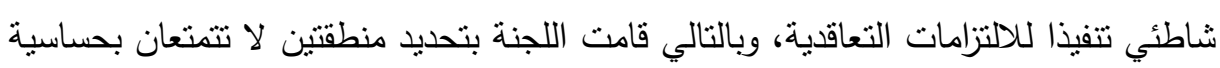

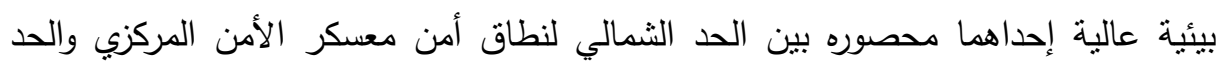

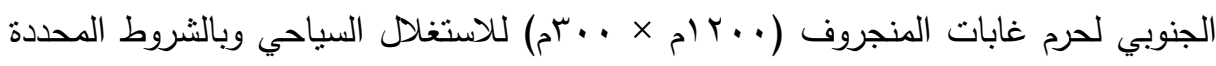

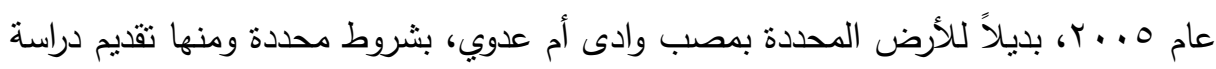

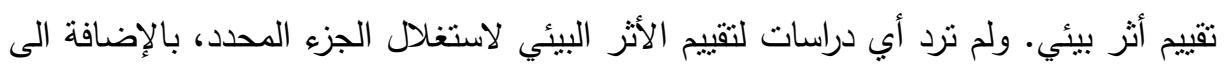

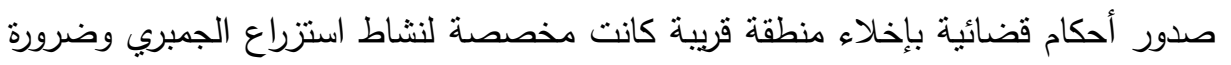
إدماج المجتمعات المحلية في الأنشطة.

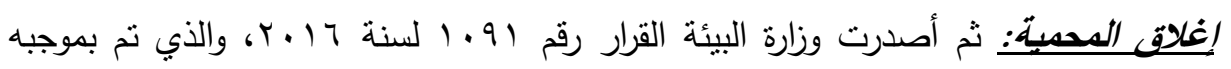

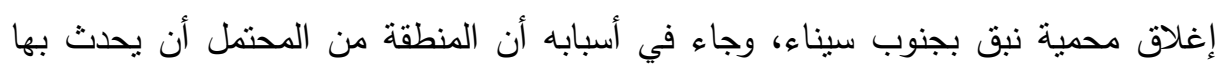

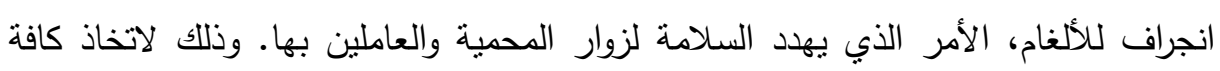

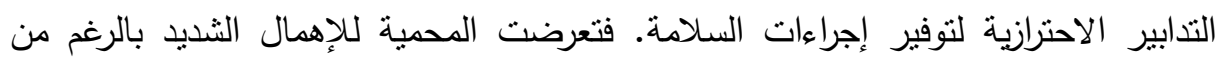
الثروات التي تضمها، ولكن تم تركها عرضة للسرقة.

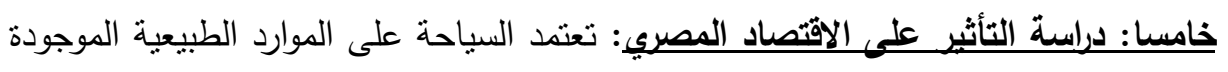

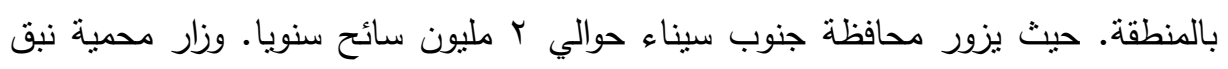

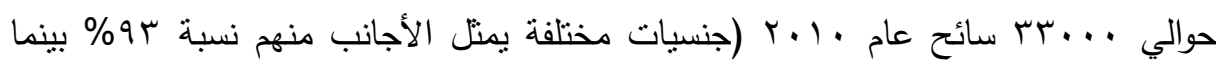

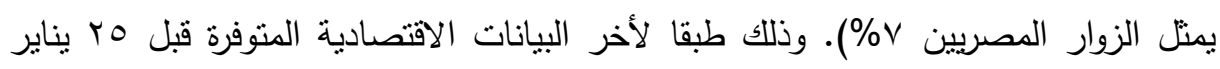

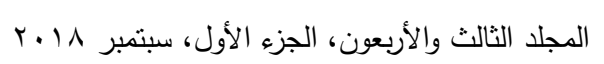




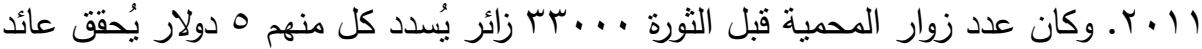

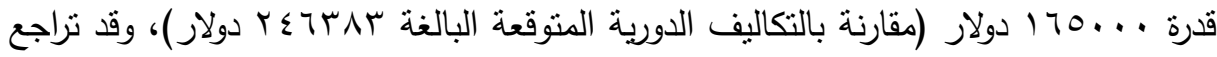

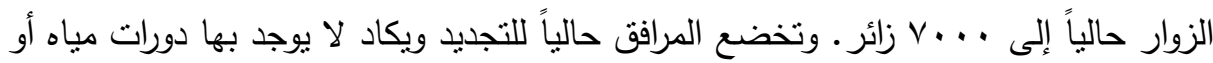

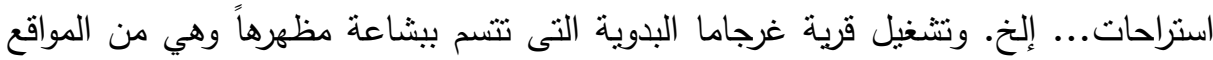
الرئيسية. ويخضع الطريق الرئيسى للصيانة، كما توجد بعض المنشآت العسكرية والسياج القديم والنفايات الصلبة قبيحة المظهر مما يعكس مظهراً سلبياً، وكذلك الوضع بالنسبة لمزرعة الجمبرى المهجورة. وفى ضوء الاستثمارات، يمكن إعادة معدلات الزوار الى المستويات

المبحث الثالث: نموذج التنمية المستدامة للمحميات الطبيعية: نوجد مجموعة خطوات للتتمية المستدامة للمحيات الطبيعية يجب اتباعها بدقة حتى لا يؤثر هذا على التتمية المستدامة تأثيرا سلبيا، وعلى نظام حماية المناطق الدحمية، وهذه الخطوات تتدرج على أربعة مراحل، وفيما يلي تفصيل لهذه المراحل ويوضح الثكل خطوات أعداد مخطط للتنمية

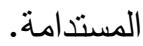




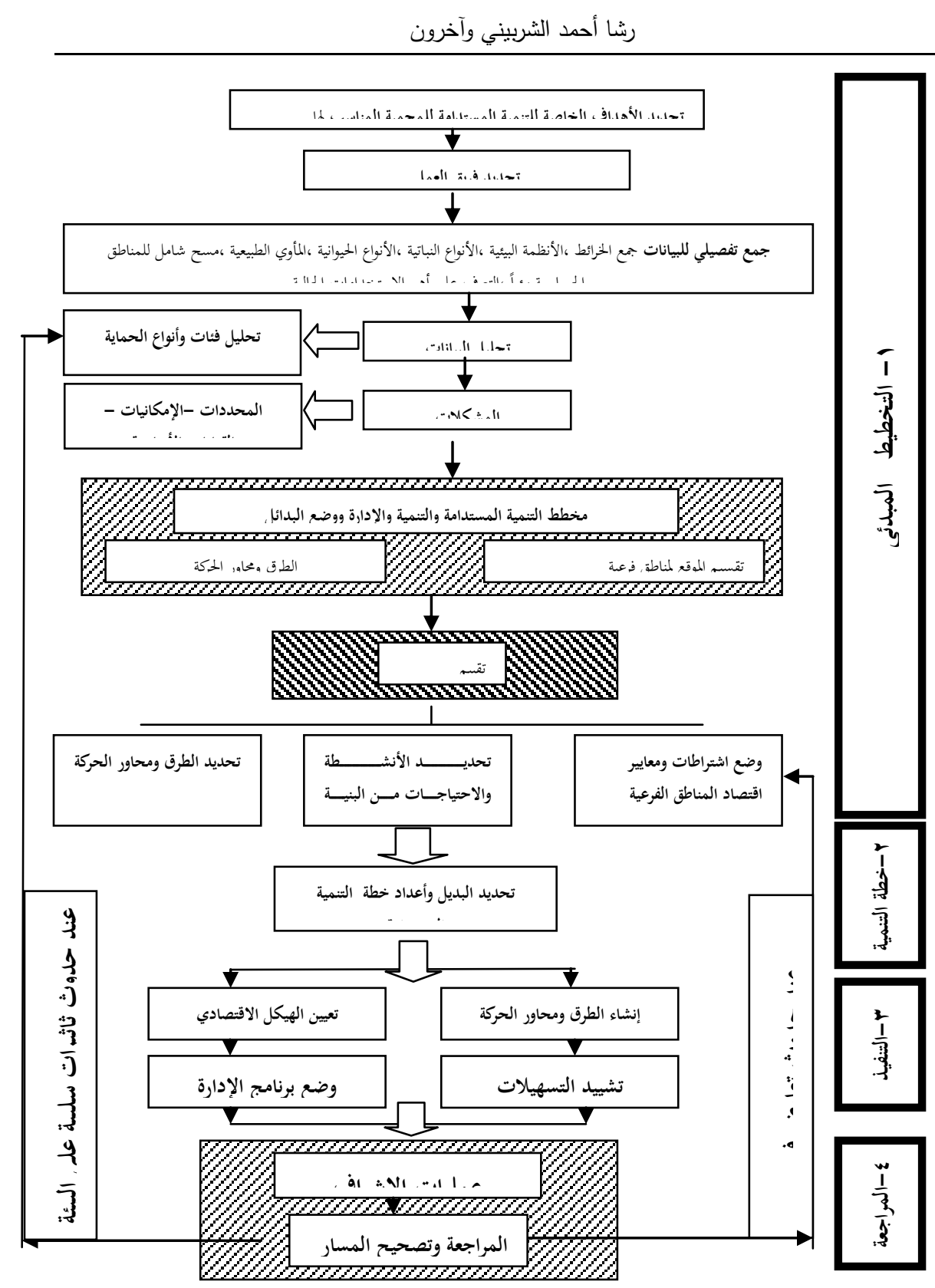

شكل رق ب: خطوات أعداد مخطط للنتمبة المستدامة لمحمبة ندة، 
أولاً: التخطيط المبدئي:

•تحديد الأهداف الخاصة التي يسعى مخطط التتمية المستدامة للمحمية إلى تحقيقها.

تحديد فريق العمل اللازم لإعداد المخطط.

جمع تفصيلي للبيانات الوضع الراهن من حيث جمع الخرائط، وحصر البيئات الطبيعية والأنواع النباتية والحيوانية، وتحديد المواقع ذات الحساسية البيئية والأهمية العلمية،

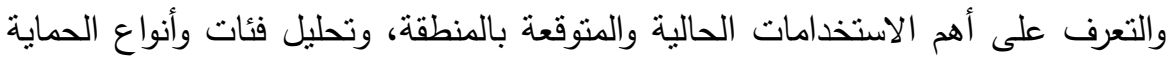
وتصنيف المحمية.

تحليل بيانات الوضع الراهن للوصول إلى تتخيص كامل للمنطقة. وضع مخطط التتمية المستدامة ووضع بدائل للمخطط من تقسيم الموقع إلى مناطق فرعية، ووضع بدائل الطرق ومحاور الحركة الرئيسية.

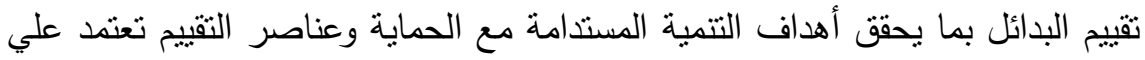
قياس مدي تحقيق كل بديل للأهداف الرئيسية الموضوعة للمحمية.وعليه كان هنالك مجموعة من المعايير موضحة بالجدول التي يمكن من خلالها القيام بعملية التقييم وهي:

• المعابير البيئية: الحفاظ على المأوى الطبيعية الرئيسية الأمر الذي يساعد علي عدم قطع حركة الكائنات داخل تللك المأوي وإعاقة حركتها. الحفاظ علي مستوى مناسب من القدرة الاستيعابية للنظام البيئي دون آن تتخطى الحد المسموح به والذي ينتج عن تخطيه آثار سلبية علي البيئة الطبيعية للموقع.

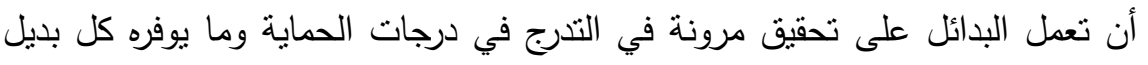
من مساحة تخصص لأغراض الحماية والبحث العلمي. الحفاظ علي القيمة الطبيعية والبصرية والجمالية للموقع. سهولة إدارة عمليات الحماية.

( المعابير الاقتصادبة: • الكفاءة الاقتصادية في معرفة حجم الاستثمارات المطلوبة لكل بديل والعوائد المتوقعة منه. 
• مدى الطلب علي الأنشطة وتعني بأهمية توفير الأنواع المختلفة من الأنشطة ومدى

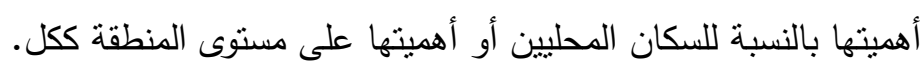

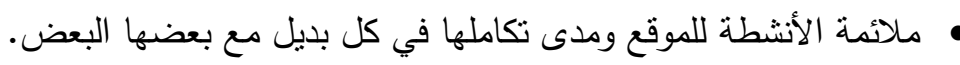

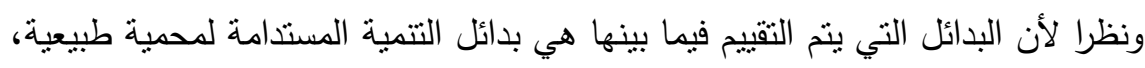
وحيث إن الهدف الرئيسي من الدارسات الاقتصادية هو توفير سبل حماية البيئة الطبيعية

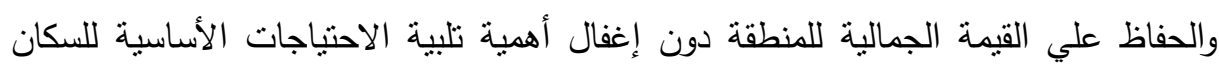

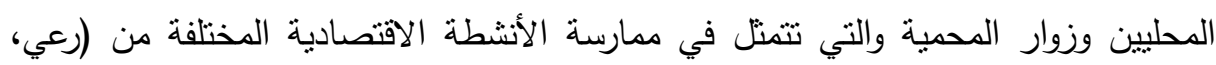

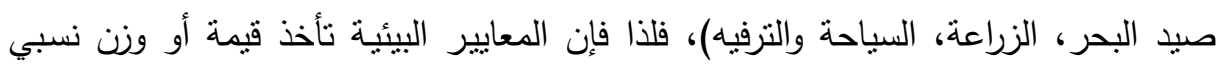
مضاعف عن المعايير الاقتصادية ويكون تقييم البدائل المقترحة. جدول(؟): تقييم البدائل المختلفة للتتمية المسندامة المحميات الطبيعية

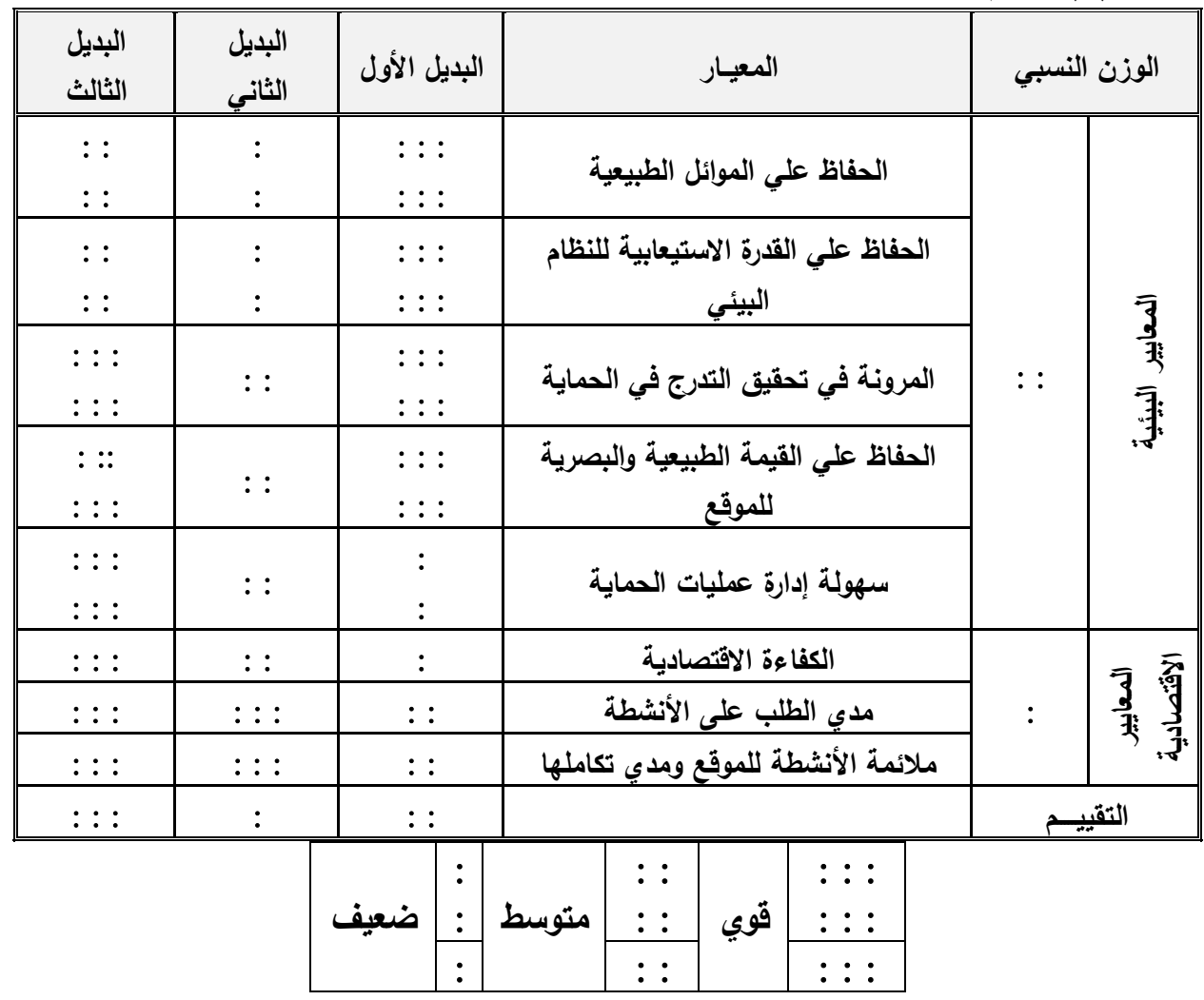


مدى تحقيق البدائل للأهداف (فرضيا): وبعد تقييم البدائل من حيث المعايير البيئية

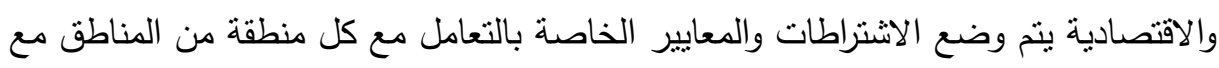

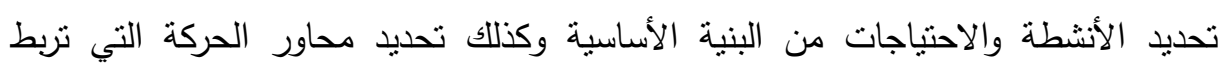
وتحيط بهذه المناطق ولاحقا يتم تطبيق هذه الخطوات على محمية نبق.

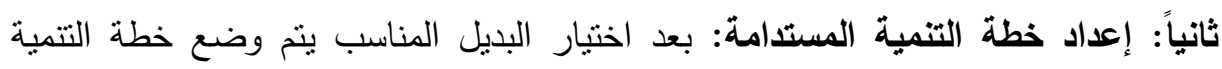

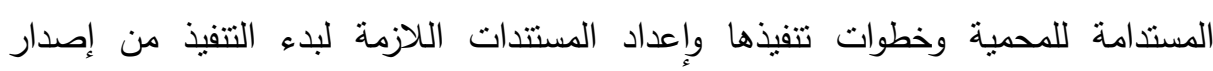
تشريعات أو وضع الخطة المالية للتنفيذ.

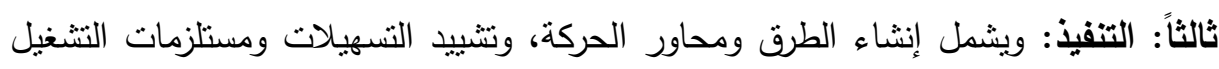

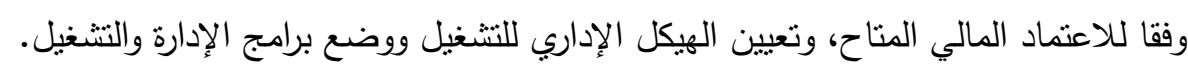

\begin{tabular}{|c|c|c|}
\hline التشغيل والمراجعة & تنفيذ الخطة & الدراسات \\
\hline & & ممثل للحكومة \\
\hline & مختصسون بيئة بحرية & مختصون بيئة بحرية \\
\hline & مختصون بيئة برية & مختصون بيئة بريـة \\
\hline & مختصون الاجتماع & مختصون الاجتماع \\
\hline & مخططون ومصممون & مخططون ومصممون \\
\hline & مشرعون واقتصـاديون & مشرعون واقتصـاديون \\
\hline مدير منطقة محمبة & مدير منطقة محمية & \\
\hline مختص علاقات عامة & مختص علاقات عامة & \\
\hline مدرب ورئيس جوالين & مدرب و رئيس جوالين & \\
\hline فرق صيانة وتفتيش & & \\
\hline
\end{tabular}
وابعاً: المراجعة المراقة الإدارة الحكومية

بالدولة، ومصادر التمويل المختلفة. ولذا فإن وضع تصور لتتغيل خطة التنمية المستدامة

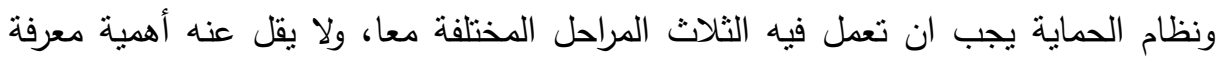

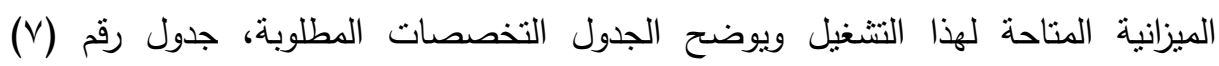

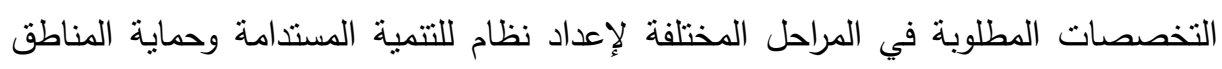




\section{المبحث الرابع: تطبيق نموذج التنمية المستدامة على محمية نبق:}

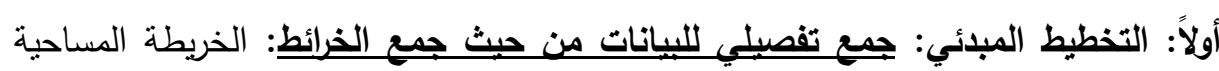

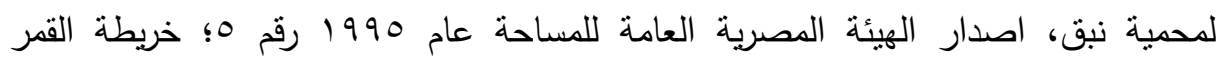

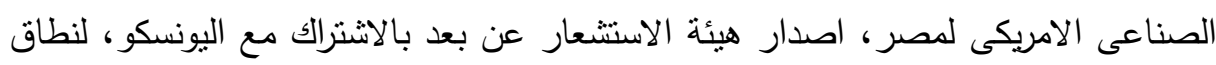

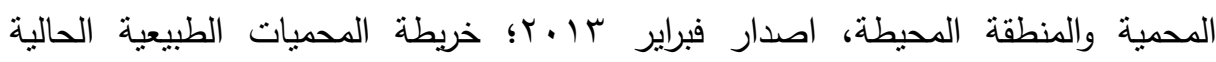

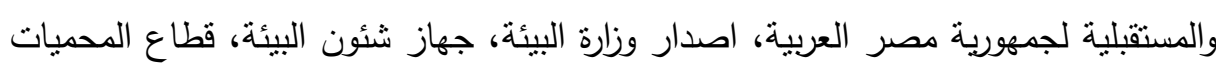

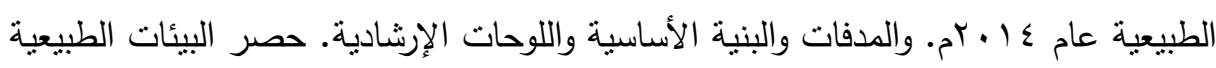

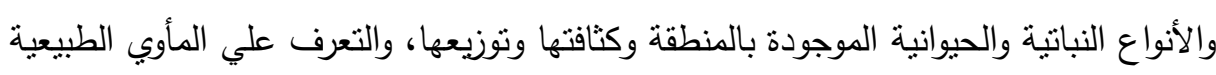

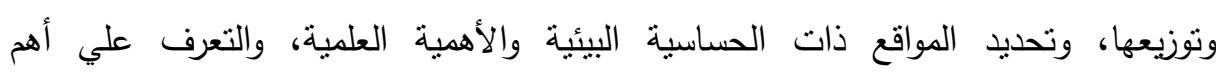
الاستخدامات الحالية والمنوقعة بالمنطقة، وتحليل فئات وأنواع الحماية وتصنيف الحتئة الحمية.

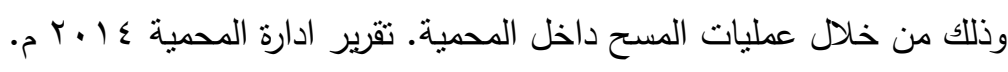

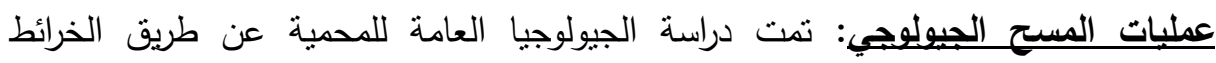
الجيولوجية المرفقة والمسح الميداني بالمحمية وذلك بطريقة سطحية غير متخصصة. لهيدة الخريطة

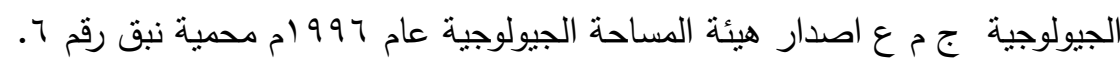

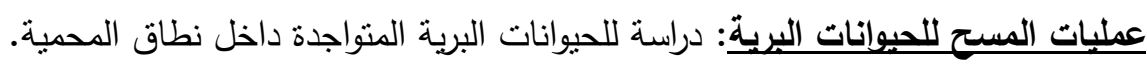

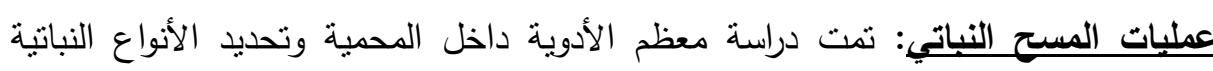

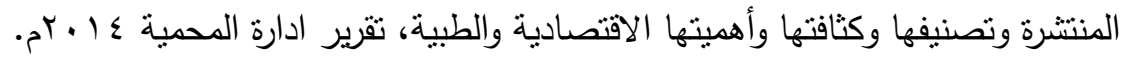




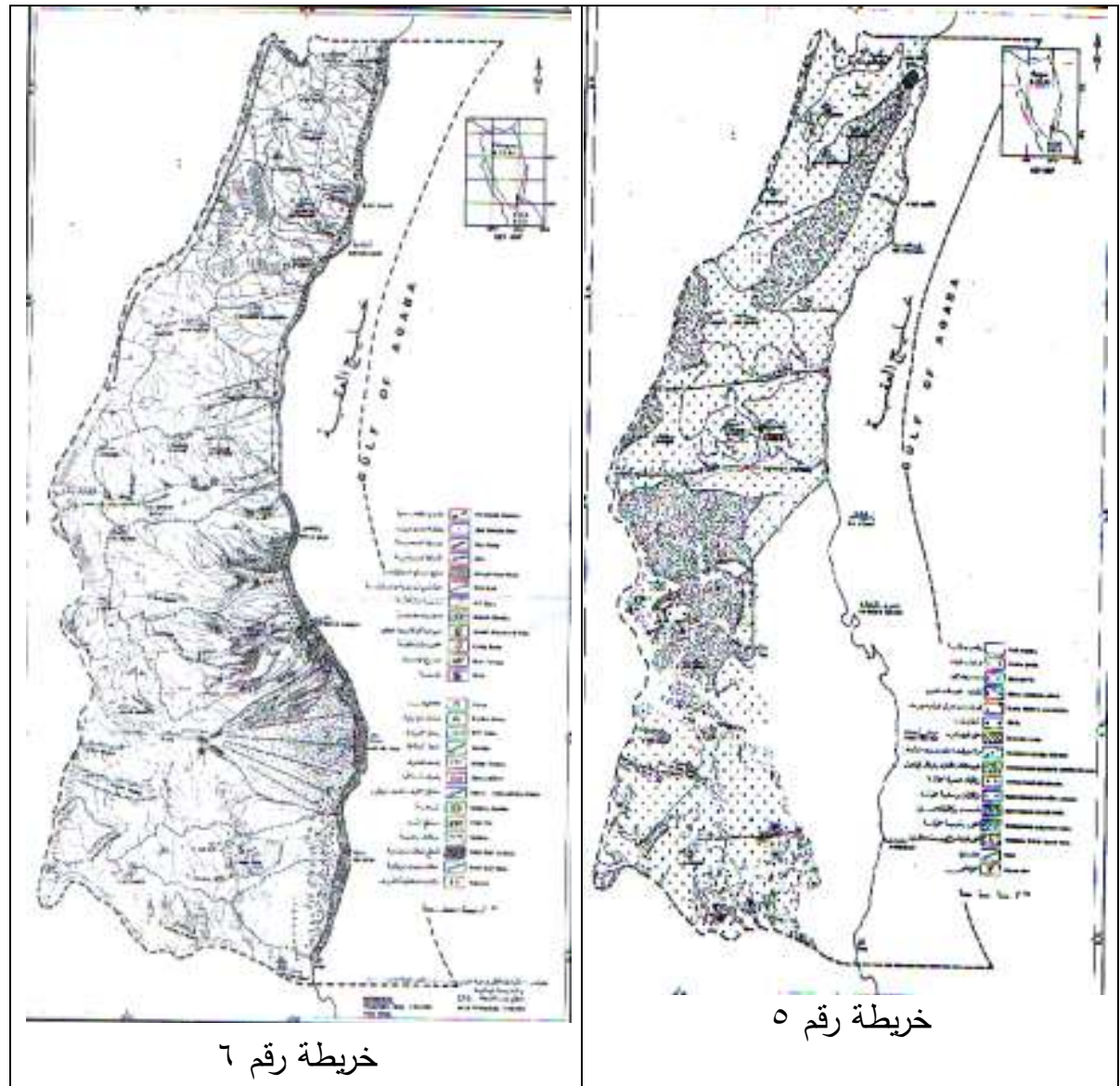

عمليات المسح الاجتماعى للسكان: تقرير ادارة المحمية §1 ـ rم. النشاط الاقتصادى ومنه الصبد والحالة العامة للمصايد بالمنطقة والسياحة والغطس والطرق.

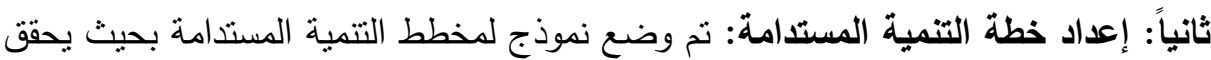
مجموعة من الاثتراطات والتوصيات المختلفة لكل من عناصر التنمية المستدامة. البيئة المشبدة لمخطط التنمبة المستدامة: البيئة المشيدة تتلائم مع طبيعة ونظم التصميم

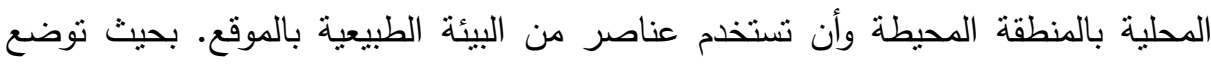
أماكن إقامة طاقم إدارة المحمية في مكان مناسب و ليس بداخل أو بالقرب من منطقة الحماية

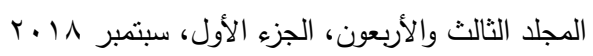


المركزية الميزة، وأن تكون غير واضحة أو ظاهرة وبعيدة عن المررات وطرق الاتصال. أما

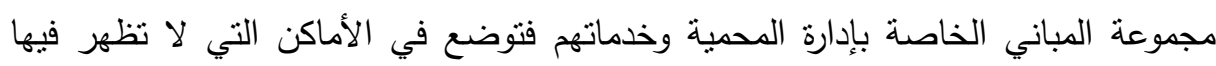

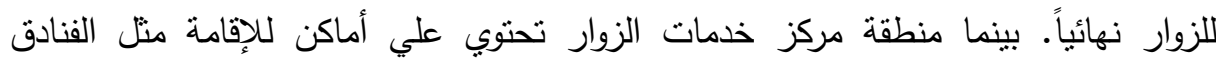

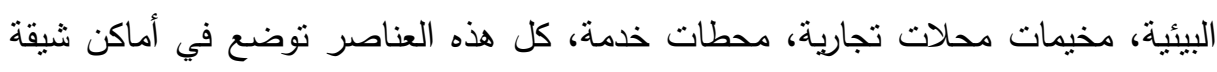

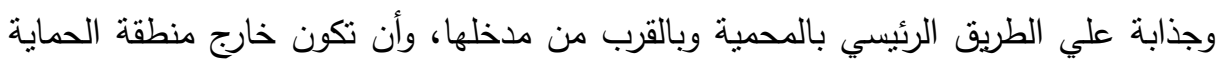

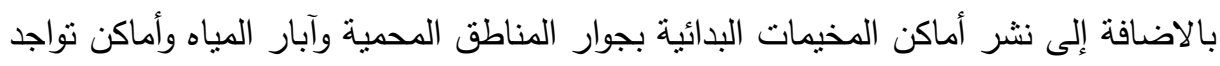

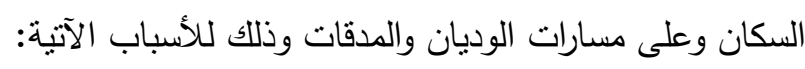

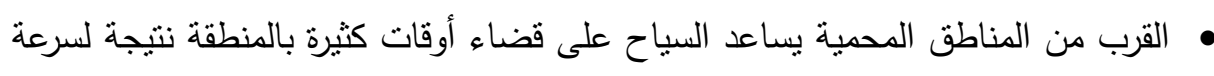

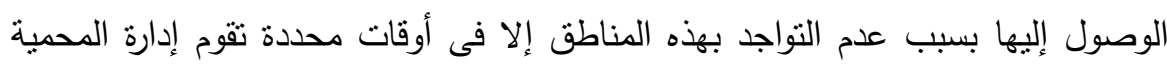

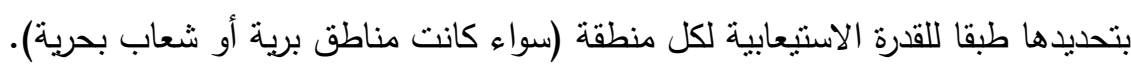
• الاستفادة من الآبار فى التغذية بالمياه وروئية الحيوانات والنباتات المستفيدة من الماء.

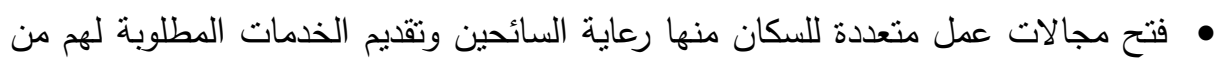

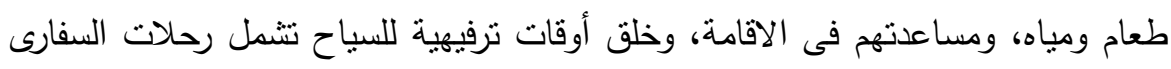

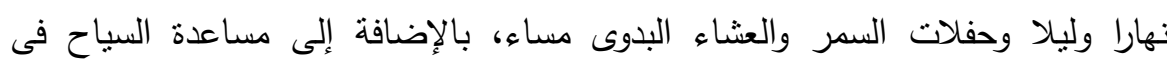

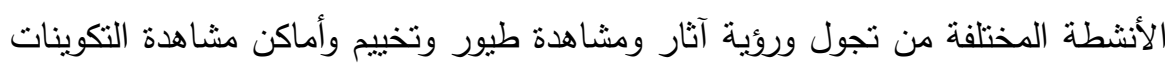

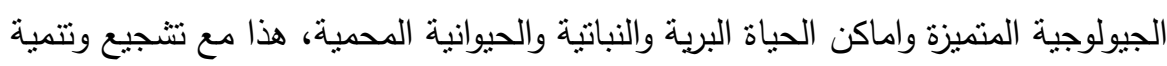

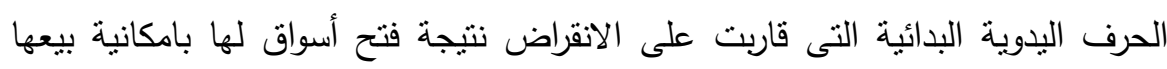

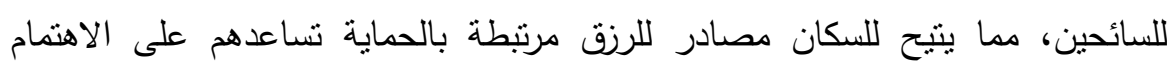
بحماية المنطقة. 
مجلة العلوم البيئية

معهد الدراسات والبحوث البيئية - جامعة عين شمس لئس

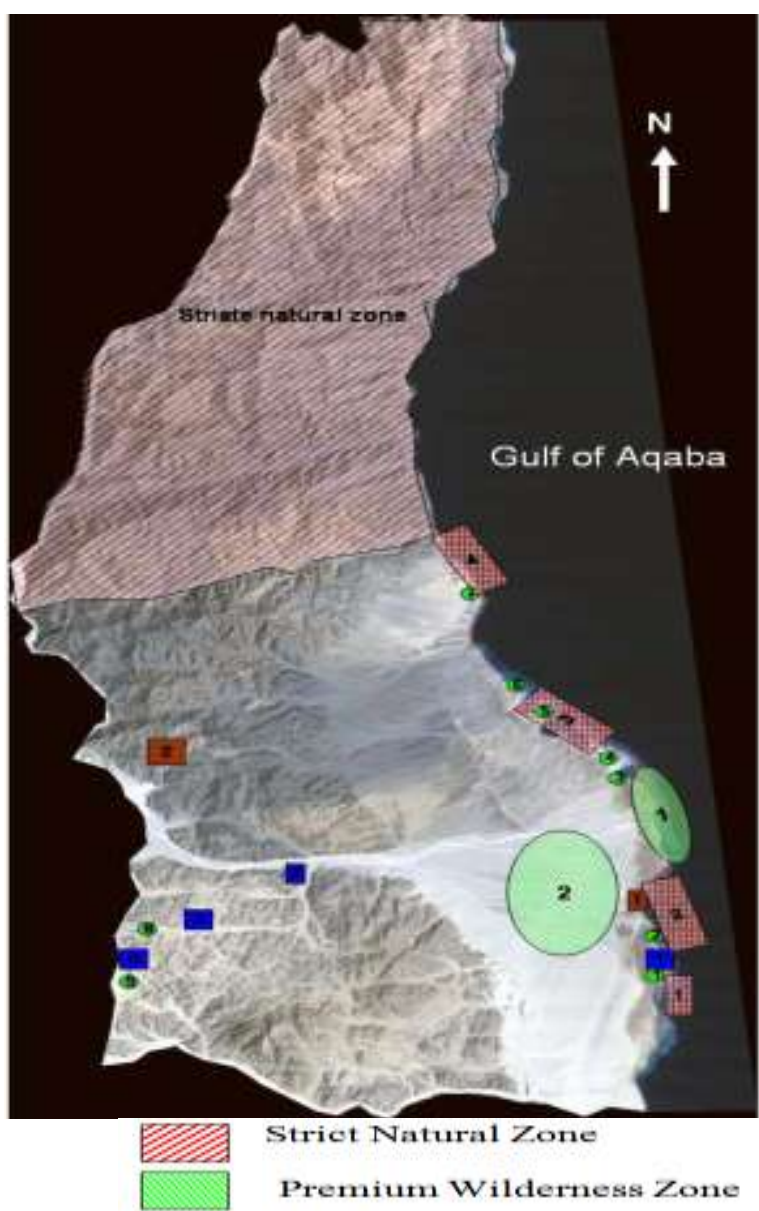

Traditional Use Zone

|

Recreational Zone
Multiple Use Zone

$$
\text { خر بطة رقد }
$$

• القرب من مسارات الوديان الجافة ومسارات المدقات يعنى سرعة الوصول للمخيم فى حالة

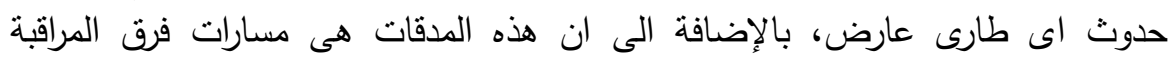

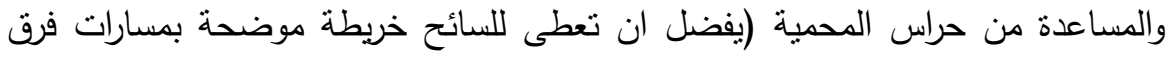

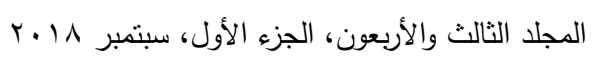


المساعدة وتوقيتات وصولها للنقط المختلفة بالمحمية لامكانية الوصول السهل لها فى أي

هاستغلال ساحل خليج العقبة وما يتميز به من خلجان كثيرة وتعرجات تتيح مناظر طبيعية

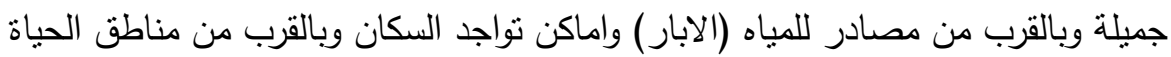

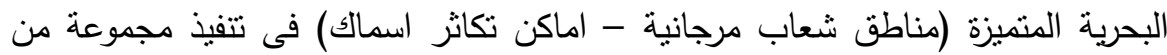

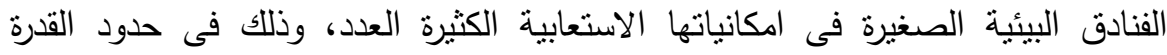

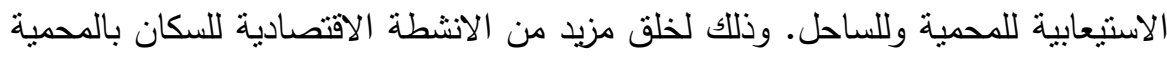
الاستفادة من هذه العوائد للمحمية وتعويض اللانس السكان.

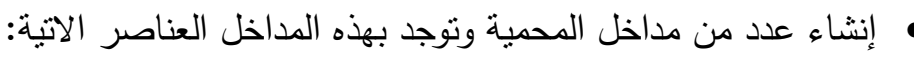

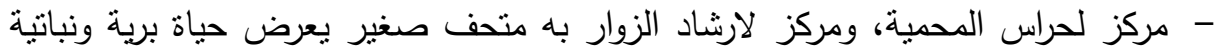

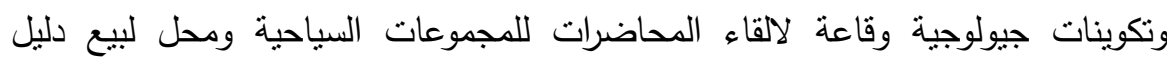
للمحمية موضح به الاعمال المسموح بها وغير المسموح بها والقواعد العامة لتتفيذ الانشطة البيئية المختلفة.

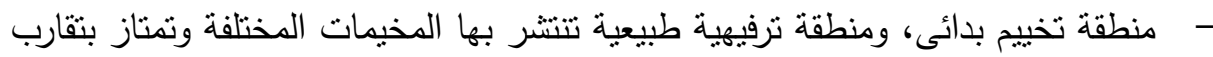

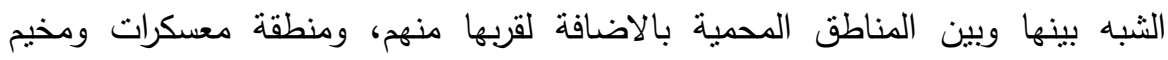
للكرافانات حتى سعات محددة تنتاسب مع المسارات بالمحمية، وبها مواقد لاعداد الطعام ودورات مباه لزائرين.

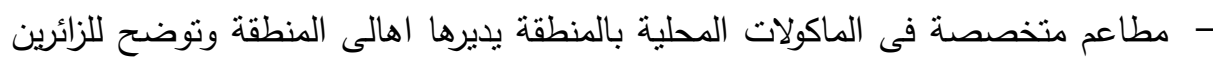

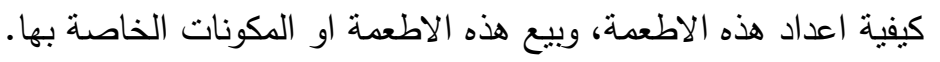

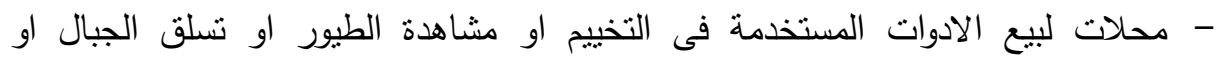
ممارسة الغطس السطحى او العميق. ومحلات لبيع المنتجات المحلية والتى تشتهر بهات التها

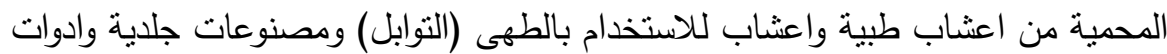

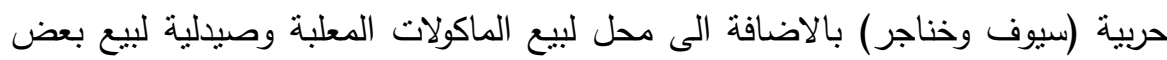
الادوية.

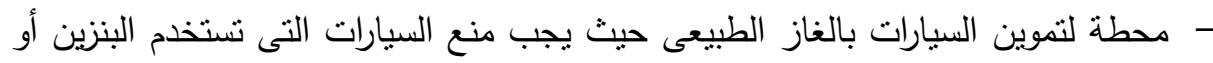

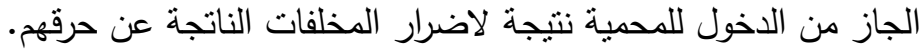

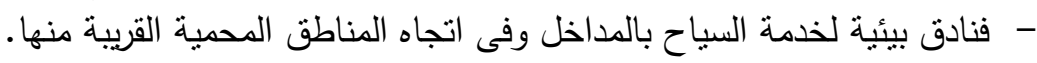

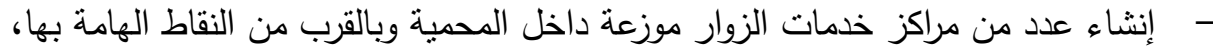

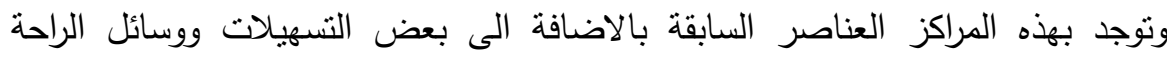

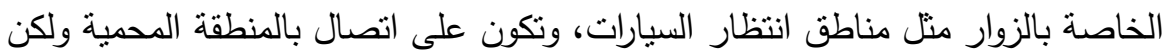


ليس قريبة منها جدا حتى لا تقلل من قيمتها وطبيعتها وتكون فى الغالب فى النطاق

البنية الأساسبة لمخطط التنمبة المستدامة:

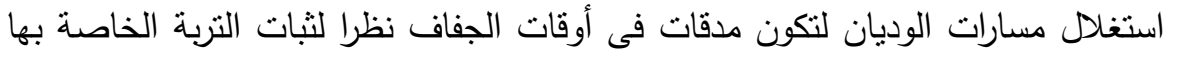

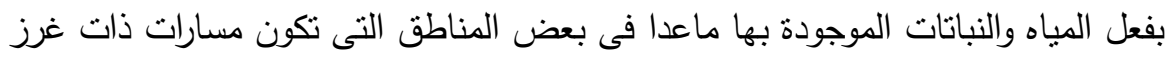

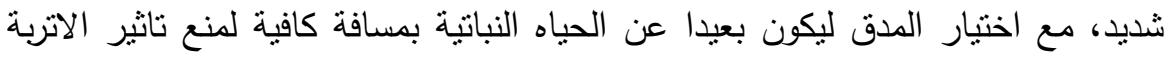
ومخلفات الوقود.

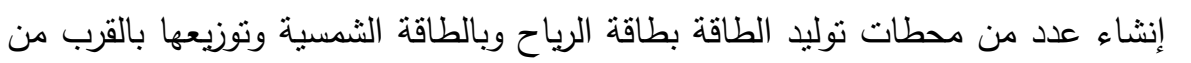

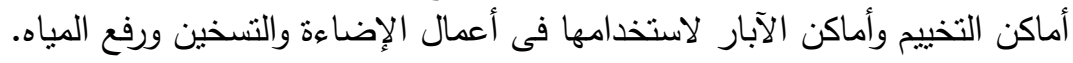

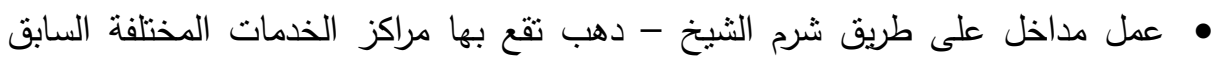

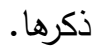

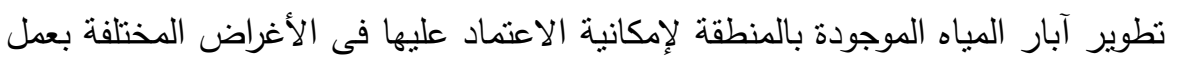

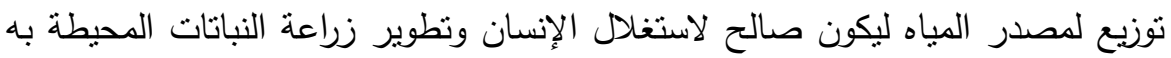
مع استغلاه لثرب الحياة البرية المعتمدة عليه. الأنثطة والاستخدامات المختلفة المقترحة لمخطط التنمبة المستدامية: يتم تحديد الانشطة

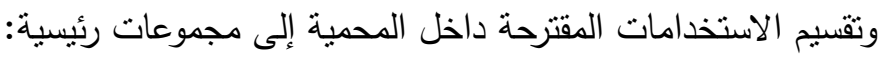
أنشطة اقتصادية: الجولات السياحية التجارية، معسكرات السفاري، أنشطة التصادية التصادية أخرى، أنشطة السكان المحليين.

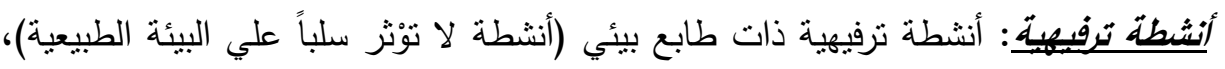

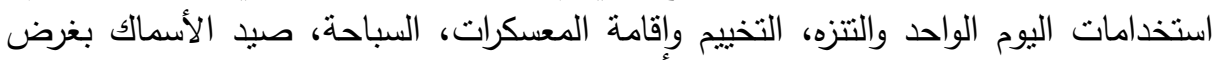
الترفيه، المشي، الرياضات المائية.

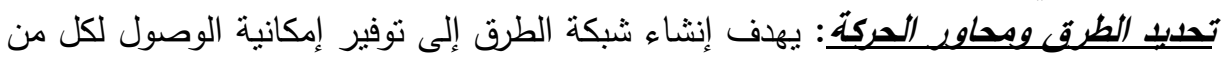

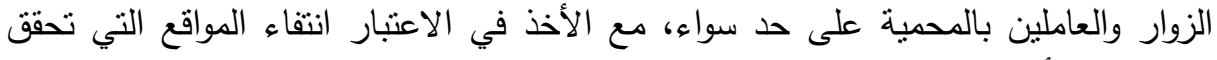

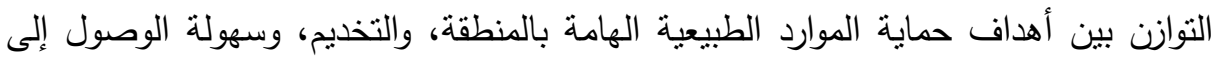

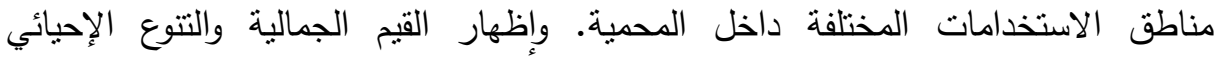

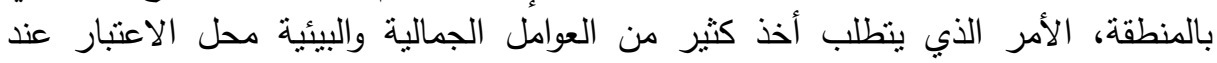

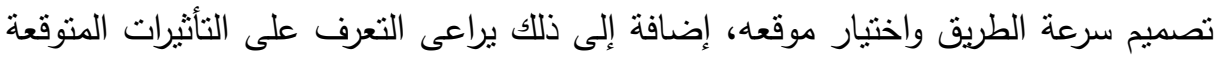

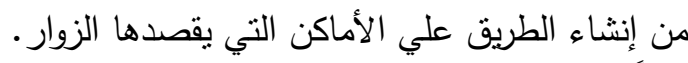

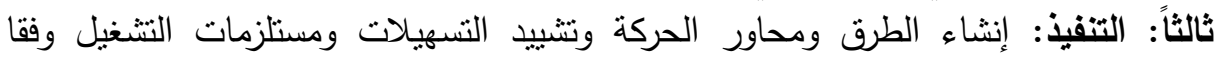

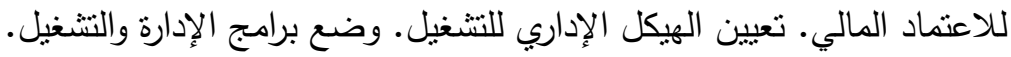

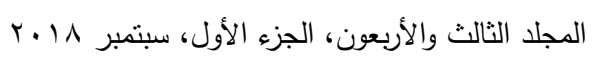


رابعا: المراجعة: بدء عمليات المراقبة والإشراف. ومراجعة البرنامج وتصحيح المسار .

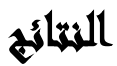

قد توصل البحث إلى النتائج الآتية التي أهمها: إنثات صحة الفرضية أن خلق وتتظيم

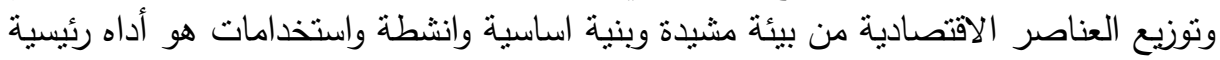

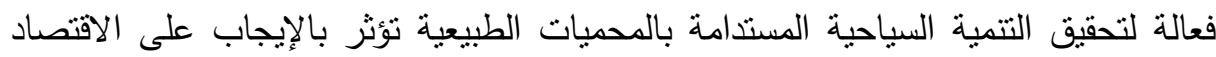

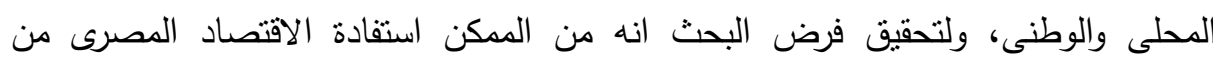

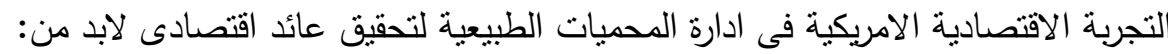

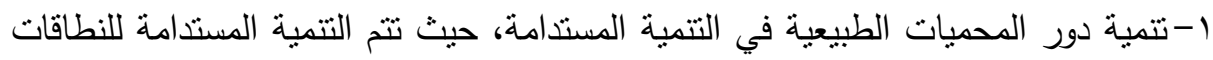

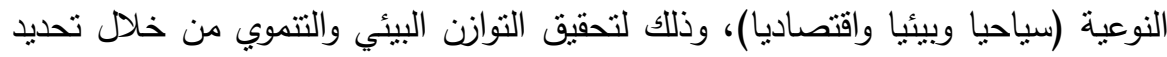

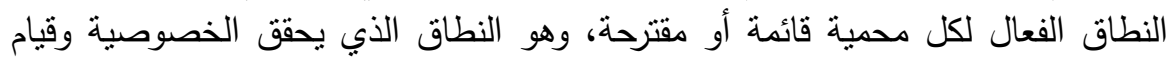

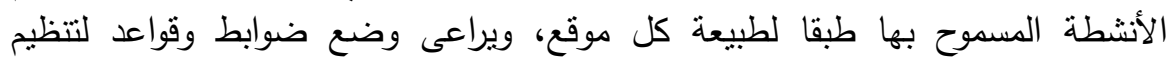

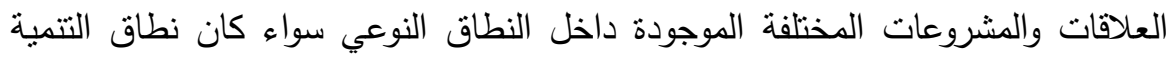

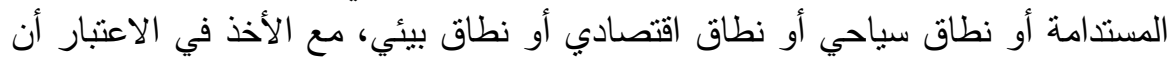

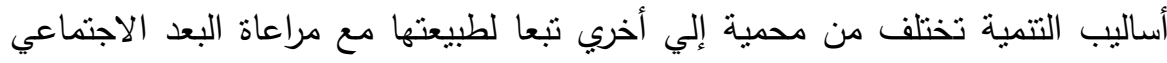

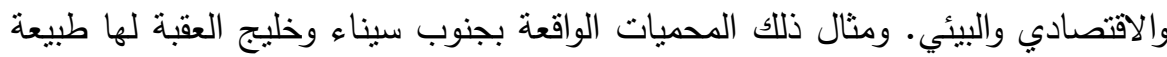

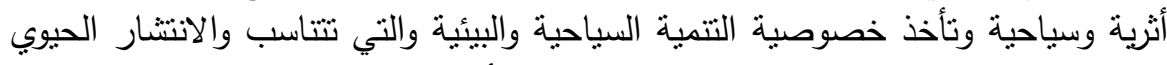

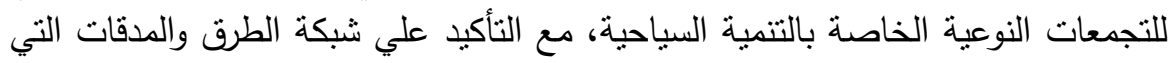
تربط المناطق البيئة بالمنتجعات السياحية. ومن خلال ذلك تتأكد أعمال التتمية السياحية

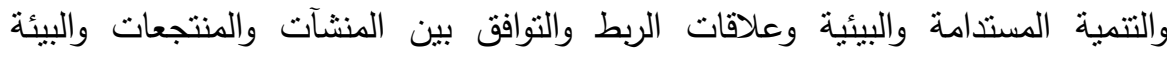

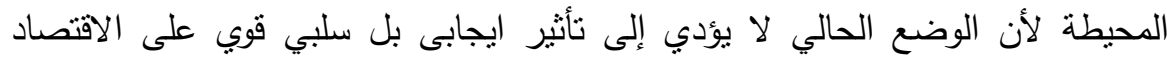

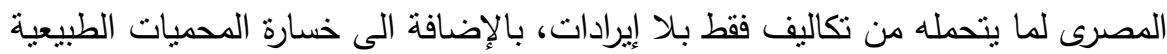
التي يجب الحفاط عليها. r-تطبيق المحدادت المختلفة للتتمية المستدامة وتثمل المحددات المختلفة لعناصر التتمية

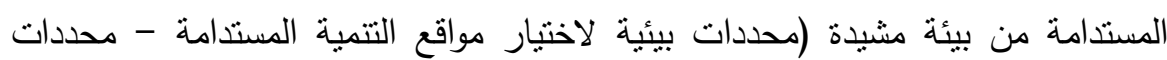

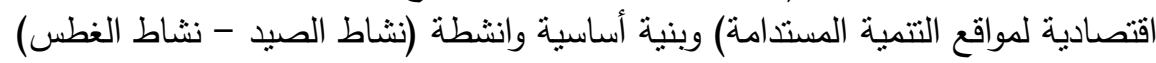

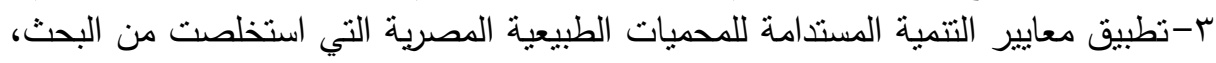

حيث لا توجد معايير محددة يمكن من خلالها تطبيق التنمية المستدامة الملائم لها.

\section{الليوكيايت المبحث الأول: مستوى استغلال مساحة المحمية الطبيعية:}




\section{1-توصيات خاصة بإدارة المحميات الطبيعية:}

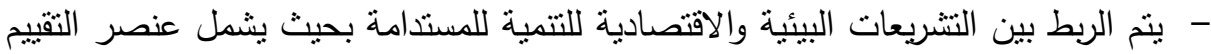
البيئي للمشروعات إعداد التقارير التفصيلية لتوضح العلاقة بين مشروعات البنية الأساسية للية لإنية

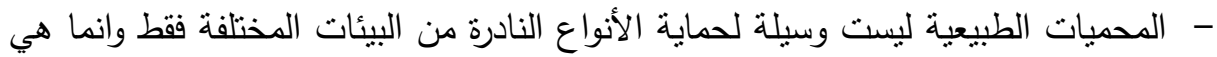

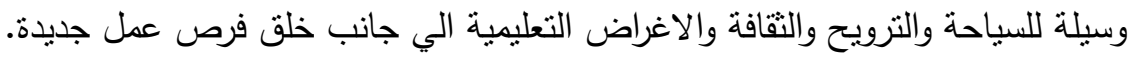

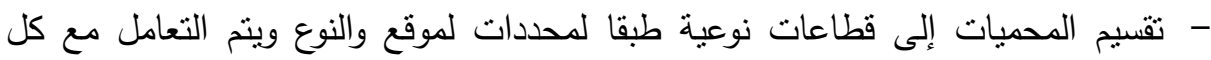

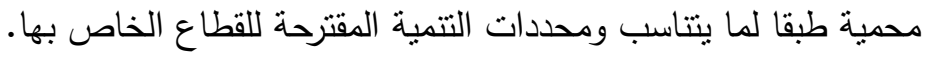

- الاهتمام بتتمية قطاع المحميات الطبيعية وربطها ببرامج التتمية القطاعية والثاملة حيث الثيثة

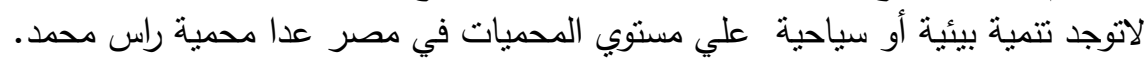

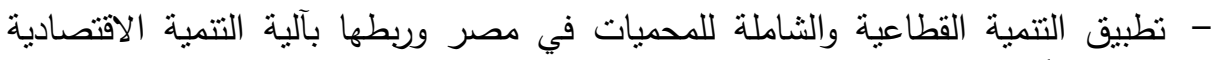

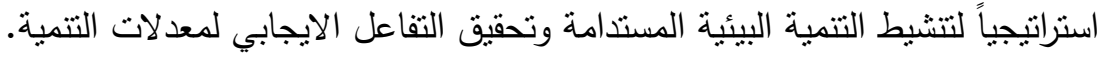
r- بوصيات خاصة بقطاع السياحة: - - إدارة الأنشطة السياحية وفق مخطط تنموي بئئي في إطار زمني يقنن أساليب التعامل مع

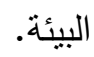
- إعداد البرامج الخاصة للتتمية البيئية والسياحية وحماية الثواطئ وإقامة الأحزمة الخضراء

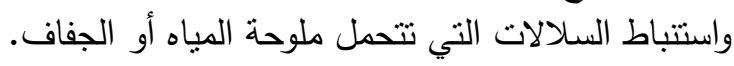

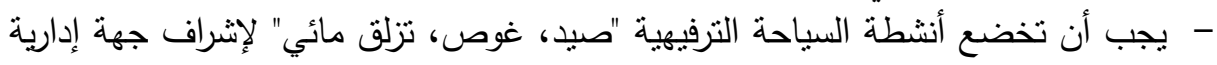

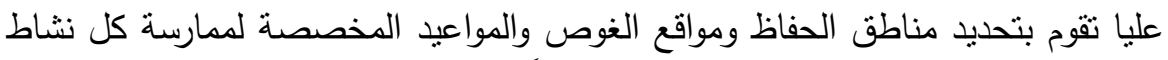

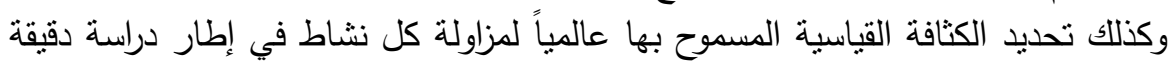
للمدخلات والمخرجات لتدور في إطار من عدم الإضرار بالبيئة. - إقامة مشروعات المخيمات والمعسكرات في المناطق البيئية المفتوحة وربطانها بالئة بالمحميات. تتظيم التتمية السياحية والبيئية المحيطة بما يؤكد التكامل البيئي بين المجتمع وبيئنة

المبحث الثانى: مستوى الأنشطة الترفيهية:

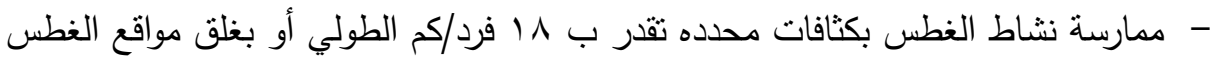

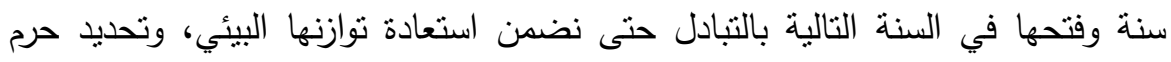
لمناطق الحفاظ ومواقع الغطس، لا يسمح إلا لقوارب بغاطس صغير نضير وتعتمد على الطاقة

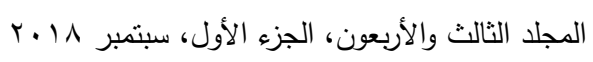


النظيفة مع مراعاة منع مرور القوارب من وإلى البيئة البحرية حتى نحافظ على القيعان

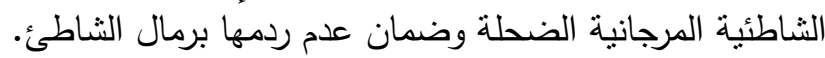

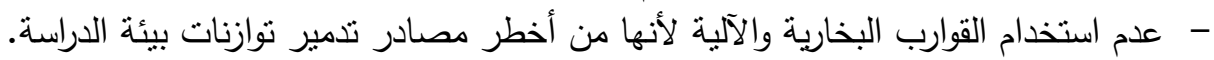

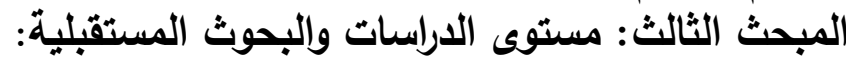
- ضرورة استمرار البحوث في القطاعات المختلفة بحيث تشمل الأبحاث التى براعى اجراءها بمحمية نبق.

- - برنامج إدارة التتمية المستدامة بالمحمية وتأثيراته المتوقعة علي البيئة الطبيعية بالمحمية.

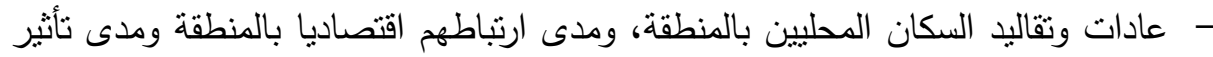
التتمية المستدامة الحادث عليهم ومدى نأثثرهم على التتمية المستدامة والحمايدة الحماية.

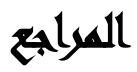

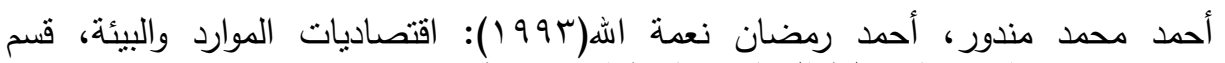
الاقتصاد، كلية التجارة، جامعة الإسكندرية.

تقارير منظمة السياحة العالمية التابعة لهيئة الأمم المتحدة.

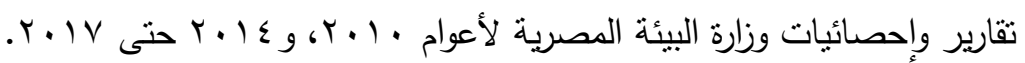

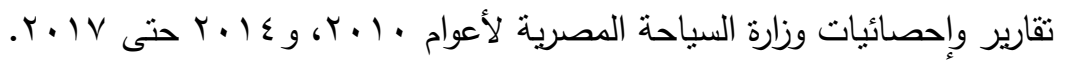

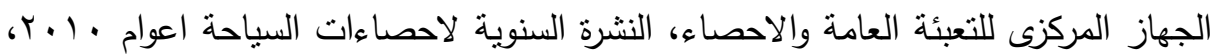

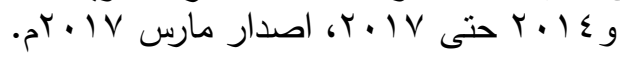

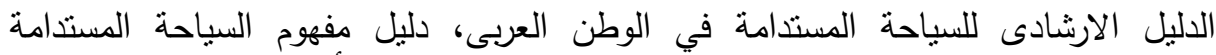
وتطبيقها، سلسلة ال، جامعة الدول العربية وبرنامج الأمم المتحدة للبيئة.

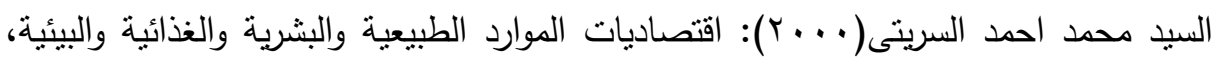
الدار الجامعية، الإسكندرية.

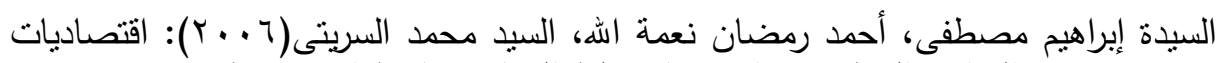
الموارد والبيئة، قسم الاقتصاد، كلية التجارة، جامعة الإسكندرية.

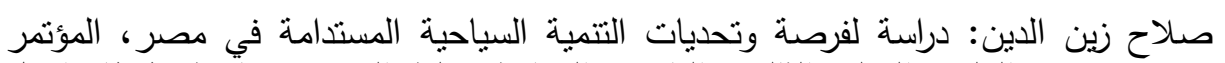
العلمى الدولى الثالث، القانون والسياحة، كلية الحقوق، جأمعة طنطا، البرانية البريل

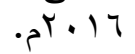
فرج عبد العزيز عزت، إيهاب عز الدين نديم(991 (1)): الموارد الاقتصادية. فؤاده البكرى، التتمية السياحية في مصر والعالم العربى، دار عالم الكتب للنشر ، القاهرة. 
محمد عبد الفتاح القصاص، الانسان والبيئة والتتمية، بحث علمى منشور، المؤتمر التانى البى للبحوث البيئية، القاهرة الانيان ولبئة 999 ام.

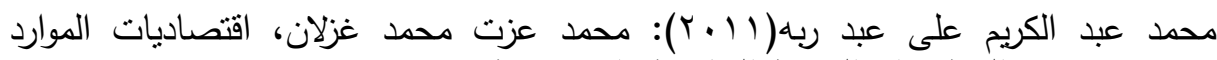
والبيئة، دار المعرفة الجامعية، الإسكندرية.

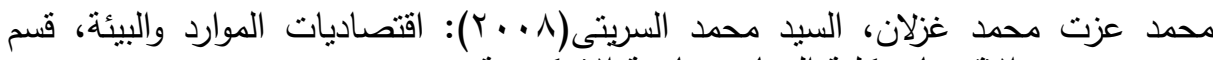
الاقتصاد، كلية التجارة ،جامعة الإسكندرية

مركز المعلومات ودعم اتخاذ القرار ، وصف محميات مصر طبعة 10 • بrم.

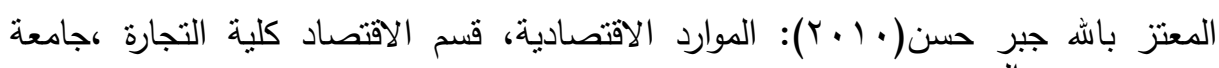
المنصورة.

المنظور البيئي لمحافظة جنوب سيناء - مكتبة محافظة جنوب سيناء الطور .

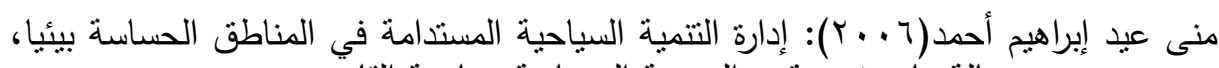

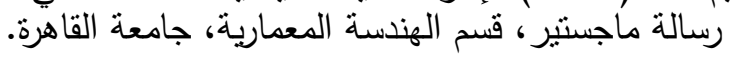

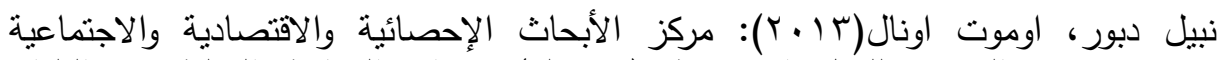

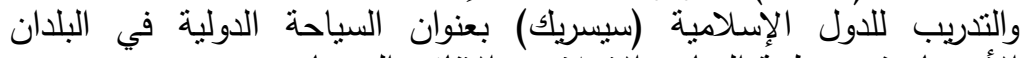

الأعضاء في منظمة التعاون الاسلامى: الافاق والتحديات

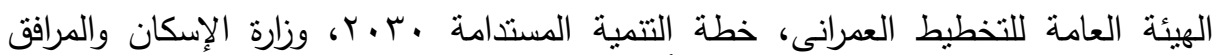

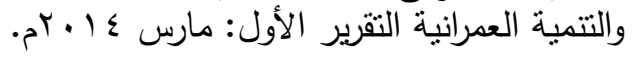

وزارة التخطيط والتعاون الدولى، الاطار الاستراتيجي لخطط التتمية الاقتصادية والاجتماعية ماردية

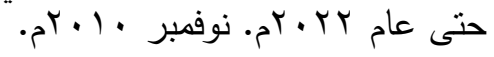

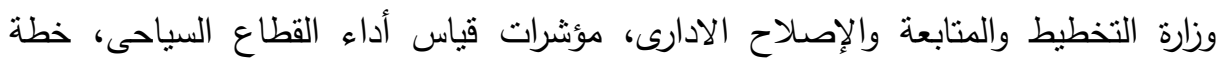

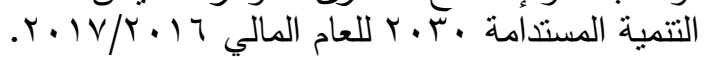

موقع الهيئة العامة للاستعلامات بوابتك الى مصر الحكومة المصرية.

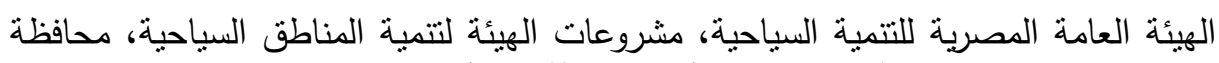

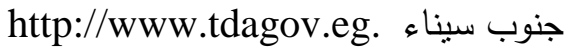

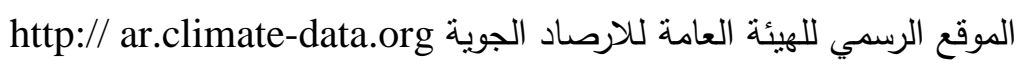

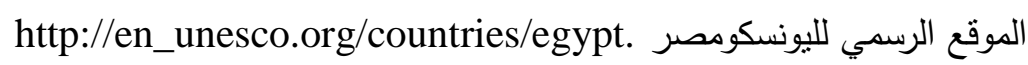
http://www.sis.gov.eg http://www.unwto.org http://www.photos.google.com

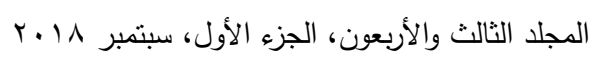


رشا أحمد الثربيني وآخرون

http://www.wikipedia.org

Lundberg, Donald, E.(1997): Tourism Economic. London.

Red Sea Life Project, United State Agengy for International Development, Chemonics International.Septermber 2007.

United Nations World Tourism Organization UNWTO: The Standard International Classification of Tourism Activities (SICTA).

Lea, J.: Tourism and Development in the third world.

\title{
A PROPOSED FRAME WORK FOR SUSTAINABLE DEVELOPMENT OF THE EGYPTIAN NATURAL RESERVES AND ITS IMPACT ON THE EGYPTIAN ECONOMY - COMPARATIVE STUDY BETWEEN CAPE MAY PROTECTORATE IN USA AND NABQ PROTECTORATE IN EGYPT
}

El Sherbiny, Rasha, A. ${ }^{(1)}$; Mandour, A. F. ${ }^{(2)}$; Khalil, M. T. ${ }^{(3)}$ and Salaam, S. $^{(2)}$

1) Institute of Environmental Studies and Research, Ain Shams University 2) Faculty of Commerce, Ain Shams University 3) Faculty of Science, Ain Shams University

\begin{abstract}
After the tourism recession resulting from depletion of resources, poor environmental conditions and deterioration of the social and economic situation, a number of tourism experts pointed to the weakness of Egypt's share of the international tourism movement, which is only $0.57 \%$ of the total international tourism, Egypt's tourism product for the global market, and the need to develop it, and through


the questionnaire conducted by a group of German experts to the markets of a dozen countries for the movement of tourism to Egypt, including 140 tourist companies in these countries, it was possible to conclude an important result is the need to develop the Egyptian tourism product. "A distinct tourist product for the sake of distinguished tourist markets" as a clear goal Egypt seeks to achieve, so increased efforts and trends of the State to direct many investments for the industry and development of Egyptian tourism. As sustainable tourism is a trend that seeks to integrate development movements under a system that has the capacity to absorb all development inputs and deal with them in order to preserve the right of future generations in the presence of resources for development.

Therefore, there is a need to dissect the concepts of development and sustainable tourism of natural reserves to achieve the main objective is to study and analyze how the Egyptian economy can benefit from the sustainable development of the Egyptian natural reserves and its impact on the Egyptian economy and how to preserve environmental resources as an important economic components can not be relied upon.

On the theoretical method of inductive and analytical deductive and applied, through the review of theoretical studies with a view to exit some theoretical relations, through the tools of research books, research, periodicals, reports and Rasa Scientific and research papers in the Egyptian, Arab and international, followed by field analytical studies and followed the deductive approach, study and analysis of a sample similar to the reserves of positive impact on the local and national economy of the United States, the Cape May Reserve, which was closed and developed within 3 years and then exploited environmentally as a model for the exploitation of nature reserves In the United States of America, and evaluated with the extraction and conclusion of the elements and criteria to be provided in the protected area, and then achieve sustainable tourism development, then the applied study was followed by the applied method of deductive which is based on a practical scientific approach based on a set of steps where applied what has been drawn from the theoretical and analytical study on the Nabq Reserve because it is a protected nature reserves of

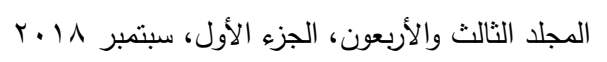


environmental economic fundamentals and has been developed methodology for analysis, and it has been monitoring the problems and possibilities and limitations and constraints of development, And thus develop a model for the sustainable development of the Nabqah sanctuary in which the elements of environmental economic activities are organized and distributed from a built environment, activities and uses in line with the achievement of the goals of the establishment of protected areas, and contrary to other objectives, whether environmental or history Cultural, legal, and study and analyze its application to the reserve and compare it with the status quo in Egypt.

Through analyzing the results, the most important are the various indicators of sustainable development, the sustainable development criteria of the Egyptian reserves and the role of protected areas in sustainable development; the level of exploitation of protected land, recreational activities and future research.

Keywords: Sustainable Development - Protected Areas - Cape May Reserve - Nabq Reserve. 